\title{
How to Foster Prosocial Behavior?
}

\section{Essays on Experimental Economics}

\author{
Dissertation zur Erlangung des Grades eines \\ Doktors der Wirtschaftswissenschaften (Dr. rer. pol.) \\ an der \\ Wirtschaftswissenschaftlichen Fakultät \\ der \\ Georg-August-Universität Göttingen
}

Autor:

Maximilian Georg Späth

Geboren am 05.07.1990 in Freiburg im Breisgau

Göttingen, Januar 2021 


\section{Betreuungsausschuss}

Erstgutachterin:

Zweitgutachter:

Drittgutachter:
Prof Dr. Claudia Keser

Georg-August-Universität Göttingen

Platz der Göttinger Sieben 3

37073 Göttingen

Prof. Dr. Holger A. Rau

Georg-August-Universität Göttingen

Platz der Göttinger Sieben 3

37073 Göttingen

Prof Dr. Kilian Bizer

Georg-August-Universität Göttingen

Platz der Göttinger Sieben 3

37073 Göttingen 


\section{Versicherung gem. § 12 PStO}

Ich versichere,

1. dass ich die eingereichte Dissertation How to Foster Prosocial Behavior? - Essays on Experimental Economics selbstständig angefertigt habe und nicht die Hilfe Dritter in einer dem Prüfungsrecht und wissenschaftlicher Redlichkeit widersprechenden Weise in Anspruch genommen habe,

2. dass ich das Prüfungsrecht einschließlich der wissenschaftlichen Redlichkeit - hierzu gehört die strikte Beachtung des Zitiergebots, so dass die Übernahme fremden Gedankenguts in der Dissertation deutlich gekennzeichnet ist - beachtet habe,

3. dass beim vorliegenden Promotionsverfahren kein Vermittler gegen Entgelt eingeschaltet worden ist sowie im Zusammenhang mit dem Promotionsverfahren und seiner Vorbereitung

a) kein Entgelt gezahlt oder entgeltgleiche Leistungen erbracht worden sind

b) keine Dienste unentgeltlich in Anspruch genommen wurden, die dem Sinn und Zweck eines Prüfungsverfahrens widersprechen

4. dass ich eine entsprechende Promotion nicht anderweitig beantragt und hierbei die eingereichte Dissertation oder Teile daraus vorgelegt habe.

Mir ist bekannt, dass Unwahrheiten hinsichtlich der vorstehenden Versicherung die Zulassung zur Promotionsprüfung ausschließen und im Falle eines späteren Bekanntwerdens die Promotionsprüfung für ungültig erklärt werden oder der Doktorgrad aberkannt werden kann.

Datum, Unterschrift 


\section{Erklärung über den geleisteten Eigenanteil der Arbeit}

Diese kumulative Dissertation besteht aus drei wissenschaftlichen Beiträgen. In der Folge werde ich den von mir jeweils geleisteten Eigenanteil aufzeigen.

1. The value of bad ratings: An experiment on the impact of distortions in reputation systems

Dieser wissenschaftliche Beitrag ist in Zusammenarbeit mit Prof. Dr. Claudia Keser erschienen und ist durch Mittel ihrer Professur für Mikroökonomik finanziert. Prof. Dr. Claudia Keser trug zur Konzeptualisierung, zum Forschungsdesign, zur Literaturanalyse und zur Erstellung des Forschungsartikels bei. Ich führte die Experimente und die Datenanalyse unter Supervision von Prof. Dr. Claudia Keser durch. Zudem trug ich zur Konzeptualisierung, zum Forschungsdesign, zur Literaturanalyse und zur Erstellung des Forschungsartikels bei.

2. Its me again... Ask avoidance and the dynamics of charitable giving

Dieser wissenschaftliche Beitrag ist in Alleinautorenschaft entstanden. Der Beitrag ist durch Mittel der Professur für Mikroökonomik finanziert.

\section{Charitable giving: framing and the role of information}

Dieser wissenschaftliche Beitrag ist in Zusammenarbeit mit Prof. Dr. Claudia Keser erschienen und ist durch Mittel ihrer Professur für Mikroökonomik finanziert.

Claudia Keser trug zur Konzeptualisierung, zum Forschungsdesign, zur Literaturanalyse und zur Erstellung des Forschungsartikels bei. Ich führte die Experimente und die Datenanalyse unter Supervision von Prof. Dr. Claudia Keser durch. Zudem trug ich zur Konzeptualisierung, zum Forschungsdesign, zur Literaturanalyse und zur Erstellung des Forschungsartikels bei.

Datum, Unterschrift 


\section{Danksagung}

Ich möchte den Moment nutzen, um Danke zu sagen.

Mein Dank gebührt meinem Betreuungssauschuss. Ein herzliches Dankeschön an Claudia Keser, die mich in meiner Forschung, in meiner beruflichen Weiterbildung und in meiner persönlichen Entwicklung immer tatkräftig mit Rat und Reflektion unterstützt hat. Ein herzliches Dankeschön an Holger Rau, der mir wertvolles Feedback und spannende Einsichten in das Unileben gewährt hat. Ein herzliches Dankeschön an Kilian Bizer, der mich in freundlicher und sachlicher Weise unterstützt hat.

Von ganzen Herzen möchte ich allen Weggefährtinnen und Weggefährten von der wissenschaftlichen Fakultät der Georg-August-Universität Göttingen und aus benachbarten Fakultäten danken. In alphabetischer Reihenfolge sind dies Pooja Balasubramanian, Laura Barros, Raphael Brade, Daniel Celis, Elias Cisneros, Melanie Dunger, Christina Ehrich, Elaheh Ehsani, Anna Gasten, Alexia Gaudeul, Robert Genthner, Nina Grassnick, Laura Henkel, Denise Hörner, Marcela Ibañez, Krisztina Kis-Katos, Christina Martini, Alexander Merz, Stefan Moser, Stephan Müller, Tatiana Orozco, Asri Özgümüs, Florian Rottner, Katrin Rudolf, Claudia Schupp, Robert Schwager, Ann-Marie Sommerfeld, Sebastian Trabert, Kerstin Unfried, Viviana Urueña, Liza von Grafenstein, Feicheng Wang, Ann-Charlene Weber, und Christoph Weisser. Diese Auflistung ist ausführlich, aber nicht ausschließlich.

Mein letzter, aber nicht minder wichtiger, Dank gilt meiner Ehefrau, meiner Familie, meinen Mitbewohnern und meinen Freundinnen und Freunden. Diejenigen von ihnen, die diese Danksagung lesen, werden wissen, dass sie gemeint sind. In dem Maße, wie ich viele der oben genannten Mitstreiterinnen und Mitstreiter zu meinem Freundeskreis zähle, haben mich auch die Menschen aus meinem privaten Umfeld in meiner wissenschaftlichen Arbeit unterstützt.

Den mir unbekannten Leserinnen und Lesern möchte ich viel Vergnügen mit dieser Forschungsarbeit wünschen. 


\section{Table of contents}

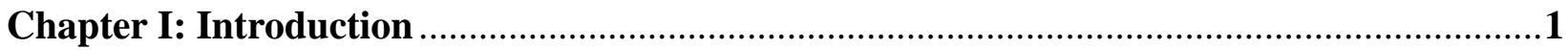

\section{Chapter II: Study 1}

The value of bad ratings: An experiment on the impact of distortions in reputation systems .........5

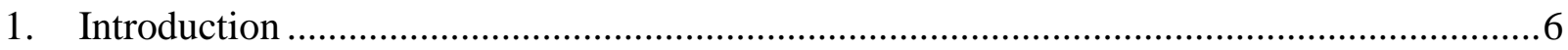

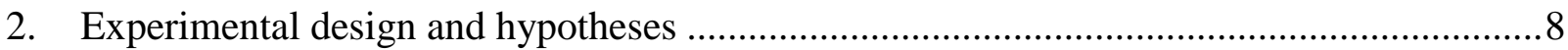

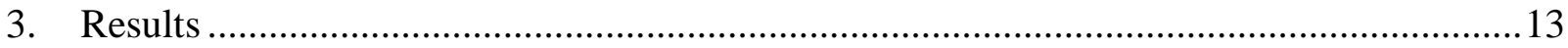

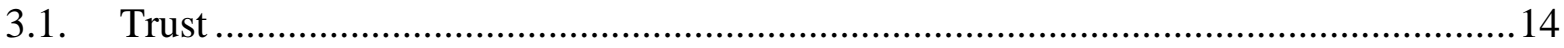

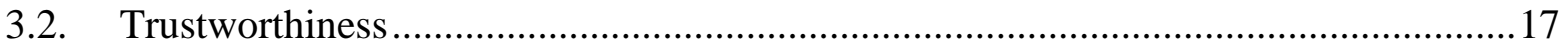

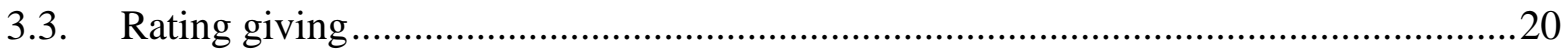

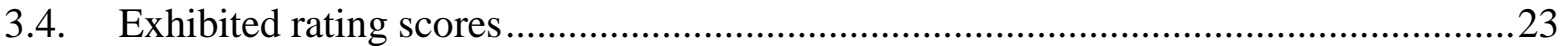

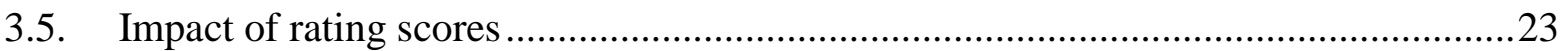

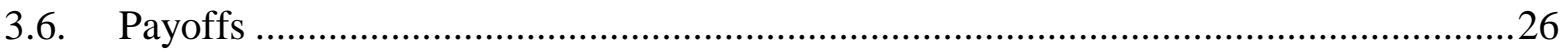

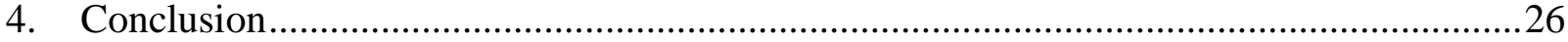

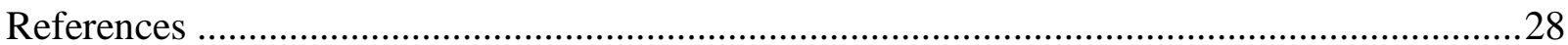

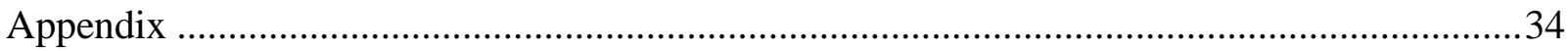

\section{Chapter III: Study 2}

Its me again... Ask avoidance and the dynamics of charitable giving ........................................35

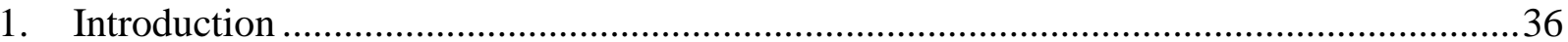

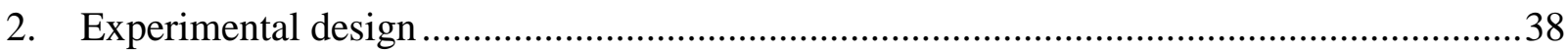

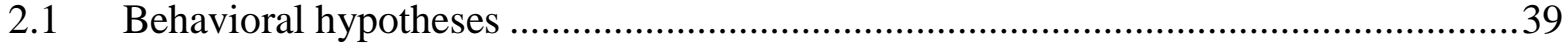

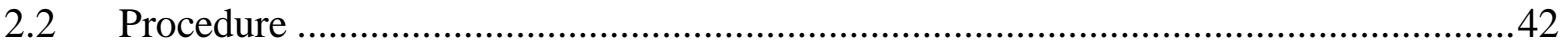

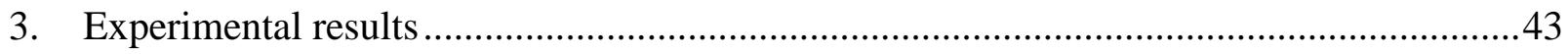

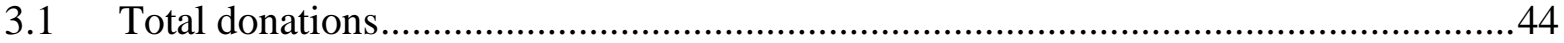

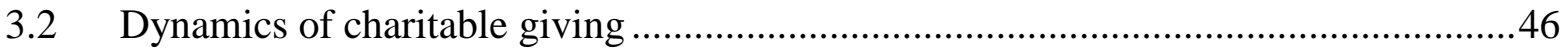

3.3 Gain perceivers and loss perceivers ....................................................... 47

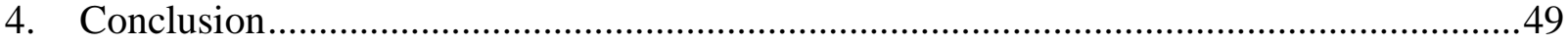

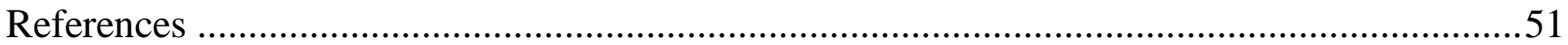




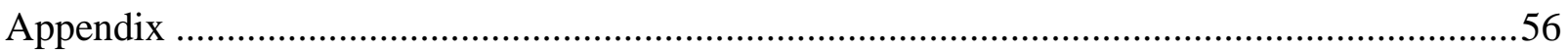

A.1 Instructions to be read aloud (in English) ................................................................56

A.2 On-screen instructions, decision stages, and inquiries from before and in between decision stages (in English)...............................................................................................56

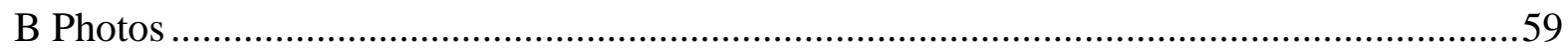

\section{Chapter IV: Study 3}

Charitable giving: framing and the role of information ......................................................60

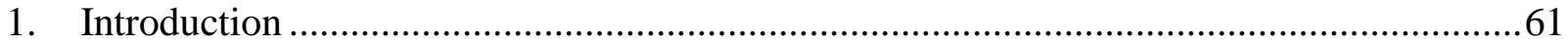

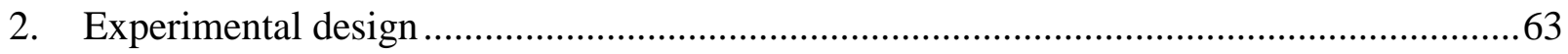

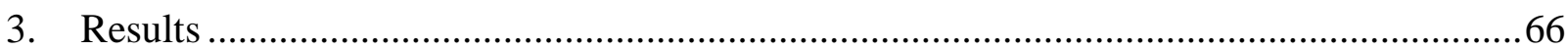

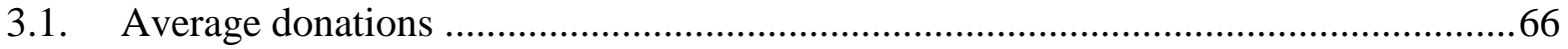

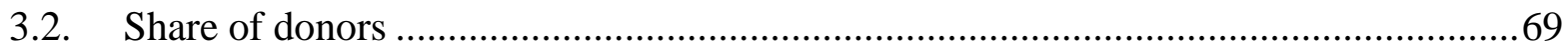

3.3. Share of donors with substantial donations ...........................................................

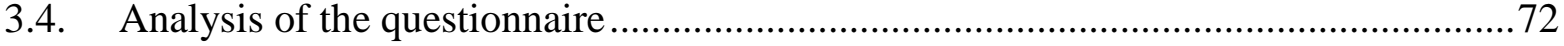

4. Application to organ donations ……………………...................................................

5. Conclusion..............................................................................................................

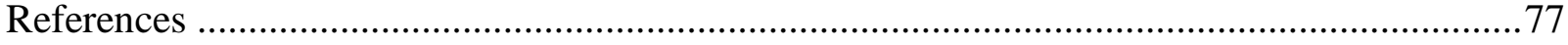

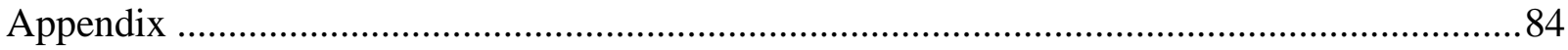

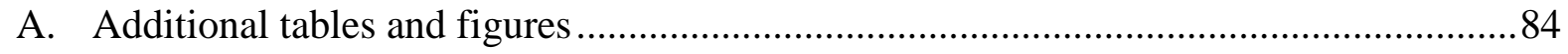

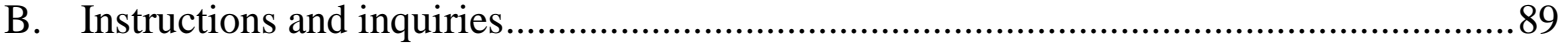

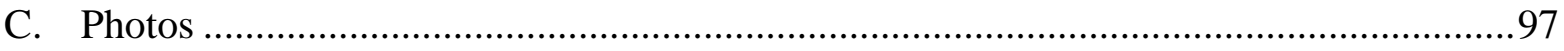

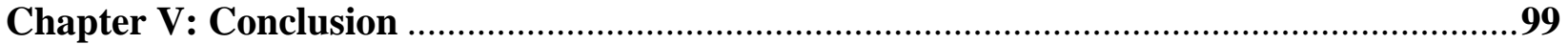

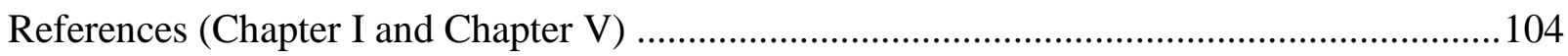




\section{Chapter I: Introduction}

Prosocial behavior can be beneficial for the society. A donation by a rich person to a beggar might help the latter to survive. Friends support each other in times of need. Individuals donate blood and organs to improve the health of strangers. Children are happy when they receive presents from their parents. Lange et al. (1997) provide a twofold definition of a prosocial person. First, the authors define prosocial persons as individuals who want to maximize the outcome of relevant others together with their own outcome. Second, the behavior of prosocials is aiming on the equalization of their outcome and the outcome of others. I add to this definition that prosocial acts are voluntary. ${ }^{1}$ They do not come with a legally enforceable complete compensation. ${ }^{2}$ Hence, I define prosocial behavior as a voluntary and potentially uncompensated act that is aiming on the maximization and equalization of the outcome of the agent and of relevant others. Prosocial behavior is socially optimal when the gain for the relevant others (and any related gain) is larger than the sum of the loss for the agent and of the transaction costs. When (voluntary) prosocial actions are beneficial for the society, it might also be beneficial for the society to foster prosociality. For this reason, a large body of literature analyzes which measures effectively and efficiently increase prosocial behavior.

In this thesis, I consider three strategies to foster prosociality that taken together represent a wide spectrum of measures. First, the implementation of a reputation system might motivate agents to behave in a prosocial way. The experimental studies by Keser (2003), Boero et al. (2009), Masclet and Pénard (2012), and Lumeau et al. (2015) provide evidence for a positive effect of reputation management systems on prosocial behavior. Second, individuals might be motivated by merely being asked to behave prosocially. Freeman (1997) and Yörük $(2008,2009)$ show that most individuals only donate when being solicited. The result of an experimental study by Andreoni and Rao (2011) demonstrate that voluntary transfers to another person increase when the recipient has the possibility to speak to the agent. Third, a change in the framing might positively affect prosocial behavior. Krupka and Weber (2013), Korenok et al. (2014), Oxoby and Spraggon (2008), and

\footnotetext{
${ }^{1}$ I do not define an action that is demanded by law to be prosocial behavior.

${ }^{2}$ This excludes trading where a buyer (at least in expectation) is completely compensated for the loss by receiving the product or service.
} 
Brosig-Koch et al. (2017) analyze the effect of framing a prosocial act as not taking rather than as giving. The authors report a positive impact of such a taking frame on prosocial behavior.

While there is evidence that the three measures can induce prosocial behavior, it remains unclear under which conditions this is the case. First, reputation systems rely on adequate rating giving by individuals. Yet, Tadelis (2016) and Dellarocas and Wood (2008) observe a positive bias in ratings on online markets. The researchers find that some individuals seem to avoid evaluating others negatively. Such a positive bias might diminish the effectiveness of reputation systems. Second, while asking individuals once seems to be an effective strategy to promote prosocial behavior, the impact of repeated requests is less obvious. Irritation about the repeated request (van Diepen et al., 2009) and the licensing effect with little prosocial behavior after first good deed (Monin and Miller, 2001; Merritt et al., 2010; Mazar and Zhong, 2010) might cause the repetition to have at best no effects on charitable giving. Third, while Krupka and Weber (2013), Korenok et al. (2014), Oxoby and Spraggon (2008), and Brosig-Koch et al. (2017) find evidence for an impact of the taking frame, Dreber et al. (2013), Chowdhury et al. (2017), Kettner and Cecatto (2014), Smith, (2015), Grossmann and Eckel (2015), and Suvoy (2003) report no effect of the frame.

Therefore, the aim of this dissertation is to analyze under which conditions a reputation system, donation requests, and a taking frame cause agents to behave prosocially. This contributes to the discussion on how to foster prosocial behavior. In Study 1 with the title "The value of bad ratings: An experiment on the impact of distortions in reputation systems" that is joint work with Claudia Keser, we analyze the effect of a positive bias (and of a negative bias) in rating giving on the functioning of reputation systems. Study 2 called "Its me again... Ask avoidance and the dynamics of charitable giving" is on the dynamics of charitable giving. I analyze how a repetition of the donation request and the possibility to avoid the repetition impacts donations to a charity. In Study 3 titled "Charitable giving: framing and the role of information" that is joined work with Claudia Keser, we follow the comments by Grossmann and Eckel (2015), Johnson and Goldstein (2003), and Thaler and Goldstein (2009) stating that a taking frame is most effective when the context is vague. For this reason, we study the interaction between information about the receiving charity and the taking frame.

We analyze the robustness of the three measures (reputation systems, donation requests, and taking frame) by conducting laboratory experiments. The laboratory provides a controlled environment that allows for causal interference. Regarding reputation systems, lab experiments offer the 
possibility to exogenously introduce a positive distortion in rating giving and to isolate its effect. With respect to repeated donation requests, the lab environment ensures that agents receive neither new income nor new information between the donation decisions. Regarding the taking frame, conducting a lab experiment allows to vary the frame in an easy and controlled manner. In the following, I provide a short summary of the experimental design and the results of the three studies. Then, I derive some implications.

In Study 1, we examine the impact of distortions in reputation systems using a "trust game" (Berg et al., 1995). We modify the repeated trust game with reputation introduced by Keser (2003). In this game, randomly matched pairs of trustors and trustees interact. Each trustor receives an endowment and may send a share of it to the trustee. The amount invested is tripled. The trustee might return a share of the tripled amount. Finally, the trustor may rate the interaction. The ratings are visible to the newly matched subsequent interaction partners of the trustee. We exogenously introduce a positive bias (negative bias) by censoring rating options to positive ratings and no ratings (negative rating and no ratings), which we compare to a system with positive ratings, negative ratings and no ratings. The experimental results show that the positive distortion in rating giving weakens the power of reputation systems. The positively biased system yields significantly lower trust (the amount that the trustor invests) and somewhat lower trustworthiness (the share of the amount received that the trustee returns). The negative bias has no adverse effects.

In Study 2 and Study 3, we use a version of the "dictator game" (Kahneman et al., 1986; Forsythe et al., 1994) with a charity as the recipient (Eckel and Grossman, 1996). In this game, the decision maker receives an endowment. The agent can then freely choose to donate a share of this initial endowment to a charity. In the two studies presented in this thesis, the recipient is the International Federation of the Red Cross and the Red Crescent (IFRC). In Study 2, I vary the number of opportunities for the agent to donate. In addition to this, I introduce the option to avoid the repetition of the ask. I find that the mere repetition is not an effective measure to foster prosocial behavior (when the repetition does not come along with new income or new information). Most important, the results show that the system in which subjects could avoid the repetition yields the highest average donation. In Study 3, we vary the frame and the information provided about the receiving charity. We either provide only the name of the charitable organization, read aloud some supplementary information on its operative goals, or additionally show a video explaining the principles of the organization. We vary the frame by either stating that the initial endowment is 
dedicated to the decision maker (giving frame) or to the charity (taking frame) while leaving the decision maker with full decisional power. We find that the effect of the taking frame decreases with the amount of information that is provided about the charity. This highlights that the taking frame is most effective in a low information environment.

These findings have important implications for policy makers, market designers, and fundraisers. The results of Study 1 show that reputation systems are negatively impacted by distortions in rating giving. This implies that markets should be designed in a way that motivates agents to rate truthfully. Especially, the fear of retaliation after negative ratings as a driver of a positive distortion must be diminished (Dellarocas and Wood, 2008; Bolton et al., 2013). The findings reported in Study 2 suggest that the mere repetition of donation requests is ineffective to increase donations. Appeals seem to lose their impact when they come at a high frequency. If each donation request comes with a cost for the charity, a repetition might even imply a loss. Offering agents the option to avoid the repetition of the request can help to decrease the costs of fundraising and to identify those individuals who are willing to donate repeatedly. The results of Study 3 exhibit that policy makers can expect a strong effect of a taking frame in a low information environment. In a high information environment, the effect would be less pronounced. In the course of Study 3, we apply our results in the field of organ donations. The findings suggest that an Opt-Out system (taking frame) might increase organ donations the most in comparison to an Opt-In system (giving frame) when the public is poorly informed about organ donations. Yet, it is debatable if a donation in such a little knowledge regime can be seen as informed consent.

The remaining dissertation is structured as follows: Chapter II describes Study 1 on reputation systems. In Chapter III, I present Study 2 on repeated donations requests. Chapter IV presents Study 3 on the taking frame. In Chapter V, I provide a short summary of the three studies, discuss an application of the results to prosocial behavior during pandemics, and conclude. 


\title{
Chapter II: Study 1
}

\section{The value of bad ratings: An experiment on the impact of distortions in reputation systems *}

\author{
with Claudia Keser
}

\begin{abstract}
We study the robustness of reputation management systems against distortions in rating behavior. In a laboratory trust experiment with reputation management, we mimic a positive bias by exclusively offering the option to rate positively or to give no rating. As predicted by theoretical considerations, this bias leads to significantly less trust than a system that additionally offers a negative rating option. A system relying solely on negative ratings does not have such an adverse effect. This highlights the importance of negative ratings for the effectiveness of reputation systems.
\end{abstract}

Keywords: Trust, Trustworthiness, Reputation System, Experiment

JEL classification: C91, L14, C73

* We have received helpful comments from participants of the seminar on economics and management at the University of Paderborn, from participants of the CollEcons colloquium at the University of Goettingen, from participants of the 19th ZEW Summer Workshop for Young Economists, from participants of the annual conference of the Gesellschaft für experimentelle Wirtschaftsforschung (GfeW) in Kassel and from participants of the annual conference of the Verein für Socialpolitik (VfS) in Freiburg. We would like to thank Stephan Müller for his helpful comments and suggestions.

The article is in a revise and resubmit stage at the Journal of Behavioral and Experimental Economics. 


\section{Introduction}

Many (online-) markets like, for example, eBay, Marketplace at Amazon, Airbnb, or Uber rely on reputation systems allowing potential buyers of goods and services to be informed of the experiences that other customers have had with the respective seller. Reputation systems thus permit sellers to build a reputation of trustworthiness and gain trust with potential customers. Increased trust and trustworthiness in a market is likely to lead to more trade. From a theoretical perspective, reputation systems can be implemented to reduce inefficiencies that occur due to moral hazard in markets with asymmetric information (e.g., Bar-Isaac and Tadelis, 2008). Experimental research (e.g., Keser, 2003; Boero et al., 2009; Masclet and Pénard, 2012; Lumeau et al., 2015) provides evidence for the power of reputation systems to enhance both investment and relative return in the "trust game" introduced by Berg et al. (1995). Still, in practice there are many open questions with respect to the design of efficient reputation systems (see Ahmed et al., 2019; Sherchan et al., 2013; Tavakolifard and Almeroth, 2012; Swamynathan et al., 2010; and Josang and Golbeck, 2009, for interdisciplinary overviews).

One important issue is an apparent inflation toward favorable evaluations. Some unsatisfied buyers do not rate negatively, although they have the option to do so. This distortion toward positive ratings is a frequently observed phenomenon in (online-)reputation systems (see Tadelis, 2016, for a review). ${ }^{3}$ Dellarocas and Wood (2008) and Bolton et al. (2013) find that some dissatisfied buyers do not rate negatively, when they must fear the seller's retaliation. Even without the possibility to directly retaliate, Nosko and Tadelis (2015) report a mismatch between the share of negative ratings and the relatively much higher share of complaints by buyers on eBay. Fradkin et al. (2017) find that 20 percent of Airbnb guests, who privately state that they would not recommend a host, still give a favorable public rating.

On some markets, a distortion toward positive ratings might be even exogenously caused by the design of the reputation systems. Li et al. (2016) describe that not providing a rating on the Chinese online-market Taobao is automatically interpreted as a positive evaluation. On the German onlinemarket Otto (www.otto.de) and on product-comparison portals like CHECK24 (www.check24.de), potential customers receive information on the share of previous customers who would recommend

\footnotetext{
${ }^{3}$ Likewise, in education, a grade inflation with a trend toward a higher share of good grades is apparent (e.g., Jewell at al., 2013).
} 
the product. ${ }^{4}$ In general, the giving of prizes, awards, certification marks for commercial goods and services may be seen as the attribution of (mostly) positive evaluations.

The aim of our research is to analyze the effects that a positive (or negative) bias might have on trust and trustworthiness. We design a controlled laboratory experiment to measure if and how distortions built into the design of the rating system impact the effectiveness of the system to inform trustors and discipline trustees. Our experiment is based on the trust-and-reputation-management game introduced by Keser (2003). Trustors (which may represent customers of an online market) are invited to rate the trustees (sellers) after having interacted with them. In each of 20 periods, a trustor is randomly matched with a trustee under the constraint that a trustor never meets the same trustee more than once in a row. All the ratings that a trustee has received are made public to future trustors. Trustees are not informed about their reputation score.

In our baseline treatment POSNEG, participants can decide between a positive, a negative, or a no rating option. In treatment POS, we censor rating options to the positive and the no rating option. This mimics a positive bias that might, for example, be statistically induced by a high (nonmonetary) cost of giving a negative rating, or, by a system that by design is relying solely on positive evaluations. In our third treatment, NEG, rating options are censored to the negative and the no rating option. POS and NEG induce structural biases.

As predicted by theoretical considerations and empirically grounded arguments, we find that the structural positive bias in the reputation system leads to inefficiencies: trust is significantly lower in POS than in the baseline treatment POSNEG. It is also significantly lower than in NEG. We observe no significant difference in trust between NEG and POSNEG. Trustworthiness is significantly higher in NEG than in POS. The trustworthiness in POSNEG does not differ significantly from the trustworthiness in POS or NEG. Finally, the structural positive bias leads to lower payoffs for trustors and thus a greater inequality between market sides.

These findings highlight the relevance of measures designed to combat a positive bias and to motivate customers to truthfully give a negative rating, when they are unsatisfied. As described by Bolton et al. (2013) and Klein et al. (2016), it is important that buyers are able to leave negative ratings without fearing retaliation from sellers. Furthermore, not providing a rating should be made

4 Similarly, social networks such as Facebook, Instagram and Twitter use "likes" or "hearts" as recommendations, but do not offer a direct opportunity to show dislike. 
visible as no rating or a neutral rating. Customers should be able to easily report any attempt of sellers to prevent a negative rating. It might be considered to reduce the identifiability of raters, since a possible identification seems to promote the transmission of positive but not of negative signals (Rockenbach and Sadrieh, 2012). Negative ratings might be framed in a more positive way. By officially linking the best possible rating (e.g., five of five stars) to a "normal" quality, any intermediate rating is a criticism framed in a more positive way.

\section{Experimental design and hypotheses}

The design of our computerized laboratory experiment is based on Keser (2003). Pairs of trustors and trustees interact in a repeated trust game (Berg et al., 1995) with random strangers matching (Andreoni, 1988). Participant roles do not alter during the experiment. In each of 20 rounds, trustors and trustees are endowed with 10 experimental currency units (ECU) each. They decide sequentially. In the first of three decision stages, trustors have the opportunity to send any share of their individual endowment (restricted to integer amounts between zero and the endowment) to the trustee they are matched with. By allowing for investments of zero, we give trustors the opportunity to refrain from interacting with trustees. Any positive amount sent is tripled by the experimenter. This represents a situation in which investments are beneficial from a societal perspective. In the second decision stage, the trustees may return any share of the amount received (restricted to integer amounts between zero and the tripled amount invested by the trustor). In the third stage, those trustors that have invested positive amounts in the first stage are requested to rate the trustworthiness of their trustee with respect to the amount returned. If no investment has been made, the system automatically records that no rating is given. A summary of all the received ratings will be visible to a trustee's future interaction partners, when they make their investment decisions. After every round, trustors and trustees are re-matched. The matching protocol satisfies the constraint that no pair is interacting more than once in a row, but is random otherwise. This implies that the strangers matching is imperfect since two players can meet again in a later period. ${ }^{5}$

With respect to the rating system we consider three treatments: POSNEG, POS and NEG. In our baseline treatment POSNEG, trustees can give a positive, a negative or no rating. This treatment is

\footnotetext{
${ }^{5}$ We acknowledge that we cannot entirely rule out that trustors use strategies trying to identify the trustee they are currently paired with.
} 
comparable to the system used by Keser (2003). A trustor is informed of the number of rounds in which the trustee received a positive rating, a negative rating or no rating, respectively. To enhance intuitive understanding, a positive rating is represented by a smiling face and a negative rating by a frowning face. The information on the number of no ratings does not differentiate between rounds where no investment was made and rounds where no rating was given. Taking into account the findings of Lumeau et al. (2015) and Boero et al. (2009) that trustees even react to ratings that are never communicated to other trustors or ratings that are communicated to trustors only after they have made their investment decision, we attempt to isolate the pure reputation effect by not informing trustees about the ratings received.

In the POS treatment, we censor the reputation system to the options positive rating or no rating. Since we do not allow for negative ratings in this treatment, the no rating option will have to cover both the neutral and the negative experiences. Analogously, we censor the rating options to a negative rating or no rating in NEG. The no rating option will have to cover both the neutral and positive experiences. All participants, including the trustees, are informed of the reputation system that is applied.

Our treatment variation is more than a mere change in the frame. For the exhibited number of no ratings in POS, neutral evaluations are merged with automatically generated no ratings as well as with negative assessments. Similarly, neutral evaluations are merged with automatically generated no ratings as well as with positive assessments in NEG. Hence, participants in POS are not unequivocally informed about negative evaluations, while those in NEG are not unequivocally informed about positive evaluations. The exhibited number of no ratings provides little information by itself and cannot be interpreted as the direct counterpart to the number of positive or negative ratings, respectively.

Analyzing our finitely repeated trust game with reputation management by backward induction, the subgame-perfect-equilibrium solution predicts no transactions and thus no ratings. Hence, variations of the reputation management system would make no difference. The trust game represents a social dilemma: while individual rationality leads to zero investment by the trustor, collective rationality would require in each round the full investment of the trustor's endowment. Indeed, the experimental results of Berg et al. (1995) and others (see Johnson and Mislin, 2011, for a meta study) show that, even in one-shot games, most trustors do invest and many trustees return positive amounts. Bolton et al. (2005), for example, argue that such behavior might be due to 
limitations in people's ability to conduct backward induction. A number of experimental studies suggest, however, that the trustees' return transfers might be explained by other-regarding motives (e.g., Ashraf et al., 2006) and/or (intention-based) reciprocity (e.g., McCabe et al., 2003; Van den Bos et al., 2009). In other words, due to internalized social norms and values, trustees might derive more utility from reciprocating trust than from abusing trust. If we assume that with some probability a trustee is such a trustworthy type, trustors decide in a game with incomplete information. The trustors' decision to trust will, among others, depend on their willingness to assume social risks. Bohnet et al. (2004), for example, identify betrayal aversion in a binary-choice trust game.

Trust and trustworthiness can be sustained as an equilibrium outcome in infinitely repeated trust games with discounting (e.g., Kreps, 1990; Gibbons, 2001). Camerer and Weigelt (1988), Neral and Ochs (1992), Anderhub, Engelmann and Güth (2002), Brandts and Figueras (2003) as well as Grosskopf and Sarin (2010) theoretically and experimentally investigate finitely repeated binarychoice trust games with incomplete information. These studies consider reputation building equilibria similar to those identified by Kreps and Wilson (1982) and Milgrom and Roberts (1982) for the chain-store game (Selten, 1978). The basic idea behind this approach is simple: if some trustees are intrinsically trustworthy, it might be profitable for untrustworthy trustees to build a reputation of being trustworthy at least until the final rounds of the game.

Similar reasoning applies, when we add a reputation system to the finitely repeated trust game among strangers. The reputation system offers trustees the opportunity to signal or at least pretend to be of a reciprocal and trust-honoring type. If trustors can be expected to consider these signals when making their investment decisions, having a good reputation has a strategic value to the trustee. Let us take for granted the existence of reputation equilibria with positive investments by trustors and trustworthy behavior by trustees, at least until the final rounds of the game. ${ }^{6}$

Inspired by Ostrom (1998), we want to go from here with empirically grounded explanations in an attempt to build what Ostrom calls a second-generation model. Trustee's reputation, trust (trustor's investment) and trustworthiness (trustee's relative return) are all interconnected in a complex way in reputation equilibrium. Let us describe the core relationship between trustee's reputation, trust

\footnotetext{
${ }^{6}$ The modelling of this situation as a game with incomplete information is very complex, requires a number of strong assumptions and provides multiple equilibria.
} 
and trustworthiness as presented in Figure 1. These links are given by the sequential structure of the game. Moreover, consider that, theoretically, a good reputation may be considered as a signal of the trustee's trustworthiness. Many empirical and experimental studies have shown that trustors place more trust in a trustee with a good reputation (e.g., Resnick and Zeckhauser, 2002; Keser, 2003). The reputation depends on the trustee's trustworthiness in previous play. The experimental trust games with reputation management by Keser (2003), Masclet and Pénard (2012), and Abraham et al. (2016) suggest that trustors use some kind of threshold strategy in their evaluation decision: to give a positive rating they require a specific minimum level of relative return. ${ }^{7}$ If this threshold is not reached, they require some lower threshold to give a neutral rating. Otherwise, the rating will be negative.

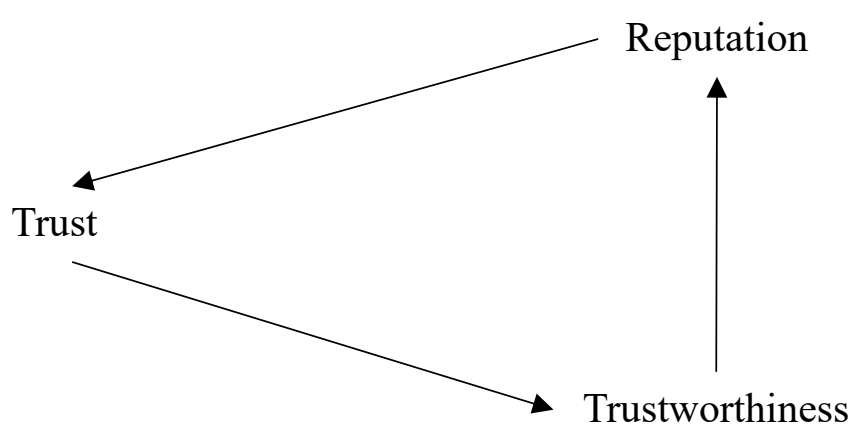

Figure 1: The core relationship between reputation, trust and trustworthiness.

Assume that, in the core relationship presented in Figure 1, the existence of a reputation management system has a strategic signaling value to the trustee. It directly affects the trustee's trustworthiness and, implicitly, the trustor's trust. Let us now consider how particular aspects of the reputation management system (as in POS, NEG and POSNEG) might affect trustworthiness.

Consider that, if trustees receive a positive rating in an encounter it increases their overall reputation score; if trustees receive a negative rating in an encounter it decreases their reputation score. In POSNEG, trustees can receive both positive ratings and negative ratings. This means that if they receive a positive rating in one period, this positive signal (increase in their rating score)

\footnotetext{
${ }^{7}$ Abraham et al. (2016) consider a 5-item Likert scale from 1 ("very unsatisfied") to 5 ("very satisfied").
} 
might be neutralized by a negative rating in a following period (for a better intuition, consider eBay's reputation score based on a " +1 " for each positive rating and a " -1 " for each negative rating). In contrast, in POS, once trustees receive a positive rating, it cannot be taken out of the reputation score any more: their overall reputation will remain positive until the end of the experiment. ${ }^{8}$ For this reason, we might expect (at least until the final periods) more continual eagerness to receive a good rating in POSNEG than in POS. This suggests overall higher trustworthiness in POSNEG than in POS.

Our argumentation for the comparison of POSNEG and NEG is twofold. On the one hand, the threshold for the most favorable rating in POSNEG (positive rating) is most likely higher than for the most favorable rating in NEG (no rating). This would suggest a higher trustworthiness in POSNEG. On the other hand, once the trustee receives a negative rating in NEG, it cannot be neutralized any more in that the trustee's overall reputation remains negative until the end of the experiment. Hence, the eagerness to avoid a negative rating in NEG might be more persistent than the eagerness to avoid a negative rating in POSNEG. Thus, overall, we do not expect significant differences in trustworthiness between POSNEG and NEG.

By transitivity, it follows that we can expect NEG to lead to more trustworthiness than POS. This is in keeping with empirical evidence by Shankar (2015), who finds that users at the online knowledge exchange Stack Overflow (a question-and-answers site for programmers) react more strongly, in terms of the quantity of contributions, to downvotes than to upvotes received to their answers. Similarly, Standifird (2001) and Lucking-Reiley et al. (2007) find a stronger impact of negative ratings than of positive ratings on prices on eBay. Capraro et al. (2016) study the impact of reputation information about an interaction partner in a prisoner's dilemma game. The reputation information is given in terms of stars with one star being the lowest reputation and five stars being the highest reputation. The authors find an effect of negative information (one star) but not of positive information (five stars) on cooperative behavior. Finally, studies in psychology provide evidence for a fear of negative evaluation (Watson and Friend, 1969) and, in general, a stronger psychological effect of bad than of good events and information (Baumeister et al., 2001).

\footnotetext{
${ }^{8}$ Furthermore, recall that in our experiment the reception of no rating does not reveal whether the trustor did choose to give no rating or was not allowed to rate after having invested zero.
} 
Reconsidering the core relationship presented in Figure 1, we assume that trustworthiness determines reputation (as specified by the reputation system). This reputation, in turn, may determine trust. Therefore, we argue that trust shows the same pattern as trustworthiness. In summary, our hypotheses are the following:

H1a: Trust is higher in POSNEG than in POS.

H1b: Trustworthiness is higher in POSNEG than in POS.

H2a: Trust is higher in NEG than in POS.

$\mathrm{H} 2 \mathrm{~b}$ : Trustworthiness is higher in NEG than in POS.

H3a: Trust is similar in NEG and in POSNEG.

H3b: Trustworthiness is similar in NEG and in POSNEG.

To test these hypotheses, we conducted our experiment in the period from 2016 to 2018 in the Göttingen Laboratory of Behavioral Economics at the University of Göttingen, Germany. Recruitment was done via ORSEE (Greiner, 2015). The experiment was programmed using z-Tree (Fischbacher, 2007). All instructions were read aloud by the same experimenter in all sessions. The instructions can be received upon request. In total, 300 individuals participated in 21 sessions. For treatments POS and NEG, we collected the data of nine independent populations with ten participants (five trustors and five trustees) each. For POSNEG we collected data of twelve independent populations. Every session was concluded by a questionnaire. The average age of the participants was around 24 and approximately 53 percent of them were female. ${ }^{9}$ Each ECU earned during the experiment was converted to 0.03 euro. On average, participants stayed about 75 minutes in the laboratory and were paid around 14 euros, including a show-up fee of 4 euros.

\section{Results}

We denote the Wilcoxon rank-sum test as rank-sum test and the Wilcoxon matched-pairs signedrank test as signed-rank test. Unless stated otherwise, we base the non-parametric tests on

\footnotetext{
${ }^{9}$ We find no significant differences in age (Kruskal-Wallis test, $\mathrm{p}=0.313$ ) and gender (Fisher's exact test, $\mathrm{p}=0.254$ ) between treatments.
} 
population averages, i.e., on nine or twelve observations per treatment. All tests are two-sided and we require $\mathrm{p}=0.05$ for significance.

\subsection{Trust}

Trust is measured by the investments of trustors. Comparing the amounts invested between treatments, we find evidence for an adverse impact of the structural positive bias. Table 1 conveys that average investments are lower in POS than in POSNEG. The difference in trust is statistically significant (rank-sum test, $\mathrm{p}=0.033$ ). Furthermore, the average investments are significantly lower in POS than in NEG (rank-sum test, $\mathrm{p}=0.012$ ). The reputation system in NEG performs slightly better than the unrestricted system in POSNEG but the difference is statistically not significant (rank-sum test, $\mathrm{p}=0.749$ ). Hence, we find evidence supporting our three hypotheses $\mathrm{H} 1 \mathrm{a}, \mathrm{H} 2 \mathrm{a}$, and $\mathrm{H} 3 \mathrm{a}$ on trust.

Table 1: Descriptive statistics on investments per treatment (POSNEG, POS, and NEG).

\begin{tabular}{cccc}
\hline Investment & Average & Median & Standard deviation \\
\hline POSNEG & 7.04 & 9 & 3.55 \\
POS & 6.07 & 7 & 3.89 \\
NEG & 7.11 & 10 & 3.68 \\
\hline
\end{tabular}

Note: In ECU. Median and standard deviation are on the individual level.

Figure 2 conveys the average investments per period. In POSNEG and NEG investments are above those in POS in every period of the game, though the difference between POSNEG and POS in the very first period is only marginal. Indeed, considering the first period in isolation, we find no significant differences in investments between treatments. ${ }^{10}$ This is in keeping with our assumption of an indirect impact of reputation management on trust. For all treatments, Figure 2 suggests a typical endgame effect with relatively low investments in the last two periods. Comparing the last

\footnotetext{
${ }^{10}$ Individual level rank-sum tests: POSNEG vs POS, $\mathrm{N}=105, \mathrm{p}=1.000$; POSNEG vs NEG, $\mathrm{N}=105$, $\mathrm{p}=0.297 ;$ POS vs NEG, $\mathrm{N}=90, \mathrm{p}=0.377$.
} 
two periods with the average of the earlier periods, we find that the differences are not significant, though. ${ }^{11}$

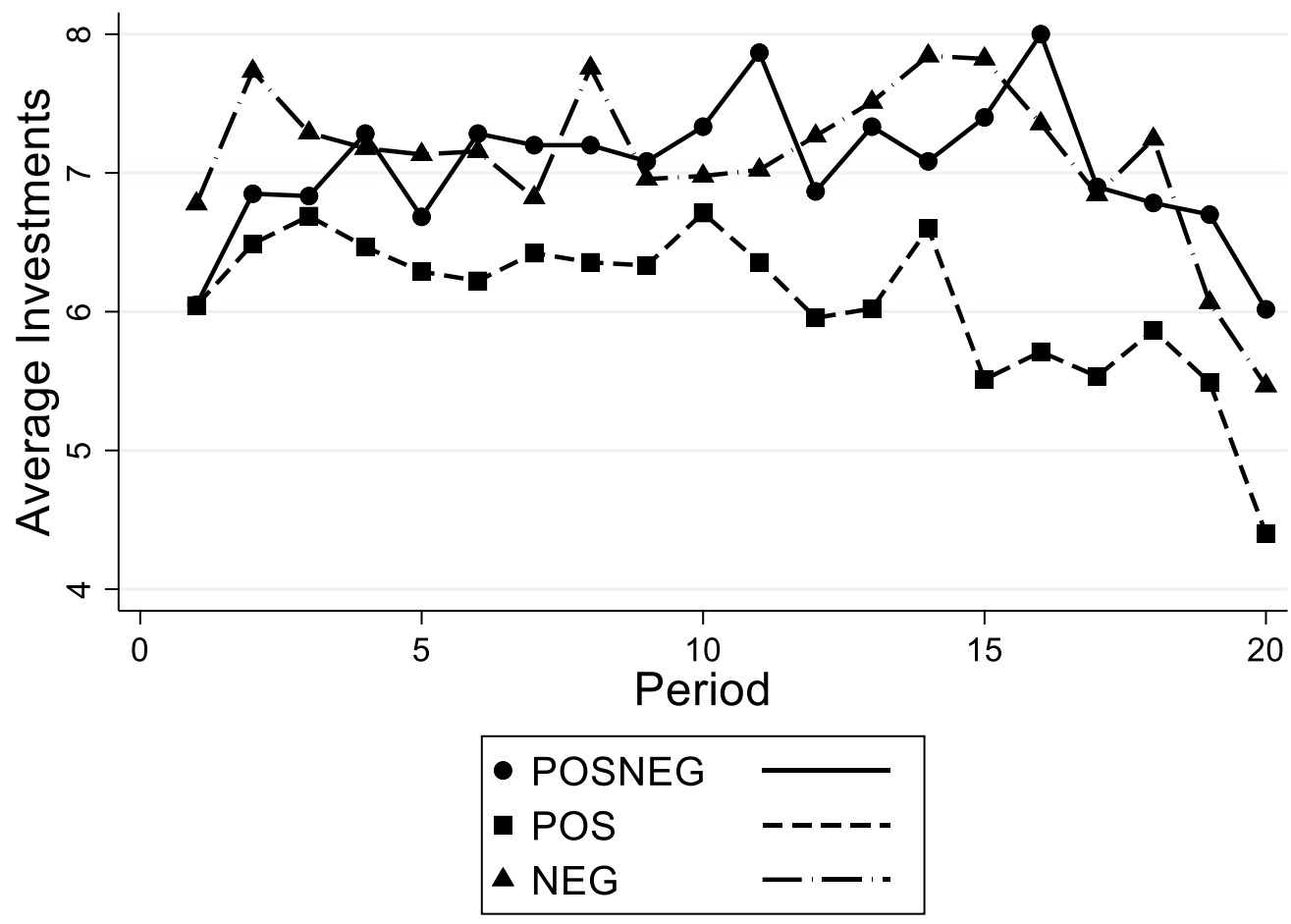

Figure 2: Average investments per period (by treatment: POSNEG, POS, and NEG).

Figure 3 provides the distribution of individual investment decisions. It reveals that more than half of the investments are either zero or 10 ECU. Specifically, it is the maximum investment of 10 ECU that is chosen most often. The relative frequencies of the maximally possible investment are 0.55 in NEG, 0.48 in POSNEG and 0.44 in POS. The difference in these relative frequencies is statistically significant between NEG and POS, while the differences between POSNEG and POS and POSNEG and NEG are not. ${ }^{12}$ The relative frequencies of zero investments are 0.10 in POSNEG, 0.11 in NEG, and 0.15 in POS. The differences between these shares are not statistically significant. ${ }^{13}$ Note that the occurrence of zero investments might lead to an overestimation of the adverse effect of a positive bias on investments. The reason is that the reputation score that is presented to trustors does not differentiate between the no ratings that were actually given and no

\footnotetext{
${ }^{11}$ Signed-rank tests: POSNEG, $\mathrm{p}=0.136 ;$ POS, $\mathrm{p}=0.051 ; \mathrm{NEG}, \mathrm{p}=0.066$.

${ }^{12}$ Rank-sum-tests: POSNEG vs POS, $\mathrm{p}=0.117$; POSNEG vs NEG, $\mathrm{p}=0.270$; POS vs NEG, $\mathrm{p}=0.031$.

${ }^{13}$ Rank-sum-tests: POSNEG vs POS, $\mathrm{p}=0.126$; POSNEG vs NEG, $\mathrm{p}=0.498$; POS vs NEG, $\mathrm{p}=0.251$.
} 
ratings that were automatically recorded. An automatically created no rating would be interpreted as a sign of untrustworthiness in POS, but as a sign of trustworthiness in NEG and as neutral information in POSNEG.

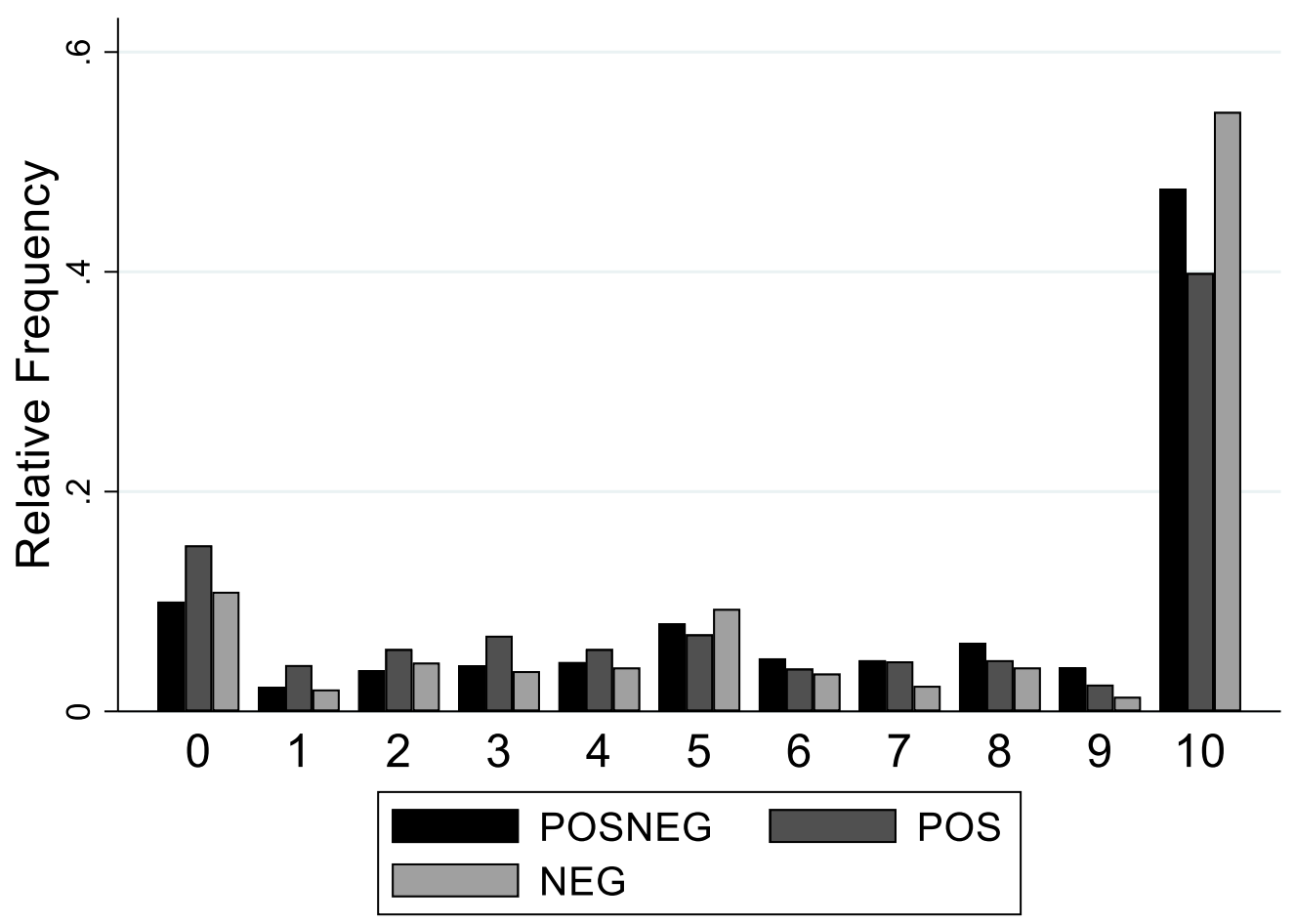

Figure 3: Relative frequency of individual investments (by treatment: POSNEG, POS, and NEG).

In keeping with Houser et al. (2010), we find no significant correlation between the trustors' (selfassessed) degree of being risk-seeking and average investments. ${ }^{14}$ The self-assessment was part of the ex-post questionnaire. Following Dohmen et al. (2011), we asked the question: "Generally speaking, are you a risk seeking person?'. We used a 7-point Likert scale, with $1=$ not risk seeking at all to 7 = very risk seeking.

\footnotetext{
${ }^{14}$ Spearman's rank correlation: $\mathrm{p}=0.124$.
} 


\subsection{Trustworthiness}

Trustworthiness is measured by the relative returns of trustees. To calculate relative returns we divide the amount returned by the amount received. Note that the level of trustworthiness that we measure is influenced by potentially untrustworthy trustees being taken out of the analysis since they do not receive an investment. However, as discussed in Section 3.1 above, we do not observe significant differences in the shares of zero-investments across treatments and, therefore, no evidence of a distortion.

Table 2 reveals that, on average, we find the highest relative returns in NEG and the lowest in POS. Relative returns in POSNEG are in between and very close to those in NEG. Contradicting our hypothesis H1b, we do not find a statistically significant difference in trustworthiness neither between POSNEG and POS (rank-sum test, $\mathrm{p}=0.155$ ) nor between POSNEG and NEG (rank-sum test, $\mathrm{p}=0.569$ ). However, we do find a significantly higher trustworthiness in NEG than in POS (rank-sum test, $\mathrm{p}=0.031$ ). Hence, we find evidence for hypotheses $\mathrm{H} 2 \mathrm{~b}$ and $\mathrm{H} 3 \mathrm{~b}$ on trustworthiness.

Table 2: Descriptive statistics on relative returns per treatment (POSNEG, POS, and NEG).

\begin{tabular}{cccc}
\hline Relative return & Average & Median & Standard deviation \\
\hline POSNEG & 0.51 & 0.50 & 0.197 \\
POS & 0.46 & 0.50 & 0.228 \\
NEG & 0.52 & 0.57 & 0.198 \\
\hline
\end{tabular}

Note: Median and standard deviation are on the individual level.

Figure 4 shows the average relative return per period. In all treatments, we observe an endgame effect with decreasing relative returns toward the end of the game. Comparing the last two periods - when the strategic value of reputation has vanished-with the average of the earlier periods, we find this endgame effect to be significant in POSNEG (signed-rank test, $\mathrm{p}=0.004$ ) and in NEG (signed-rank test, $p=0.008$ ), but insignificant in POS (signed-rank test, $p=0.173$ ). This might be seen as support of our theoretical argument that the strategic value of a favorable reputation (in the first 18 periods) is higher in POSNEG and in NEG than in POS, where any 
positive rating received can never be neutralized. Considering the first period in isolation, we find statistically significant differences in relative returns between POSNEG and POS (individual level rank-sum test, $\mathrm{N}=101, \mathrm{p}=0.033$ ) as well as $\mathrm{NEG}$ and POS (individual level rank-sum test, $\mathrm{N}=$ 89, $\mathrm{p}=0.012$ ), but not between POSNEG and NEG (individual level rank-sum test, $\mathrm{N}=102, \mathrm{p}=$ 0.517). This again, is in keeping with our theoretical assumption that reputation management impacts trustworthiness; trust is only indirectly affected. Recall that we found no significant difference in the trust exhibited in the first period. Additionally, in this period, we can detect no significant correlation between the investment of trustors and the relative returns of trustees on the individual level. ${ }^{15}$ This suggests that the first-round differences in trustworthiness between treatments are not caused by the differences in trust, but by the fear of receiving a negative rating being stronger than the desire for a positive rating.

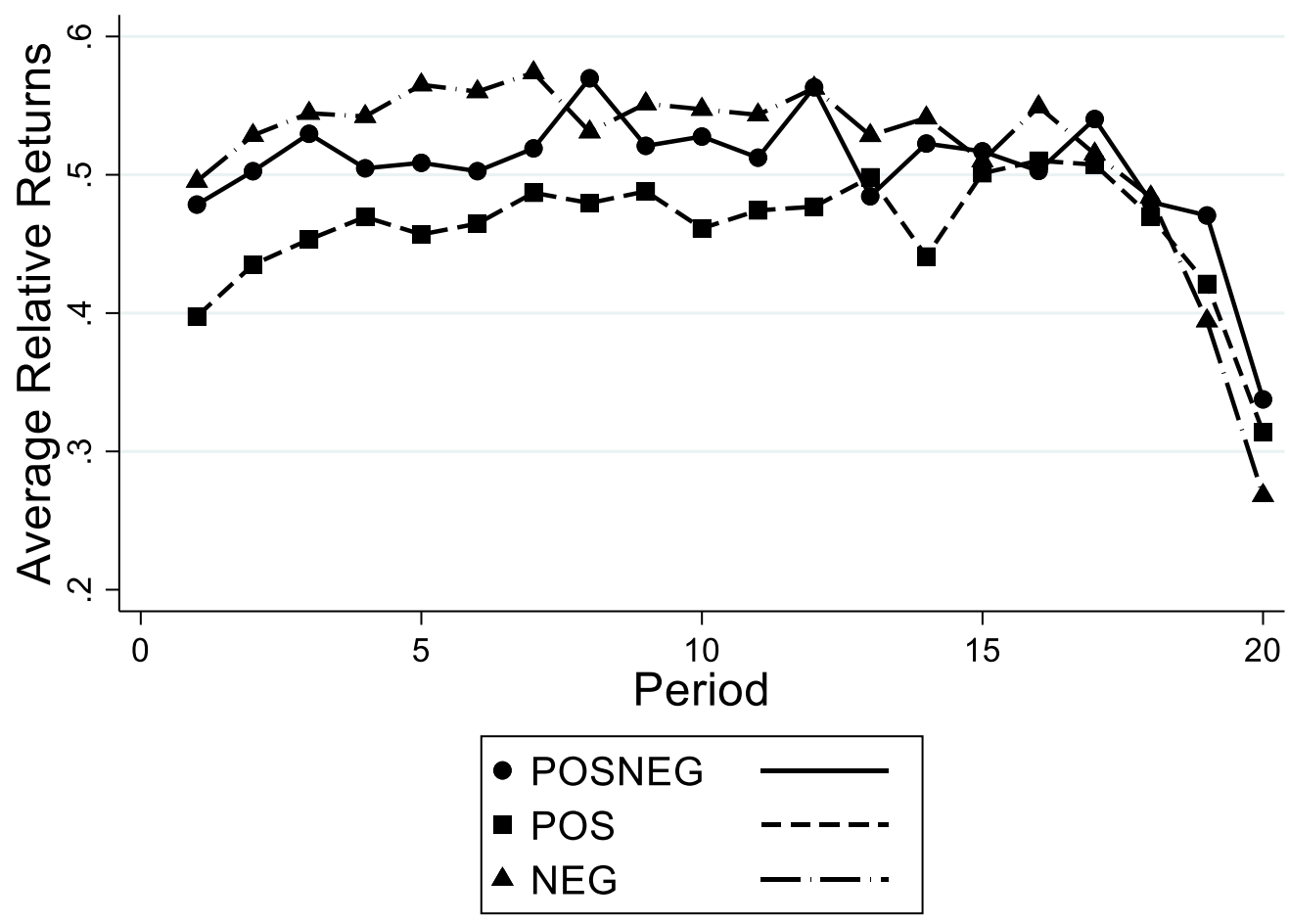

Figure 4: Average relative returns per period (by treatment: POSNEG, POS, and NEG).

${ }^{15}$ Individual level Spearman's rank correlation: POSNEG, $N=57, p=0.500 ;$ POS, $N=44, p=0.462$; NEG, $\mathrm{N}=45, \mathrm{p}=0.138$. 
Figure 5 displays the distribution of individual relative returns, considering several prominent levels of relative returns and the intervals in-between. Concretely, we focus on relative returns of one, two thirds, one half, one third and zero. We find that the most frequent level is a relative return of two thirds of the amount received. This share implies that trustor and trustee have identical payoffs in this period. The relative frequency of such a relative return is 0.24 in POS, 0.20 in POS, and 0.38 in NEG. The high share of trustees choosing this relative return in NEG suggests that trustees are eager to prevent a negative rating. None of the differences between these relative frequencies are statistically significant, though. ${ }^{16}$ Another, lower bulk of relative returns that we observe is at the equal split of the amount received. A further, again lower, spike is at one third, the share to exactly return the trustor's investment. Finally, we find occurrences of a relative return of zero, which means a full exploitation of trust. Relative returns of more than two thirds, which would imply higher payoffs of trustors than of trustees, are very rare.

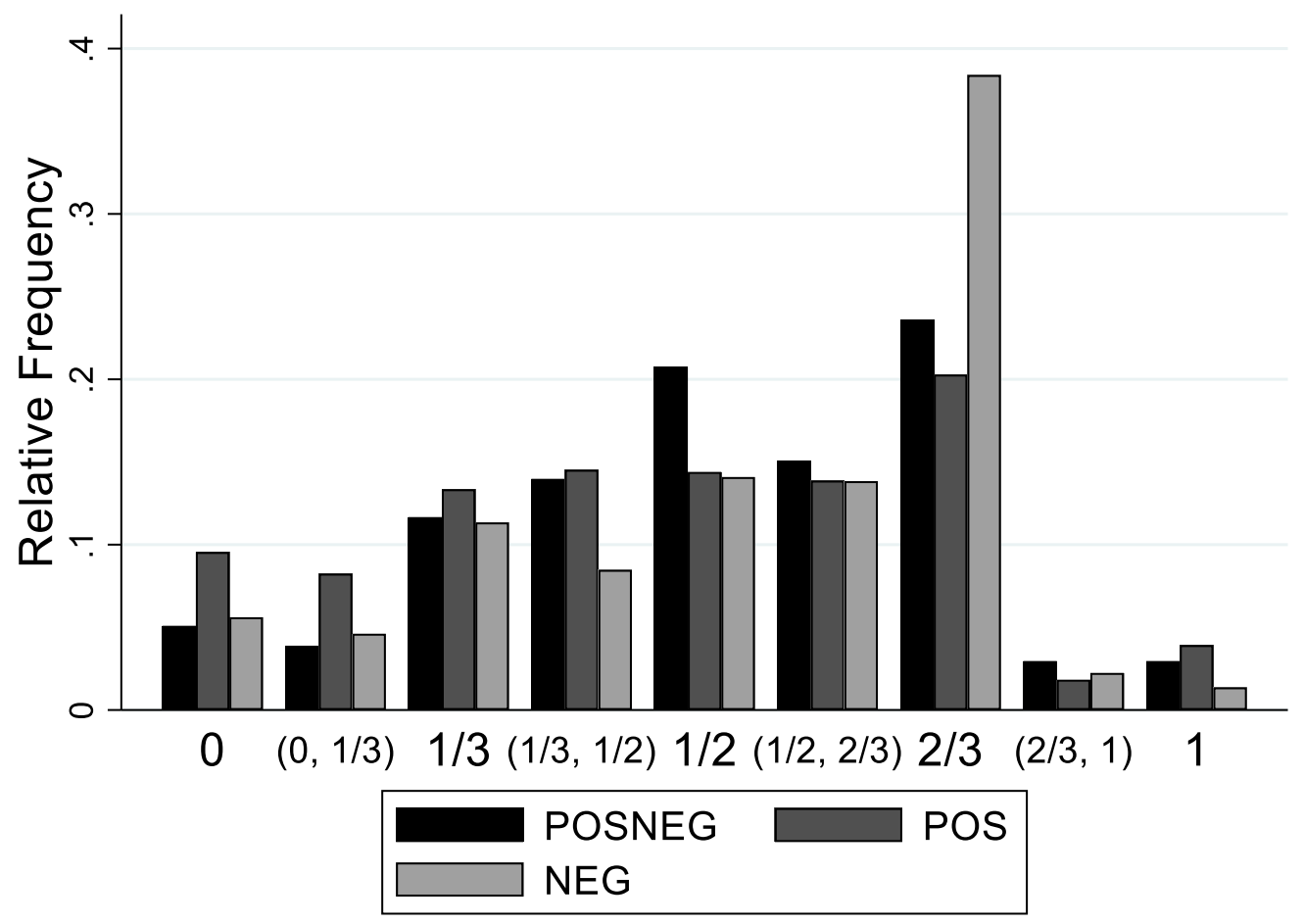

Figure 5: Relative frequency of individual relative returns of $0,1 / 3,1 / 2,2 / 3,1$, and in the respective intervals in-between (by treatment: POSNEG, POS, and NEG).

${ }^{16}$ Rank-sum tests: POSNEG vs POS, $\mathrm{p}=0.500 ;$ POSNEG vs NEG, $\mathrm{p}=0.088$; POS vs NEG, $\mathrm{p}=0.058$. 


\subsection{Rating giving}

Ratings are the connecting element between trustworthiness and trust. The cumulative distributions of relative returns per rating and treatment can be found in the Appendix (Figure A1). Comparing the distribution functions of positive ratings in POS and POSNEG as well as those of negative ratings in NEG and POSNEG, we do not observe important differences. We do observe, though, that the distribution functions of no ratings largely differ between POS, POSNEG and NEG. To provide statistical support for these findings, we consider that a positive rating corresponds to an average relative return of 0.59 (median 0.60) in POSNEG and to a relative return of 0.58 (median 0.58 ) in POS. The difference is not statistically significant. ${ }^{17}$ A negative rating corresponds to an average relative return of 0.27 (median 0.27) in POSNEG and of 0.30 (median 0.28) in NEG. The

difference is not significant, either. ${ }^{18}$ No rating corresponds to an average relative return of 0.46 (median 0.46) in POSNEG, to an average relative return of 0.29 (median 0.30) in POS, and to an average relative return of 0.62 (median 0.62 ) in NEG. All of the three differences are statistically significant. ${ }^{19}$

To summarize, only the distribution functions of no rating differ between treatments. This is due to the different meanings of no rating. In NEG, where no rating also comprises positive evaluations, a no rating is given for an average relative return of 0.62 , which is about as high as the average relative return of 0.59 for which a positive rating is given in POSNEG. In POS, where no rating also comprises negative evaluations, a no rating is given for an average relative return of 0.29 , which is about as high as the average relative return of 0.27 for which a negative rating is given in POSNEG.

\footnotetext{
${ }^{17}$ Rank-sum test: $\mathrm{p}=0.722$.

${ }^{18}$ Rank-sum test: $\mathrm{p}=0.434$.

${ }^{19}$ Rank-sum test: POSNEG vs POS: $\mathrm{p}=0.002$; POSNEG vs NEG: $\mathrm{p}=0.001$; POS vs NEG: $\mathrm{p}=0.003$.
} 

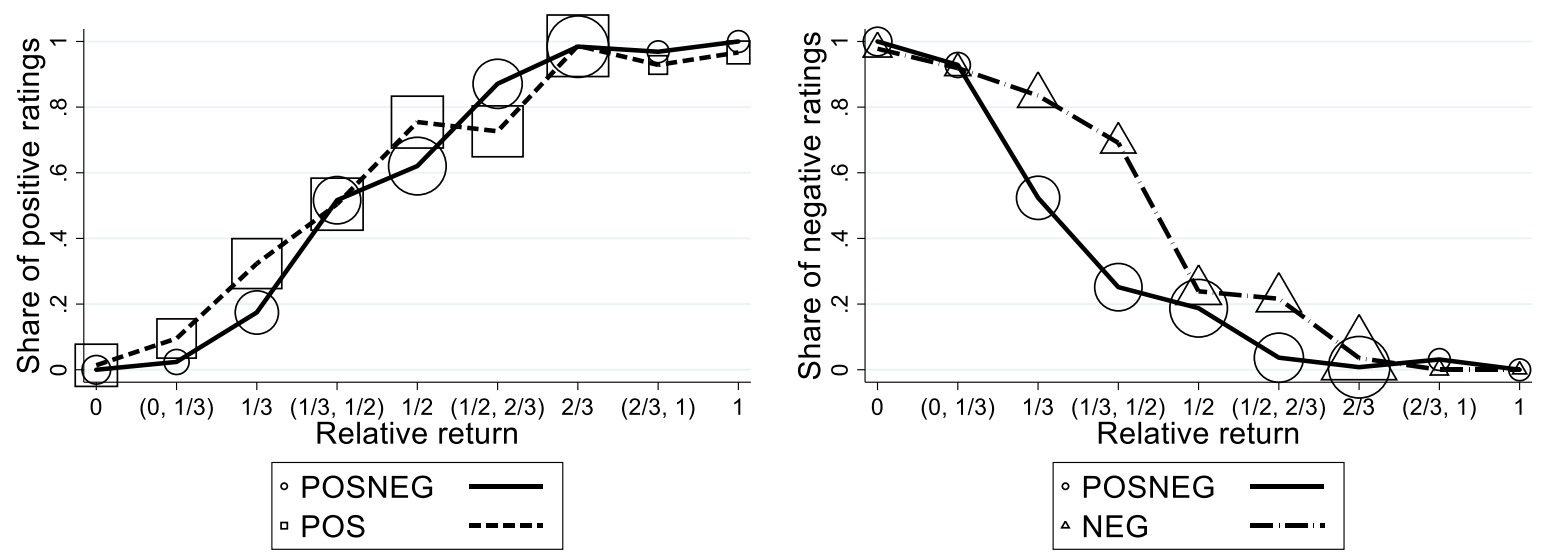

Figure 6: Left side: Share of positive ratings given to relative returns of $0,1 / 3,1 / 2,2 / 3,1$, and in the respective intervals in-between (by treatment: POSNEG, POS, and NEG). Right side: Share of negative ratings (by treatment: POSNEG, POS, and NEG). Note: The size of the circles, squares, and triangles increases with the number of observations with such a relative return level in each treatment.

For a more detailed inspection of rating behavior, Figure 6 exhibits the share of positive ratings (left side) and negative ratings (right side) for each of the five levels of trustworthiness and the intervals in-between, that we considered in Figure 5. The size of the circles, squares, and triangles increases with the number of cases with such a trustworthiness level in each treatment. Obviously, trustors tend to base their ratings on the relative returns of trustees. In POSNEG and POS, trustors give more often a positive rating the higher the relative return. In POSNEG and NEG, trustors give more often a negative rating the lower the relative return. Shares above 90 percent are reached, for positive ratings, at relative returns of two thirds and above in POSNEG and POS, and, for negative ratings, below relative returns of one third in POSNEG and NEG. In other words, trustees can be 'pretty sure' to receive a positive rating, if they return at least two thirds of the amount received. At the same time, trustees can be 'pretty sure' to receive a negative rating, if they returns less than of one third. Note also that trustees can be 'pretty sure' to avoid a negative rating, if they return more than one half in POSNEG and at least two thirds in NEG. 
Table 3: Multilevel mixed-effects logit regression on giving a positive rating (1) or negative rating (2)

\begin{tabular}{ccc}
\hline & $(1)$ & $(2)$ \\
& Positive rating & Negative rating \\
\hline Relative return & $21.474 * * *$ & $-21.283^{* *}$ \\
POS & $(1.236)$ & $(1.310)$ \\
& 0.626 & \\
NEG & $(0.458)$ & $1.709 * *$ \\
& & $(0.574)$ \\
constant & & $7.814 * * *$ \\
& $-9.619 * * *$ & $(0.650)$ \\
level-3 variance & $(0.655)$ & 0.623 \\
level-2 variance & 0.000 & 4.009 \\
N & 4.413 & 1882 \\
\hline
\end{tabular}

Note: Standard errors in parentheses. Reference category for POS and for NEG: POSNEG. Column 1 regards treatments POSNEG and POS, Column 2 regards treatments POSNEG and NEG. * $\mathrm{p}<0.05$, $* * \mathrm{p}<0.01, * * * \mathrm{p}<0.001$.

Table 3 provides the results of a multilevel mixed-effects logit regressions on rating giving of trustors. The use of a multilevel approach seems inevitable given that observations are clustered in subjects and populations. Table 3, Colum 1 displays the determinants of giving a positive rating in POSNEG or POS. We find a significantly positive coefficient for Relative return $(\mathrm{p}<0.001)$, indicating that trustors indeed base their rating on the trustworthiness of trustees in these two treatments. However, controlling for Relative return, we do not find differences in positive rating giving between POSNEG and POS ( $\mathrm{p}=0.171)$. Similarly, we analyze the determinants of giving a negative rating in POSNEG or NEG (Table 3, Column 2). Again, we find a significantly negative coefficient for Relative return $(\mathrm{p}<0.001)$. In addition, the treatment dummy for NEG has a significantly positive coefficient $(\mathrm{p}=0.003)$. Since we control for Relative return, this indicates that trustors are more willing to give a negative rating in NEG than in POSNEG. This suggests that the threshold for not giving a negative rating is higher in NEG than in POSNEG. Recall that we do not observe such a difference for the giving of a positive rating, when we compare POSNEG and POS. 


\subsection{Exhibited rating scores}

Table 4 displays the shares of positive, nil, and negative ratings as exhibited to trustors. Recall, that these ratings include the automatically created no ratings. Considering our baseline treatment POSNEG, we observe a large share of positive ratings and smaller shares of negative ratings or no ratings. We observe a lower share of positive ratings in POS than in POSNEG. This difference is not statistically significant, though. ${ }^{20}$ The lack of a negative rating option in POS apparently causes participants to give no rating instead. Similarly, in NEG, participants cannot give a positive rating; the best evaluation they may provide is a no rating. We observe a higher share of negative ratings in NEG than in POSNEG. The difference is statistically not significant, though. ${ }^{21}$

Table 4: Average share of exhibited positive, nil, and negative ratings per treatment (POSNEG, POS and NEG).

\begin{tabular}{cccc}
\hline & Positive rating & No rating & Negative rating \\
\hline POSNEG & 0.624 & 0.182 & 0.193 \\
POS & 0.557 & 0.443 & n. p. \\
NEG & n. p. & 0.744 & 0.256
\end{tabular}

Note: It is not possible (n. p.) to receive negative ratings in POS or positive ratings in NEG.

\subsection{Impact of rating scores}

Analyzing the reaction of trustors to reputation scores, Figure 7 displays the average investments per shares of positive ratings (left side) and of negative ratings (right side) in reputation scores. We arbitrarily choose intervals of 0.1 for the share of positive/negative ratings. ${ }^{22}$ The size of the circles, squares, and triangles increases with the number of cases with such a rating share in the treatment under consideration. We observe that investments are larger, the larger the share of

\footnotetext{
${ }^{20}$ Rank-sum test: $\mathrm{p}=0.177$.

${ }^{21}$ Rank-sum test: $\mathrm{p}=0.118$.

${ }^{22}$ Note that not the shares but absolute numbers of ratings are visible to trustors. We use the intervals of shares for the purpose of illustration.
} 
positive ratings. Investments are smaller, the larger the share of negative ratings in the reputation scores. These observations indicate that ratings determine the investment level.
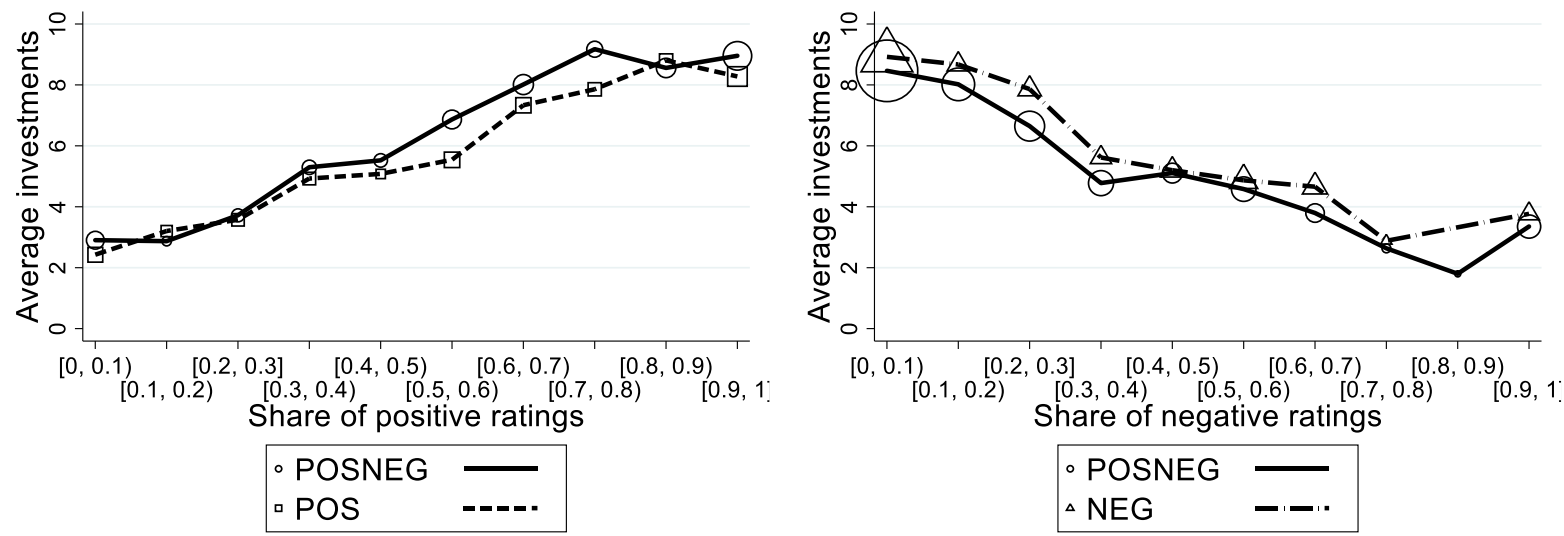

Figure 7: Left side: Trustors' average investments depending on the share of positive ratings (in intervals of 0.1) previously attributed to the respective trustee (by treatment: POSNEG and POS). Right side: Average investments depending on the share of negative ratings (by treatment: POSNEG and NEG). Note: The size of the circles, squares, and triangles increases with the number of observations with such a share of the respective rating in the respective treatment.

We run multilevel mixed-effects regressions on the investment by trustors on the individual level. Table 5, Column (1) serves as a reference and confirms the adverse effect of a structural positive bias on investments: with POSNEG as the reference category, the coefficient of the treatment dummy POS is significantly negative $(\mathrm{p}=0.007)$. The coefficient of NEG is statistically not different from zero $(\mathrm{p}=0.918)$. Next, we add variables representing the reputation scores. Since, by design, reputation scores differ in their composition between treatments, we consider the comparisons between POSNEG and POS separately from the comparison between POSNEG and NEG. Column (2) in Table 5 displays the determinants of trustors' investments in POSNEG and POS. It shows that trustors react to the reputation score of the respective trustee they are interacting with: the coefficient of the Share of positive ratings in the reputation score is significantly positive ( $\mathrm{p}<0.001)$. Controlling for the Share of positive ratings, we do not find treatment differences between POSNEG and POS ( $\mathrm{p}=0.092$ ). The now statistically insignificant coefficient of the POS dummy in Column (2) suggests that the differences in trust between POSNEG and POS are largely driven by the differences in the shares of positive ratings. The statistically insignificant interaction term in Column (3) confirms that trustors react to positive ratings similarly in POSNEG and POS $(\mathrm{p}=0.414)$. Table 5, Column (4) displays the determinants of investments in POSNEG and NEG. 
We find a significantly negative coefficient of the share of negative ratings $(\mathrm{p}<0.001)$ but no significant treatment effect $(\mathrm{p}=0.206)$. Finally, the insignificant interaction term in Column (5) shows no differences in trustors' reaction to negative ratings between POSNEG and NEG $(\mathrm{p}=$ $0.842)$.

Table 5: Multilevel mixed-effects regression on investment

\begin{tabular}{|c|c|c|c|c|c|}
\hline Investment & (1) & (2) & (3) & (4) & (5) \\
\hline POS & $\begin{array}{c}-1.015^{* *} \\
(0.379)\end{array}$ & $\begin{array}{l}-0.586 \\
(0.348)\end{array}$ & $\begin{array}{l}-0.768 \\
(0.414)\end{array}$ & & \\
\hline $\begin{array}{c}\text { Share of positive } \\
\text { ratings }\end{array}$ & & $\begin{array}{c}6.397 * * * \\
(0.189)\end{array}$ & $\begin{array}{c}6.261 * * * \\
(0.252)\end{array}$ & & \\
\hline $\begin{array}{l}\text { Share of positive } \\
\text { ratings x POS }\end{array}$ & & & $\begin{array}{c}0.311 \\
(0.380)\end{array}$ & & \\
\hline NEG & $\begin{array}{c}0.039 \\
(0.379)\end{array}$ & & & $\begin{array}{c}0.537 \\
(0.424)\end{array}$ & $\begin{array}{c}0.514 \\
(0.440)\end{array}$ \\
\hline $\begin{array}{c}\text { Share of negative } \\
\text { ratings }\end{array}$ & & & & $\begin{array}{c}-7.913 * * * \\
(0.256)\end{array}$ & $\begin{array}{c}-7.963 * * * \\
(0.355)\end{array}$ \\
\hline $\begin{array}{c}\text { Share of negative } \\
\text { ratings } \mathrm{x} \text { NEG }\end{array}$ & & & & & $\begin{array}{c}0.102 \\
(0.512)\end{array}$ \\
\hline constant & $\begin{array}{l}7.089 * * * \\
(0.248)\end{array}$ & $\begin{array}{l}3.095 * * * \\
(0.257)\end{array}$ & $\begin{array}{c}3.179 * * * \\
(0.277)\end{array}$ & $\begin{array}{c}8.619 * * * \\
(0.282)\end{array}$ & $\begin{array}{l}8.629 * * * \\
(0.286)\end{array}$ \\
\hline level-3 variance & 0.000 & 0.000 & 0.000 & 0.265 & 0.265 \\
\hline level-2 variance & 3.134 & 2.769 & 2.776 & 2.951 & 2.951 \\
\hline level-1 variance & 10.567 & 6.575 & 6.571 & 6.612 & 6.612 \\
\hline $\mathrm{N}$ & 2850 & 1995 & 1995 & 1995 & 1995 \\
\hline
\end{tabular}

Note: Standard errors in parentheses. Only periods $>1$ are considered. Reference category for POS and for NEG: POSNEG. Columns (2) and (3) regard treatments POSNEG and POS, Columns (4) and (5) regard treatments POSNEG and NEG. $* \mathrm{p}<0.05, * * \mathrm{p}<0.01, * * * \mathrm{p}<0.001$. 
To summarize, the regression results suggest that trustors react to the share of positive and negative ratings, respectively. We find no differences in this reaction, when we compare the behavior in POSNEG to the one in POS and NEG, respectively. Furthermore, we find that once we control for the share of positive ratings, the treatment effect between POSNEG and POS becomes statistically insignificant. This might be seen as evidence for our theoretical argument (based on Figure 1) implying that the higher trustworthiness and the consequential higher share of positive ratings in POSNEG than in POS are driving the result of higher trust in POSNEG than in POS.

\subsection{Payoffs}

Considering the average payoff per round, we find that trustors earn significantly less than trustees in all treatments. ${ }^{23} \mathrm{We}$ observe that the treatments have an impact on the payoffs of trustors: their payoffs in POS (12.7 ECU) are significantly lower than of those in POSNEG (14.1 ECU) and NEG (14.3 ECU). ${ }^{24} \mathrm{~A}$ payoff greater than $10 \mathrm{ECU}$ in a round shows us that the investment was profitable, in the sense that the amount returned exceeded the amount invested. We find a significantly lower share of profitable rounds in POS (0.58) than in POSNEG (0.71) or NEG (0.70). ${ }^{25}$ The payoffs of trustees do not significantly differ between treatments (POSNEG: 19.92 ECU, POS: 19.95 ECU, NEG: $19.45 \mathrm{ECU}){ }^{26}$

\section{Conclusion}

Our theoretical considerations as well as our experimental results demonstrate an adverse effect of a structural positive bias in reputation systems on trust: trustors' investments are significantly lower in POS than in POSNEG or NEG. The system in NEG performs as well as the unrestricted system in POSNEG in that investments reach approximately the same level in both treatments. In other words, we do not find an effect of a structural negative bias in reputation systems on trust. The analysis regarding the trustworthiness of trustees displays a similar picture with significantly lower relative returns in POS than in NEG. The relative returns in POSNEG are between those in the two

\footnotetext{
${ }^{23}$ Rank-sum tests: POSNEG, $\mathrm{p}<0.001$; POS, $\mathrm{p}<0.001$; NEG, $\mathrm{p}<0.001$.

${ }^{24}$ Rank-sum tests: POSNEG vs POS, $\mathrm{p}=0.039$; POSNEG vs NEG, $\mathrm{p}=0.972$; POS vs NEG, $\mathrm{p}=0.015$.

${ }^{25}$ Fisher's exact test: POSNEG vs POS, $\mathrm{p}<0.001$; POSNEG vs NEG, $\mathrm{p}=0.467$; POS vs NEG, $\mathrm{p}<0.001$.

${ }^{26}$ Rank-sum tests: POSNEG vs POS, $\mathrm{p}=0.477$; POSNEG vs NEG, $\mathrm{p}=0.887$; POS vs NEG, $\mathrm{p}=0.423$.
} 
other treatments, but they are not significantly different from either of them. The treatment effects on trust and trustworthiness translate into differences in payoffs between treatments. The positive bias in POS leads, among the three treatments, to the lowest payoffs of trustors and thus to the largest inequality between market sides.

Fisher et al. (2018) suggest that our results might apply to five-star rating systems, as well. They find evidence that customers think in categories of positive ratings (four or five stars) and negative ratings (one or two stars). In spite of the "well-functioning" of NEG, we do not intend to advocate the restriction of rating options, when there is no need to do so. The negative reputation system has some important downsides. Trustees have only a limited possibility to reconcile their reputation score after a negative rating. Trustors do not receive information that might be relevant for them. Unfortunately, our experimental design does not allow any inference on how this restricted information transmission is affecting beliefs. Nevertheless, our analysis highlights the high value of negative ratings. 


\section{References}

Abraham, Martin, Veronika Grimm, Christina Neeß, and Michael Seebauer. 2016. "Reputation Formation in Economic Transactions." Journal of Economic Behavior \& Organization 121:1-14. https://doi.org/10.1016/j.jebo.2015.10.010.

Ahmed, Abdelmuttlib Ibrahim Abdalla, Siti Hafizah Ab Hamid, Abdullah Gani, Suleman khan, and Muhammad Khurram Khan. 2019. "Trust and Reputation for Internet of Things: Fundamentals, Taxonomy, and Open Research Challenges." Journal of Network and Computer Applications 145:102409. https://doi.org/10.1016/j.jnca.2019.102409.

Anderhub, Vital, Dirk Engelmann, and Werner Güth. 2002. “An Experimental Study of the Repeated Trust Game with Incomplete Information." Journal of Economic Behavior \& Organization 48 (2): 197-216. https://doi.org/10.1016/S0167-2681(01)00216-5.

Andreoni, James. 1988. "Why free ride?" Journal of Public Economics 37 (3): 291-304. https://doi.org/10.1016/0047-2727(88)90043-6.

Ashraf, Nava, Iris Bohnet, and Nikita Piankov. 2006. "Decomposing Trust and Trustworthiness." Experimental Economics 9 (3): 193-208. https://doi.org/10.1007/s10683-006-9122-4.

Bar-Isaac, Heski, and Steven Tadelis. 2008. Seller Reputation. Hanover, MA: Now Publishers.

Baumeister, Roy F., Ellen Bratslavsky, Catrin Finkenauer, and Kathleen D. Vohs. 2001. "Bad Is Stronger Than Good." Review of General Psychology 5 (4): 323-70. https://doi.org/10.1037//1089-2680.5.4.323.

Berg, Joyce, John Dickhaut, and Kevin McCabe. 1995. "Trust, Reciprocity, and Social History." Games and Economic Behavior 10 (1): 122-42. https://doi.org/10.1006/game.1995.1027.

Boero, Riccardo, Giangiacomo Bravo, Marco Castellani, and Flaminio Squazzoni. 2009. "Reputational Cues in Repeated Trust Games." The Journal of Socio-Economics 38 (6): 871-77. https://doi.org/10.1016/j.socec.2009.05.004.

Bohnet, Iris, and Richard Zeckhauser. 2004. "Trust, Risk and Betrayal." Journal of Economic Behavior \& Organization 55 (4): 467-84. https://doi.org/10.1016/j.jebo.2003.11.004. 
Bolton, Gary, Ben Greiner, and Axel Ockenfels. 2013. "Engineering Trust: Reciprocity in the Production of Reputation Information." Management Science 59 (2): 265-85. https://doi.org/10.1287/mnsc.1120.1609.

Bolton, Gary E., Elena Katok, and Axel Ockenfels. 2004. "How Effective Are Electronic Reputation Mechanisms? An Experimental Investigation.” Management Science 50 (11): 1587-1602. https://doi.org/10.1287/mnsc.1030.0199.

Bolton, Gary E., Elena Katok, and Axel Ockenfels. 2005. "Cooperation Among Strangers with Limited Information About Reputation.” Journal of Public Economics 89 (8): 1457-68. https://doi.org/10.1016/j.jpubeco.2004.03.008.

Brandts, Jordi, and Neus Figueras. 2003. "An Exploration of Reputation Formation in Experimental Games.” Journal of Economic Behavior \& Organization 50 (1): 89-115. https://doi.org/10.1016/S0167-2681(02)00042-2.

Camerer, Colin, and Keith Weigelt. 1988. "Experimental Tests of a Sequential Equilibrium Reputation Model.” Econometrica 56 (1): 1. https://doi.org/10.2307/1911840.

Capraro, Valerio, Francesca Giardini, Daniele Vilone, and Mario Paolucci. 2016. "Partner Selection Supported by Opaque Reputation Promotes Cooperative Behavior.” Judgment and Decision Making 11 (6): 589-600.

Dellarocas, Chrysanthos, and Charles A. Wood. 2008. "The Sound of Silence in Online Feedback: Estimating Trading Risks in the Presence of Reporting Bias.” Management Science 54 (3): 460-76. https://doi.org/10.1287/mnsc.1070.0747.

Dohmen, Thomas, Armin Falk, David Huffman, Uwe Sunde, Jürgen Schupp, and Gert G. Wagner. 2011. "Individual Risk Attitudes: Measurement, Determiants, and Behavioral Consequences." Journal of the European Economic Association 9 (3): 522-50. https://doi.org/10.1111/j.1542-4774.2011.01015.x.

Fischbacher, Urs. 2007. "z-Tree: Zurich toolbox for ready-made economic experiments." Experimental Economics 10 (2): 171-78. https://doi.org/10.1007/s10683-006-9159-4.

Fisher, Matthew, George E. Newman, Ravi Dhar, Gita Johar, and Stijn van Osselaer. 2018. "Seeing Stars: How the Binary Bias Distorts the Interpretation of Customer Ratings.” Journal of Consumer Research 31 (2): 191. https://doi.org/10.1093/jcr/ucy017. 
Fradkin, Andrey, Elena Grewal, and David Holtz. 2017. "The Determinants of Online Review Informativeness: Evidence from Field Experiments on Airbnb.” MIT Sloan School of Management and Airbnb Working Paper.

Gibbons, Robert. 2001. Trust in social structures: Hobbes and Coase meet repeated games. In K. S. Cook (ed.), Russell Sage foundation series on trust 2: 332-353. Russell Sage Foundation. Greiner, Ben. 2015. "Subject pool recruitment procedures: Organizing experiments with ORSEE." Journal of the Economic Science Association 1 (1): 114-25. https://doi.org/10.1007/s40881-015-0004-4.

Grosskopf, Brit, and Rajiv Sarin. 2010. "Is Reputation Good or Bad? An Experiment.” American Economic Review 100 (5): 2187-2204. https://doi.org/10.1257/aer.100.5.2187.

Houser, Daniel, Daniel Schunk, and Joachim Winter. 2010. "Distinguishing Trust from Risk: An Anatomy of the Investment Game." Journal of Economic Behavior \& Organization 74 (12): 72-81. https://doi.org/10.1016/j.jebo.2010.01.002.

Jewell, R. Todd, Michael A. McPherson, and Margie A. Tieslau. 2013. "Whose fault is it? Assigning blame for grade inflation in higher education.” Applied Economics 45 (9): 11851200. https://doi.org/10.1080/00036846.2011.621884.

Johnson, Noel D., and Alexandra A. Mislin. 2011. "Trust Games: A Meta-Analysis.” Journal of Economic Psychology 32 (5): 865-89. https://doi.org/10.1016/j.joep.2011.05.007.

Josang, Audun, and Jennifer Golbeck (2009). "Challenges for Robust Trust and Reputation Systems". 5th International Workshop on Security and Trust Management.

Keser, Claudia. 2003. "Experimental games for the design of reputation management systems." IBM Systems Journal 42 (3): 498-506. https://doi.org/10.1147/sj.423.0498.

Klein, Tobias J., Christian Lambertz, and Konrad O. Stahl. 2016. "Market Transparency, Adverse Selection, and Moral Hazard." Journal of Political Economy 124 (6): 1677-1713. https://doi.org/10.1086/688875.

Kreps, David. 1990. "Corporate Culture and Economic Theory', in James Alt and Karl Shepsle (eds.), Perspectives on Positive Political Economy. New York: Cambridge University Press, 90-143. 
Kreps, David M., and Robert Wilson. 1982. "Reputation and imperfect information." Journal of Economic Theory 27 (2): 253-79. https://doi.org/10.1016/0022-0531(82)90030-8.

Li, Lingfang, Steven Tadelis, and Xiaolan Zhou. 2016. Buying Reputation as a Signal of Quality: Evidence from an Online Marketplace. Cambridge, MA: National Bureau of Economic Research.

Lucking-Reiley, David, Doug Bryan, Naghi Prasad, and Daniel Reeves. 2007. "Pennies from eBay: The Determinants of Price in Online Auctions.” Journal of Industrial Economics 55 (2): 223-33. https://doi.org/10.1111/j.1467-6451.2007.00309.x

Lumeau, Marianne, David Masclet, and Thierry Pénard. 2015. "Reputation and social (dis)approval in feedback mechanisms: An experimental study." Journal of Economic Behavior \& Organization 112: 127-40. https://doi.org/10.1016/j.jebo.2015.02.002.

Masclet, David, and Thierry Pénard. 2012. "Do Reputation Feedback Systems Really Improve Trust Among Anonymous Traders? An Experimental Study.” Applied Economics 44 (35): 4553-73. https://doi.org/10.1080/00036846.2011.591740.

Mayzlin, Dina, Yaniv Dover, and Judith Chevalier. 2014. "Promotional Reviews: An Empirical Investigation of Online Review Manipulation.” American Economic Review 104 (8): 242155. https://doi.org/10.1257/aer.104.8.2421.

McCabe, Kevin A., Mary L. Rigdon, and Vernon L. Smith. 2003. "Positive Reciprocity and Intentions in Trust Games." Journal of Economic Behavior \& Organization 52 (2): $267-$ 75. https://doi.org/10.1016/S0167-2681(03)00003-9.

Milgrom, Paul, and John Roberts. 1982. "Predation, Reputation, and Entry Deterrence." Journal of Economic Theory 27 (2): 280-312. https://doi.org/10.1016/0022-0531(82)90031-X.

Neral, John, and Jack Ochs. 1992. "The Sequential Equilibrium Theory of Reputation Building: A Further Test." Econometrica 60 (5): 1151. https://doi.org/10.2307/2951542.

Nosko, Chris, and Steven Tadelis. 2015. "The Limits of Reputation in Platform Markets: An Empirical Analysis and Field Experiment." Cambridge, MA: National Bureau of Economic Research. 
Ostrom, Elinor. 1998. “A Behavioral Approach to the Rational Choice Theory of Collective Action: Presidential Address, American Political Science Association, 1997." American Political Science Review 92 (1): 1-22. https://doi.org/10.2307/2585925.

Resnick, Paul, and Richard Zeckhauser. 2002. "Trust among strangers in internet transactions: Empirical analysis of eBay' s reputation system", Baye, M. (ed.) The Economics of the Internet and E-commerce (Advances in Applied Microeconomics, Vol. 11) 127-156. Emerald Group Publishing Limited, Bingley. https://doi.org/10.1016/S02780984(02)11030-3.

Rockenbach, Bettina, and Abdolkarim Sadrieh. 2012. "Sharing information." Journal of Economic Behavior \& Organization 81 (2): 689-98. https://doi.org/10.1016/j.jebo.2011.10.009.

Selten, Reinhard. 1978. "The Chain Store Paradox." Theory and Decision 9 (2): 127-59. https://doi.org/10.1007/BF00131770.

Shankar, Ramesh. 2015. "Online Reputational Loss Aversion: Empirical Evidence from StackOverflow.com.” Working paper. http://dx.doi.org/10.2139/ssrn.2603303.

Sherchan, Wanita, Surya Nepal, and Cecile Paris. 2013. "A Survey of Trust in Social Networks." ACM Computing Surveys 45 (4): 1-33. https://doi.org/10.1145/2501654.2501661.

Standifird, Stephen. 2001. "Reputation and e-commerce: eBay auctions and the asymmetrical impact of positive and negative ratings." Journal of Management 27 (3): 279-95. https://doi.org/10.1016/S0149-2063(01)00092-7.

Swamynathan, Gayatri, Kevin C. Almeroth, and Ben Y. Zhao. 2010. "The Design of a Reliable Reputation System." Electronic Commerce Research 10 (3-4): 239-70. https://doi.org/10.1007/s10660-010-9064-y.

Tadelis, Steven. 2016. "Reputation and Feedback Systems in Online Platform Markets." Annual Review of Economics 8 (1): 321-40. https://doi.org/10.1146/annurev-economics-080315015325 .

Tavakolifard, Mozhgan, and Kevin C. Almeroth. 2012. "A Taxonomy to Express Open Challenges in Trust and Reputation Systems." Journal of Communications 7 (7). https://doi.org/10.4304/jcm.7.7.538-551. 
van den Bos, Wouter, Eric van Dijk, Michiel Westenberg, Serge A. R. B. Rombouts, and Eveline A. Crone. 2009. "What Motivates Repayment? Neural Correlates of Reciprocity in the Trust Game." Social cognitive and affective neuroscience 4 (3): 294-304. https://doi.org/10.1093/scan/nsp009.

Watson, David, and Ronald Friend. 1969. "Measurement of Social-Evaluative Anxiety." Journal of consulting and clinical psychology 33 (4): 448-57. https://doi.org/10.1037/h0027806. 


\section{Appendix}
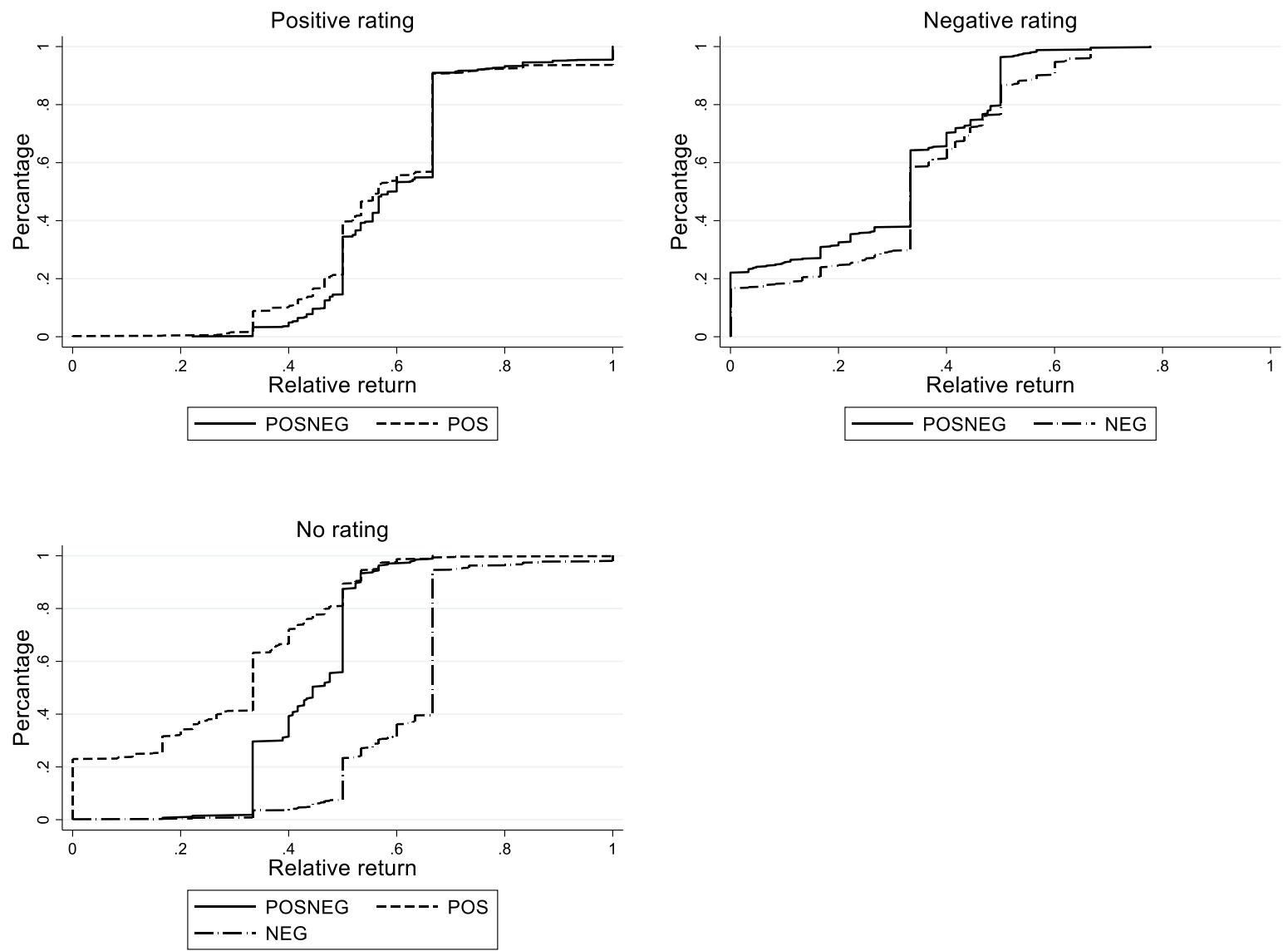

Figure A1: Upper left: Cumulative distribution of relative returns corresponding to a positive rating (by treatment: POSNEG and POS). Upper right: Cumulative distribution of relative returns corresponding to a negative rating (by treatment: POSNEG and POS). Lower left: Cumulative distribution of relative returns corresponding to no rating (by treatment: POSNEG, POS, and NEG). 


\title{
Chapter III: Study 2
}

\section{Its me again... Ask avoidance and the dynamics of charitable giving *}

\begin{abstract}
This article analyzes the impact of repeated donation requests on charitable giving. In a laboratory experiment, participants receive once an endowment and can transfer a share of it to a charity. Implementing three donation decision stages (instead of one) leads to a slight increase in donations. A treatment in which participants can avoid the repetition of the ask yields the highest average donation. One third of participants choose to avoid the repetition. "Non-avoiders" donate significantly more than "avoiders". Importantly, non-avoiders also transfer significantly more than the participants in the treatment with one decision stage. This finding suggests that offering an avoidance option might a suitable strategy to identify the most promising targets of fundraising, namely those individuals who enjoy donating repeatedly.
\end{abstract}

Keywords: Charitable giving, Repeated request, Ask avoidance, Experiment

JEL classification: C91, D64, D73

* I have received helpful comments from participants of the annual conference of the Gesellschaft für experimentelle Wirtschaftsforschung (GfeW) in Düsseldorf and from participants of the CollEcons colloquium at the University of Goettingen. I would like to thank Clauda Keser, Holger Rau, Viviana Uruena, and Kerstin Unfried for their support.

The article is under revision at the Journal of Economic Behavior \& Organization - Special Issue on the Economics of Charitable Giving. 


\section{Introduction}

At several occasions, individuals know they will be asked repeatedly for a donation or a favor. The beggar in front of the train station will ask again when the agent returns the next day. During online fundraising campaigns (for example, the Wikimedia Foundation "Big English" campaign), popups with donation requests appear every time the individual visits a specific website. In Christmas time, fundraisers await individuals when they enter and then again leave grocery stores (for example fundraisers of the Salvation Army, as described by Andreoni et al., 2017). These situations have three characteristics in common: First, irrespective of the repetition of the request, donations go to the same recipient (the beggar or a charity, respectively). Second, the potential donor receives no new information about the recipient between repetitions. Third, the agent does (in most cases) not receive new income between the donation decisions.

In the aforementioned examples, potential donors might anticipate the repeated fundraising. This may have consequences for their behavior. On the one hand, they might plan to be consistent and donate the same amount at every donation request. Donors might derive some psychological gains from giving, e.g., when they feel the "warm glow" of helping others (Andreoni, 1989, 1990). In this case, the mental accounting theory by Thaler (1985) suggests that individuals (with concave utility functions) can derive a higher utility by segregating their gains and donating repeatedly. On the other hand, individuals might decide to give only once and not thereafter. The concept of moral licensing (Monin and Miller, 2001; Merritt et al., 2010; Mazar and Zhon, 2010), suggesting that individuals use a good deed as an excuse for subsequent immoral behavior, indicates such behavior. $^{27}$

Anticipation of the repetition of the donation request might also induce ask avoidance. Results from fundraising experiments (DellaVigna et al., 2012; Knutsson et al., 2013; Andreoni et al. 2017; Exley and Petrie, 2018; Damgaard and Gravert, 2018; Adena and Huck, 2020) and from laboratory experiments (Dana et al., 2006; Broberg et al., 2007; Lazear et al., 2012) show that some agents avoid being asked for a donation, although this behavior disappears when the cost of avoidance increases (Trachtman et al., 2015). Diamond and Noble (2001) report that some individuals apply defensive strategies against frequent solicitations.

\footnotetext{
${ }^{27}$ Moral licensing might be most relevant when individuals donate due to social pressure (DellaVigna et al.,
} 2012) or to avoid guilt (Xu et al., 2012). 
But should fundraiser deliberately grant the option to avoid the repetition of the ask? On the one hand, implementing an avoidance option might leave the fundraiser with less potential targets of subsequent solicitations. DellaVigna et al. (2012) report a decrease in total donations due to the implementation of an ask avoidance option (with respect to the first ask). On the other hand, Kamdar et al. (2013) find a positive impact of granting an option to avoid the repetition of the ask on total donations. The authors argue that potential donors might perceive the existence of such an option as a generous act. Besides, the ask avoidance option has the potential to identify the individuals who derive some warm glow from donating. These individuals would choose not to avoid the ask.

In light of these open questions, the aim of the current study is twofold. First, I want to analyze the effect of an anticipated repetition of donation requests on total donations. In this context, I analyze the dynamics of charitable giving. Second, I aim to understand how granting the option to avoid the repetition of the ask affects charitable giving. To my knowledge, this is the first study on charitable giving in the context of high-frequency fundraising campaigns with a repetition of requests without new income, without new information, and without a new recipient.

To achieve a high degree of control, I make use of a laboratory experiment with a dictator game (see e.g. Kahneman et al., 1986, and Forsythe et al., 1994) as the workhorse. ${ }^{28}$ The design consists of three treatments. In $O N C E$, participants have the possibility to donate to a charity at one decision stage. In THRICE, it is common knowledge that agents can donate up to three times to the very same charitable organization. The treatment variation allows to study the impact of the mere repetition of the request on charitable giving. In ENDOGENOUS, the experimenter announces the repetition of the request but offers the option to avoid it. This allows to test if individuals avoid the ask and how this affects total donations.

The analysis of the experimental data reveals that donations to the charity are on average largest in ENDOGENOUS. Donations in THRICE are only slightly larger than in ONCE. In THRICE, participants apparently shift donations from the first decision stage to the two subsequent stages. In ENDOGENOUS, however, no such donation smoothing is observable. The analysis shows that

\footnotetext{
${ }^{28}$ Running the experiment in the lab instead of in the field allows to ensure that agents neither receive new income nor new information about the charity between the three decision stages. Furthermore, it ensures that the style of solicitation and the transaction costs for potential donors are identical in all stages and treatments.
} 
participants not avoiding the repetition of the ask in ENDOGENOUS donate significantly more than those avoiding the repetition. Importantly, average donations of non-avoiding participants are also significantly larger than donations in $O N C E$. Finally, I observe that individuals perceiving a donation as a gain to the charity (instead of a loss for themselves) are more prone to donate repeatedly substantial amounts.

These results have several important implications. This paper is the first to show that a mere repetition of donation requests is only slightly increasing donations. When each donation request comes with a cost, the repetition might even induce a loss. At the same time, I find evidence that some agents prefer to donate repeatedly. In line with the mental accounting theory by Thaler (1985), this preference is stronger for donors perceiving a donation a gain (for the charity) rather than as a loss (for themselves). Importantly, the analysis reveals that offering the possibility to donate repeatedly and, at the same time, granting the option to avoid the ask seems to be a lucrative fundraising strategy. In contrast to DellaVigna et al. (2012), I find that the ask avoidance option does not decrease total donations. Instead, the measure yields a moderate increase in donations, decreases the costs of fundraising, and allows for an identification of the individuals who like being asked. These are the most promising targets for fundraising.

\section{Experimental design}

The experimental design builds on a dictator game (see e.g. Kahneman et al., 1986; and Forsythe et al, 1994) with a charity as the recipient (Eckel and Grossman, 1996). Participants receive an endowment of 10.00 euros and have the option to donate a share of it to the charity (in increments of 0.10 euros). In this study, donations go to the International Federation of the Red Cross and the Red Crescent (IFRC).

I implement three treatments: ONCE, THRICE, and ENDOGENOUS. Between treatments ONCE and THRICE, I vary how often participants have the possibility to donate to the charity. I interpret the explicit possibility to donate as an implicit request for a donation. In treatment $O N C E$, participants have at one decision stage the opportunity to make a donation. In treatment THRICE, participants have three times the possibility to donate a share of their initial endowment. The number of donation requests is made common knowledge before the donations process starts. 
In treatment ENDOGENOUS, participants can endogenously vary the number of donation decision stages. It is common knowledge that they have at maximum three times the opportunity to donate. At the first and the second donation decision, participants have the option to avoid the subsequent donation request(s). To do so, they must click on a checkbox. Avoiding the ask does not come with any monetary costs.

An important feature of the design is that participants receive only one endowment (before the first donation decision stage) irrespective of the treatment. Furthermore, all donations go to the same charity. Finally, I do not vary the information the participants receive. I can rule out that the repetition of the donation request has worked as a signal emphasizing the neediness of the charity. A post-decisional inquiry shows no differences in the perceived neediness of the charity between treatments. ${ }^{29}$

\subsection{Behavioral hypotheses}

The behavioral hypotheses are based on the mental accounting theory by Thaler (1985). The theory states that individuals prefer to segregate gains. This suggests that donors donate at all donation decision stages. Contrary to this, the concept of moral licensing (Monin and Miller, 2001; Merritt et al., 2010; Mazar and Zhon, 2010) suggests that participants would donate at the first decision stage and then use this good deed as an excuse for not donating at subsequent stages. ${ }^{30}$ In this case, the amount donated would be identical in all treatments. I use this as a reference for my hypotheses that I derive from the mental accounting theory by Thaler (1985). ${ }^{31}$

Consider a function $v\left(x_{i}\right)$, where $x_{i}$ represents the donation by individual $i$, with $0 \leq x_{i} \leq 10$. The function $v($ ) is the individual's value function as introduced by Thaler (1985) and Kahneman and Tversky (1979). The function is concave for relative gains. As a reference, I set $v\left(x_{i}=0\right)=$ 0 . In other words, the individual derives a value of $v\left(x_{i}\right)=0$ from a donation of zero. Since individuals are not forced to donate, this value also is the minimal value of $v\left(x_{i}\right)$ in an optimum.

\footnotetext{
${ }^{29}$ Inquiry: "What do you think: How needy is the IFRC?" Scale: $1-7$, Kruskal-Wallis test: $p=0.240$.

${ }^{30}$ If individuals tend to procrastinate, they might also donate only at last decision stage.

${ }^{31}$ A further approach would be to consider prestige. Donkers et al. (2017) comment that when donating increases prestige, the dynamics would depend on the perception whether the increase is more pronounced for one large or for several small donations.
} 
I assume that for some individuals the value of any positive donation would be negative or zero, so $v\left(x_{i}\right) \leq 0$ for $x_{i}>0$. Those individuals choose not to donate (assuming that they want to maximize the value function). Other individuals might derive a positive value from a donation, so $v\left(x_{i}\right)>0$ for some $x_{i}>0$. For example, they may be impure altruists (Andreoni, 1989, 1990). These individuals would choose to donate. ${ }^{32}$ I assume that preferences are single-peaked in the sense that the function $v\left(x_{i}\right)$ has a single maximum in the considered interval of $x_{i}{ }^{33}$ The functional form (including the location of the maximum) might vary between individuals. Yet, the random allocation of individuals into treatments ensures that on average there are no differences in the functional form of $v()$ between treatment groups.

The treatment $O N C E$ serves as the baseline. I expect that a positive share of participants donates. For the prediction of the behavior in THRICE, the mental accounting theory by Thaler (1985) becomes relevant. The theory states that segregating gains is preferred to integrating them. Since participants are aware of the repetition of the donation request, they can segregate. In the case of this study, the theory suggests (for gains) the inequality presented in Equation (1).

$$
\begin{gathered}
v\left(\frac{x_{i}}{a}\right)+v\left(\frac{x_{i}}{b}\right)+v\left(\frac{x_{i}}{c}\right)>v\left(x_{i}\right) \\
\text { with } a+b+c=1 \text { and } a, b, c>0
\end{gathered}
$$

Equation (1) illustrates two results that can be derived from the functional form of the value function. ${ }^{34}$ First, donating is more attractive in THRICE than in ONCE. This is especially visible considering the behavior of individuals who are indifferent between donating and not-donating in $O N C E$. In $O N C E$, the highest value that is achievable for these individuals is $v\left(x_{i}\right)=0$. I assume that these agents are not donating. Now, Equation (1) tells us that perceiving a donation as a gain and separating it into three donations - as it is possible in THRICE - yields a higher value. Individuals that are indifferent in $O N C E$ would prefer to donate in THRICE. This suggests that a

\footnotetext{
${ }^{32}$ A meta-study by Engel (2011) reveals that 64 percent of participants in dictator games give a positive amount to the recipient.

${ }^{33}$ The function is strictly increasing for all feasible $x_{i}$ below the optimal $x_{i}^{*}$ and strictly decreasing for $x_{i}>x_{i}^{*}$.

${ }^{34}$ With a,b, and c being arbitrarily chosen real numbers.
} 
larger share of participants would donate in THRICE than in $O N C E$, which ceteris paribus increases average donations.

Some empirical studies support this theoretical argument, although none of these studies consider repeated donations to a single recipient and without renewed income. The most closely related studies are by Cairns and Slonim (2011) and by Donkers et al. (2017). ${ }^{35}$ Both studies report that repetition is increasing donations on the aggregate. ${ }^{36}$

Hypothesis 1a: Average total donations are larger in THRICE than in ONCE.

I expect a similar behavior in treatment ENDOGENOUS, when participants can avoid the ask, as in THRICE. Due to the possibility to segregate gains, donating becomes more attractive than in ONCE.

Hypothesis 2a: Average total donations are larger in ENDOGENOUS than in ONCE.

Second, Equation (1) indicates that all individuals who derive a positive utility from donating (and thus perceive a donation as a gain) would segregate their donation and donate at all three decision stages. The value of the left side of the inequality with three donations is larger than with one donation as on the right side. The individuals who derive a negative value do not donate at any decision stage.

Indeed, the empirical studies by Hamman et al. (2010), Brañas-Garza et al. (2013), Achtziger et al. (2015), Brosig-Koch et al. (2017), Gallier et al. (2017) find a high degree of consistency in the giving behavior. Other studies on the dynamics of charitable giving (Schmitz, 2019; Adena and Huck, 2019; Müller and Rau, 2020; Sass et al., 2018) report some decline in donations over time during the repetition. However in these studies, average donations at the second (and third) decision stage are substantial, indicating that individuals have a desire to segregate.

Hypothesis 1b: In THRICE, agents either donate at every decision stage or not at all.

\footnotetext{
${ }^{35}$ Cairns and Slonim (2011) consider a situation with one income but several recipients while Donkers et al. (2017) regard a situation with one recipient but renewed income.

${ }^{36}$ The repetition of the donation request might lead to irritation van Diepen et al. (2009a). Yet, van Diepen et al. (2009b) find no negative effect of irritation on charitable giving.
} 
Since only individuals who derive a positive utility from donating or, in other words, who perceive a donation as a gain would donate, the mental accounting theory (Thaler, 1985) suggests also for ENDOGENOUS that all donors prefer segregation over integration.

Hypothesis 2b: In ENDOGENOUS, agents either donate at every decision stage or not at all.

Consequently, the option to avoid the repetition would only be used by participants who perceive a donation as a net loss. Those participants are likely to not donate at all.

Hypothesis 2c: In ENDOGENOUS, participants who avoid the repetition of the ask donate a smaller total amount than those who do not avoid the repetition.

When mainly non-donors avoid, I might expect to find no impact of the option to avoid the ask on aggregate donations. As mentioned in the Introduction, DellaVigna et al. (2012) report a negative effect of an avoidance option on donations, while Kamdar et al (2013) find a positive impact.

Hypothesis 2d: There are no differences in average total donations between ENDOGENOUS and THRICE.

\subsection{Procedure}

Upon arrival, participants are informed about the rules of the laboratory (see Appendix A.1). Furthermore, the experimenter informs them about the option to transfer money to a charity during the course of the experiment. Instructions do not use the word donation. The experimenter states the name of the IFRC and that the German Red Cross is connected to the charity. It is made common knowledge that the experimenter is not related to the charity and that a receipt of the donation (sum of donations in all experimental sessions) would be posted at a bulletin board. Participants receive no further information about the organization.

In their cabin, subjects find the computer with the questionnaire, the receipt form, and the endowment of 10.00 euros. ${ }^{37}$ A photo of the cabin can be found in Appendix B. Mats, on which the money is placed, and curtains ensure that participants can make their donation decision in

\footnotetext{
${ }^{37}$ The endowment consists of three times 2.00 euros, two times 1.00 euro, five times 0.20 euros, and ten times 0.10 euros.
} 
private. At each decision stage, subjects have to wait thirty seconds until they can continue with the questionnaire. This excludes time efficiency concerns from being a motive for ask avoidance.

The donation decisions are embedded into a questionnaire. Between the three requests, general questions are placed that are unlikely to trigger prosocial behavior. The questions between the first and the second request are on demographics. The inquiries between the second and the third request, are taken from the 10 Item Big Five Inventory by Rammstedt et al. (2013). The items can be found in Appendix A.2. After completion of the questionnaire, participants are allowed to keep the coins that are not donated. They fill out the receipt by themselves and put it into a box in the waiting room. The experimenter informs that the receipts would not be revised by anyone related to the experiment. ${ }^{38}$

The experiment took place between 2017 and 2019 at the University of Goettingen, Germany. In total, I collected 134 observations, with 45 participants in treatments ONCE and ENDOGENOUS, and 44 observations in treatment THRICE. I used zTree (Fischbacher, 2007) and ORSEE (Greiner, 2015). Within each session, I run all three treatments in a between-subjects design, without participants being aware of the treatment variation. In other words, one third of participants during each session was under treatment ONCE, one third under THRICE, and one third under ENDOGENOUS. This allows to minimize the effect of confounding factors such as session effects.

\section{Experimental results}

The first subsection reports the comparison of the total donations between treatments. The second subsection elaborates on the dynamics of charitable giving. The third subsection compares the donation decision of individuals perceiving a donation rather as a gain (for the charity) to those perceiving a donation rather as a loss (for themselves). I require $\mathrm{p}=0.05$ for significance.

\footnotetext{
${ }^{38}$ In case that the actual donation does not coincide with the stated donation, I use the stated amount for the analysis. An expectation is when the participant mentions an own mistake at a later stage.
} 


\subsection{Total donations}

In treatment $O N C E$, the average total donation to the charity is 1.26 euros (median: 1.00 euro). When asked three times as in treatment THRICE, participants donate on average 1.44 euros (median: 1.00 euro). I find that participants in ENDOGENOUS donate 1.96 euros on average (median: 1.00 euro). Average donations in this study are lower than those reported by Müller and Rau $(2019,2020)$ who recruit from a similar subject pool but have the German Red Cross as the receiving organization. Figure 1a visualizes the average donations per treatment (considering the accumulated bars).

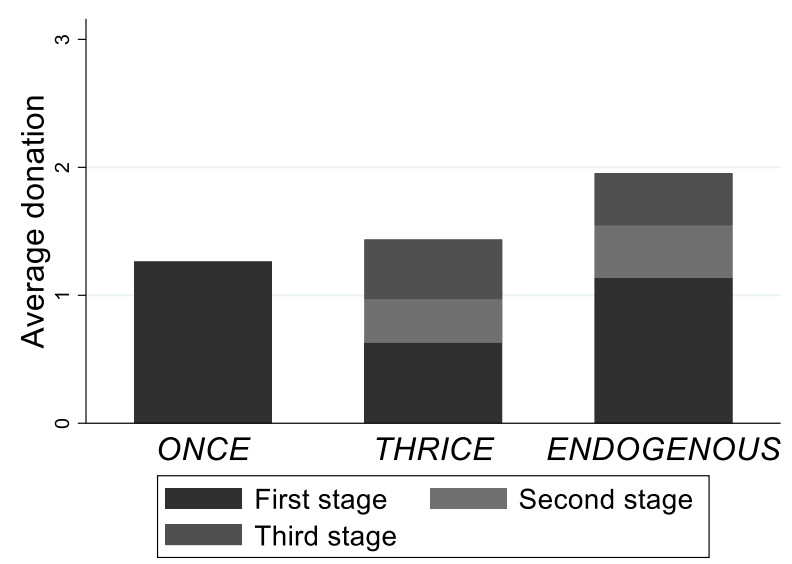

(a) Average donations per treatment and decision stage.

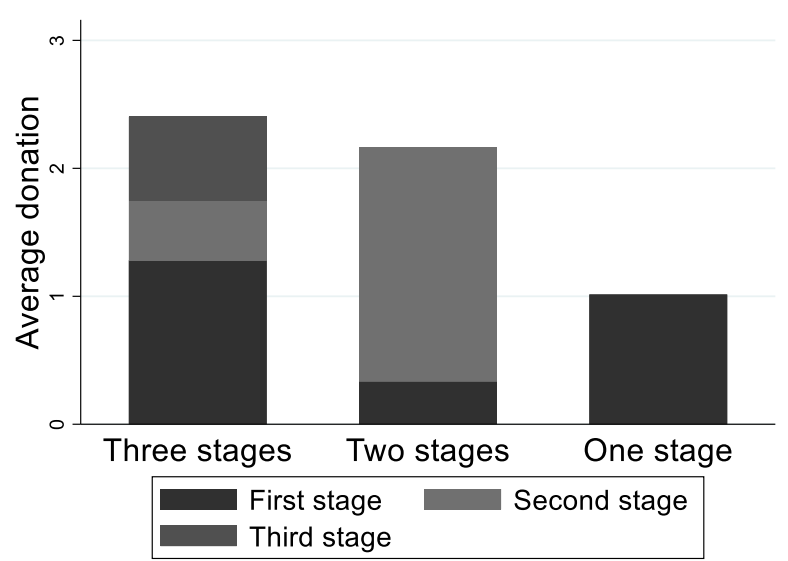

(b) Average donations in ENDOGENOUS by avoidance decision and decision stage.

Figure 1: Average donations (in euros).

A Wilcoxon rank-sum test shows that the increase of 14 percent in total donations between $O N C E$ and THRICE is not statistically significant $(\mathrm{p}=0.499)$. Hence, I do not find support for Hypothesis 1a. The average amount donated in ENDGOGENOUS represents an increase of 56 percent in comparison to $O N C E$ and of 41 percent in comparison to THRICE. I find no support for Hypothesis 2a on the comparison of ENDOGENOUS and ONCE. A Wilcoxon rank-sum test shows that the difference between the two treatments is not statistically significant $(p=0.134)$. A further Wilcoxon rank-sum test exhibits that the difference in average donations between ENDOGENOUS and THRICE is not statistically significant $(\mathrm{p}=0.358)$. This supports Hypothesis $2 \mathrm{~d}$. On the 
extensive margin, the share of donors is 64 percent in ONCE and THRICE. ${ }^{39}$ The repetition of the donation request does not affect the propensity to donate. In ENDOGENOUS, a share of 76 percent of participants donates. Fisher's exact tests show no significant differences in comparison to the exogenous treatments. ${ }^{40}$

I find substantial differences between the behavior of individuals avoiding the repetition the ask and those who do not avoid. In ENDOGENOUS, 31 percent of participants choose to avoid further asking after the first decision stage. The share of participants who avoid further asking rises to 38 percent at the second stage (corresponding to three newly avoiding subjects). Figure $1 \mathrm{~b}$ exhibits that individuals who do not avoid the repetition of the ask (and consequently have three donation stages) donate on average 2.40 euros. Those three individuals who avoid the ask after the second donation stage donate on average 2.17 euros. Individuals avoiding the repetition of the ask donate on average 1.01 euros. Due to the nearly identical average total donations in the first group (three donation stages) and the second group (two donation stages), and the small number of observations in the second group, I decide to pool these two groups. ${ }^{41}$ I compare "avoiders" (who avoid the repetition of the donation request after the first decision stage) to "non-avoiders" (who do not choose to avoid in the first decision stage). Non-avoiders donate on average 2.38 euros, while avoiders donate 1.01 euros on average. A Wilcoxon rank-sum tests shows that non-avoiders donate significantly more than avoiders $(\mathrm{p}=0.029)$. Hence, I find support for Hypothesis $2 \mathrm{c}$.

Importantly, the donations of non-avoiders in ENDOGENOUS are significantly larger than the donations given in $O N C E$ (Wilcoxon rank-sum test, $\mathrm{p}=0.019$ ). The comparison of total donations of non-avoiders in ENDOGENOUS with donations in THRICE does not show a statistically significant difference (Wilcoxon rank-sum test, $\mathrm{p}=0.090$ ). As well, I find no differences between donations of avoiders in ENDOGENOUS and donations in ONCE or THRICE. ${ }^{42}$

In total, the results presented in this subsection show that donations to the charity are highest in ENDOGENOUS. The difference in donations relative to ONCE and THRICE is statistically not

\footnotetext{
${ }^{39}$ Fisher's exact test shows no statistically significant difference $(\mathrm{p}=1.00)$.

${ }^{40}$ ENDOGENOUS vs ONCE: $\mathrm{p}=0.358 ;$ ENDOGENOUS vs THRICE: $\mathrm{p}=0.255$.

${ }^{41}$ A Wilcoxon rank-sum test shows no difference in average donations between the two groups $(\mathrm{p}=$ $0.866)$.

${ }^{42}$ Wilcoxon rank-sum tests: avoiders vs $O N C E: \mathrm{p}=0.501 ;$ avoiders vs THRICE: $\mathrm{p}=0.398$.
} 
significant, though. Non-avoiders in ENDOGENOUS donate more than avoiders. Importantly, nonavoiders donate also more than participants in treatment $O N C E$.

\subsection{Dynamics of charitable giving}

Turning to the dynamics of charitable giving, I observe that 54 percent of participants donating a positive amount in THRICE donate in all three decision stages, while 29 percent donate only once. ${ }^{43}$ Not all donors prefer to segregate but a large share of them does. ${ }^{44}$ Hence, I find some limited support for Hypothesis 1b. I find that participants in THRICE donate on average 0.63 euros at the first decision stage, 0.34 euros at the second decision, and 0.47 euros at the third. This is visualized in Figure 1a considering the three sections of the stacked bar. At the first decision stage, participants donate half as much in THRICE as in ONCE (where there is only one decision stage). The difference is statistically insignificant when I consider the full sample. ${ }^{45}$ When I drop those who do not donate anything at any stage, I find that donors donate significantly less at the first stage in THRICE than in ONCE (Wilcoxon rank-sum test, $\mathrm{p}=0.006$ ). Thus, the existence of the second and third donation option decreases donations of donors at the first stage.

In ENDOGENOUS, no shifting behavior is observable in Figure 1a. Wilcoxon ranks-sum tests show that donations in the first stage are not statistically different from those in $O N C E$, when considering the full sample $(\mathrm{p}=0.819)$ or donors, exclusively $(\mathrm{p}=0.160)$. Besides, I find that 35 percent of participants donating a positive amount in ENDOGENOUS donate at all three decision stages, while 53 percent donate only once. A binomial test shows that the share of segregating individuals is significantly smaller than the share of donating individuals $(p=0.000)$. Hence, I collect only very limited support for Hypothesis $2 \mathrm{~b}$. Not all individuals who donate also prefer to segregate, while some do.

The difference in total donations between avoiders and non-avoiders in ENDOGENOUS (as reported in Section 3.1) is driven by subsequent donations of non-avoiders at the second and third decision stage. A Wilcoxon rank-sum test shows no statistically significant differences $(\mathrm{p}=0.456)$

\footnotetext{
${ }^{43}$ Three quarters of those donating only once donate at the first stage.

${ }^{44}$ A binomial test shows that share of segregating individuals is significantly smaller than the share of donating individuals. $(\mathrm{p}=0.000)$.

${ }^{45}$ Wilcoxon rank-sum test: $\mathrm{p}=0.106$.
} 
between the donations of avoiders (1.01 euros) and non-avoiders (1.19) at the first decision stage. Likewise, the difference between non-avoiders in ENDOGENOUS and participants in ONCE is driven by subsequent donations. At the first decision stage, the difference is insignificant (Wilcoxon rank-sum test, $\mathrm{p}=0.922$ ). By design, avoiders in ENDOGENOUS and participants in $O N C E$ donate nothing at the second and third stage. I find that non-avoiders donate on average 0.76 euros at the first and 0.59 euros at the second decision stage.

Overall, I find that some but clearly not all donors in THRICE and ENDOGENOUS prefer to segregate. In THRICE, individuals seem to smooth their charitable giving by shifting donations from the first to the subsequent two decision stages. Such substitution behavior is not visible in ENDOGENOUS.

\subsection{Gain perceivers and loss perceivers}

To better understand the differences in the propensity to segregate between individuals, I consider how the participants report to perceive a donation. I classify participants based on whether they state to perceive a donation rather as a loss for themselves than as a gain for the charity. For this, I consider a questionnaire question ("I perceive a donation rather as a loss for me than as a gain for the charity.") with a scale from 1 (very little) till 7 (very much). The variable significantly correlates with donations indicating that the more individuals perceive a donation as a loss, the less they donate (Spearman's rho $=-0.237, \mathrm{p}=0.005$, considering all three treatments). Those who state an above average (3.42, considering all treatments) perception that a donation is a loss are classified as "loss-perceivers". All others are classified as "gain-perceivers".

For THRICE, I find significant differences between the two groups (Wilcoxon rank-sum test, $\mathrm{p}=$ $0.024)$ with higher average donations of gain-perceivers (1.97 euros) than of loss-perceivers $(0.80$ euros). Figure 2 exhibits that this difference is driven by higher donations of gain-perceivers at the second and third decision stage. At the first decision stage, I observe no significant differences between types, with an average donation of 0.75 euros of gain-perceivers and of 0.49 euros of lossperceivers. ${ }^{46}$ At the second stage, gain perceivers (average: 0.53 euros) donate significantly more (Wilcoxon rank-sum test: $\mathrm{p}=0.005)$ than loss perceivers $(0.11$ euros). Similarly, gain perceivers

\footnotetext{
${ }^{46}$ Wilcoxon rank-sum test: $\mathrm{p}=0.310$.
} 
(0.68 euros) donate significantly more (Wilcoxon rank-sum test: $\mathrm{p}=0.021$ ) than loss perceivers (0.21 euros) at the third decision stage. The share of segregating participants does not differ between gain-perceives and loss-perceivers. ${ }^{47}$ In $O N C E$, gain-perceivers (1.67 euros) donate slightly more than loss-perceivers (1.00 euro). A Wilcoxon rank-sum test exhibits no statistically significant differences in donations between two groups $(\mathrm{p}=0.431)$. Hence, perceiving a donation as gain for the charity motivates participants to donate more at the second and third decision stage, while it has little effect on donations at the first stage.

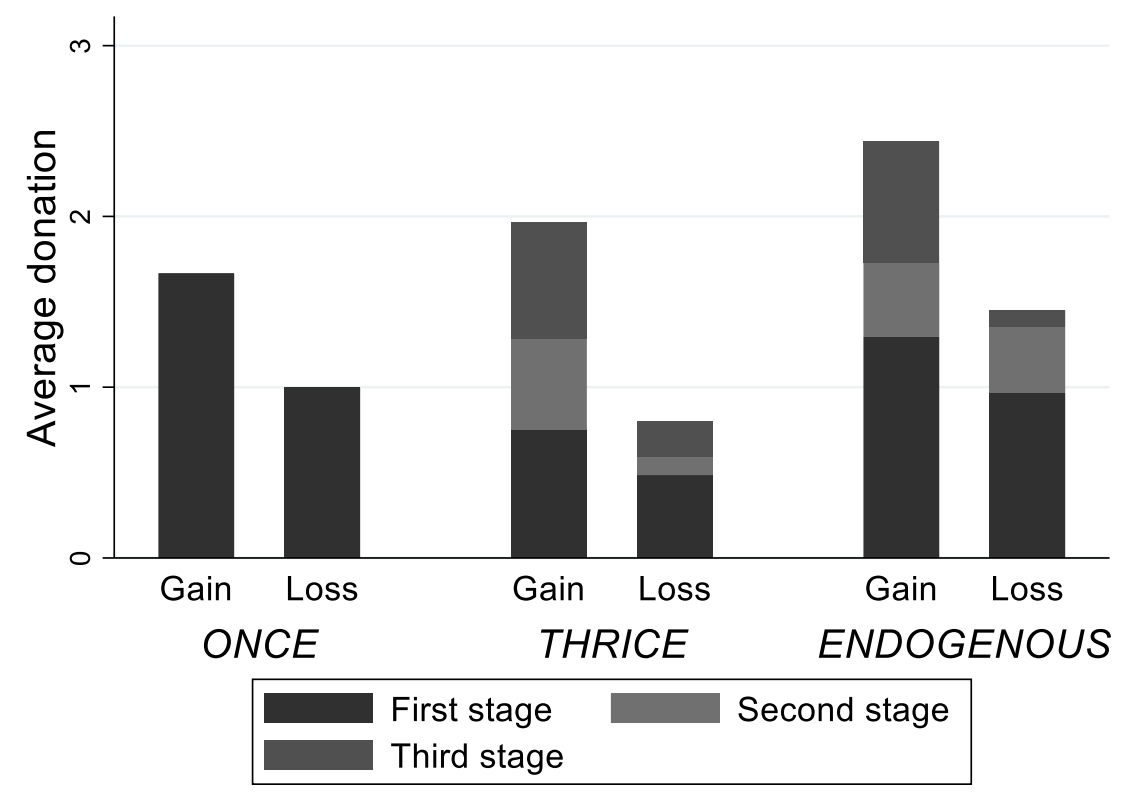

Figure 2: Average donations (in euros) by treatment, by perception of a donation as a gain or as a loss, and by decision stage.

In ENDOGENOUS, gain-perceivers (2.44 euros) donate more than loss-perceivers (1.45 euros), although the difference is not significant. ${ }^{48}$ I find no differences between the two types with respect to the propensity to avoid the repetition of ask. ${ }^{49}$ Yet, a Fisher's exact test shows that a significantly larger share of gain-perceivers than of loss-perceivers chooses to donate at all donation stages ( $<$ 0.001). This highlights the importance of the perception of the donation. Individuals perceiving the donation as a gain for the charity (rather than as a loss for themselves) prefer to segregate.

\footnotetext{
${ }^{47}$ Fisher's exact test: $\mathrm{p}=0.111$.

${ }^{48}$ Wilcoxon rank-sum test: $\mathrm{p}=0.061$.

${ }^{49}$ Fisher's exact test: $\mathrm{p}=0.208$.
} 


\section{Conclusion}

In this paper, I analyze the impact of repeated donation requests on charitable giving. The analysis of the experimental data reveals that participants donate the most when under the ENDOGENOUS treatment. In this treatment, individuals have the option to avoid the announced repetition of the ask. This finding adds to the literature on ask avoidance (DellaVigna et al., 2012; Knutsson et al., 2013; Andreoni et al., 2017; Exley and Petrie, 2018; Damgaard and Gravert, 2018; Adena and Huck, 2020). Furthermore, it adds to the related literature on strategic ignorance (Dana et al., 2007; Grossman and van der Weele, 2017), delegation (Hamman et al., 2010), and avoidance of repeated advertising (Simester et al., 2009; Sahni, 2015).

I find that around one third of participants choose to avoid. This is comparable to the estimate that Andreoni et al. (2017) report for a field experiment. In their setup, individuals could avoid being asked by fundraisers at the entrance of a grocery store by entering through a second door. Importantly, I observe that non-avoiders in ENDOGENOUS donate significantly more than avoiders. Additionally, non-avoiders in ENDOGENOUS donate more than individuals in ONCE, with one donation decision stage in the latter.

The mere repetition of the ask has only little impact. Donations in THRICE (with three donation decision stages) are only slightly larger than in ONCE. Participants in THRICE seem to shift their donation from the first to the two subsequent decision stages. This is comparable to the substitution effects observed by Cairns and Slonim (2011) and Donkers et al. (2017) for the case of several receiving charities. I find that more than half of the donors in THRICE choose to donate at all three donation decision stages. In line with the mental accounting theory by Thaler (1985), I interpret this as a sign of a preference for segregation of the (psychological) gains derived from donating. Indeed, individuals perceiving a donation rather as a gain for the charity (than as loss for themselves) donate at the second and the third decision stage significantly more.

This research contributes to the discussion on optimal strategies to request donations (e.g., Meer and Rosen, 2011; Meer, 2011; Edwards and List, 2014; Fielding and Knowles, 2015; Sanders and Smith, 2016; and Bruttel and Stolley, 2020). The results indicate that the mere repetition of the donation request does only slightly increase donations. The finding that the small positive effect is driven by individuals perceiving a donation as a gain suggests that fundraisers implementing highfrequency campaigns must be especially careful to frame the donation in a positive way. 
The experimental results indicate that it might be an efficient measure to announce a repetition of the request and, at the same time, offer the possibility to avoid the repetition. The measure allows for an identification of the most promising targets of fundraising. Those individuals who do not avoid the repetition are likely to donate more than those who avoid it. With the avoidance option, the agents who are anyway not interested in donating (and consequently would avoid it) receive no mailing and thus create no further expenses. This highlights that unsubscribe options from mailing lists and 'Don't ask me again'-buttons in online fundraising might be efficient measures to increase the revenues generated from fundraising campaigns. 


\section{References}

Achtziger, Anja, Carlos Alós-Ferrer, and Alexander K. Wagner. 2015. "Money, Depletion, and Prosociality in the Dictator Game." Journal of Neuroscience, Psychology, and Economics 8 (1): 1-14. https://doi.org/10.1037/npe0000031.

Adena, Maja, and Steffen Huck. 2019. "Giving Once, Giving Twice: A Two-Period Field Experiment on Intertemporal Crowding in Charitable Giving." Journal of Public Economics 172:127-34. https://doi.org/10.1016/j.jpubeco.2019.01.002.

Adena, Maja, and Steffen Huck. 2020. "Online Fundraising, Self-Image, and the Long-Term Impact of Ask Avoidance." Management Science 66 (2): 722-43. https://doi.org/10.1287/mnsc.2018.3232.

Andreoni, James. 1989. "Giving with Impure Altruism: Applications to Charity and Ricardian Equivalence." Journal of Political Economy 97 (6): 1447-58. https://doi.org/10.1086/261662.

Andreoni, James. 1990. "Impure Altruism and Donations to Public Goods: A Theory of WarmGlow Giving.” The Economic Journal 100 (401): 464. https://doi.org/10.2307/2234133.

Andreoni, James, Justin M. Rao, and Hannah Trachtman. 2017. "Avoiding the Ask: A Field Experiment on Altruism, Empathy, and Charitable Giving." Journal of Political Economy 125 (3): 625-53. https://doi.org/10.1086/691703.

Brañas-Garza, Pablo, Marisa Bucheli, María Paz Espinosa, and Teresa García-Muñoz. 2013. "Moral cleansing and moral licenses: Experimental evidence." Economics and Philosophy 29 (2): 199-212. https://doi.org/10.1017/S0266267113000199.

Broberg, Tomas, Tore Ellingsen, and Magnus Johannesson. 2007. "Is Generosity Involuntary?" Economics Letters 94 (1): 32-37. https://doi.org/10.1016/j.econlet.2006.07.006.

Brosig-Koch, Jeannette, Thomas Riechmann, and Joachim Weimann. 2017. "The Dynamics of Behavior in Modified Dictator Games." PLOS ONE 12 (4): e0176199. https://doi.org/10.1371/journal.pone.0176199.

Bruttel, Lisa, and Florian Stolley. 2020. "Getting a Yes. An Experiment on the Power of Asking." Journal of Behavioral and Experimental Economics 86:101550. https://doi.org/10.1016/j.socec.2020.101550. 
Cairns, Jason, and Robert Slonim. 2011. "Substitution Effects Across Charitable Donations." Economics Letters 111 (2): 173-75. https://doi.org/10.1016/j.econlet.2011.01.028.

Damgaard, Mette Trier, and Christina Gravert. 2018. "The Hidden Costs of Nudging: Experimental Evidence from Reminders in Fundraising.” Journal of Public Economics 157:15-26. https://doi.org/10.1016/j.jpubeco.2017.11.005.

Dana, Jason, Daylian M. Cain, and Robyn M. Dawes. 2006. "What You Don't Know Won't Hurt Me: Costly (But Quiet) Exit in Dictator Games." Organizational Behavior and Human Decision Processes 100 (2): 193-201. https://doi.org/10.1016/j.obhdp.2005.10.001.

Dana, Jason, Roberto A. Weber, and Jason Xi Kuang. 2007. "Exploiting Moral Wiggle Room: Experiments Demonstrating an Illusory Preference for Fairness.” Economic Theory 33 (1): 67-80. https://doi.org/10.1007/s00199-006-0153-z.

DellaVigna, Stefano, John A. List, and Ulrike Malmendier. 2012. "Testing for Altruism and Social Pressure in Charitable Giving." The Quarterly Journal of Economics 127 (1): 1-56. https://doi.org/10.1093/qje/qjr050.

Diamond, William D., and Stephanie M. Noble. 2001. "Defensive Responses to Charitable Direct Mail Solicitations." Journal of Interactive Marketing 15 (3): 2-12. https://doi.org/10.1002/dir.1012.

Donkers, Bas, Merel van Diepen, and Philip Hans Franses. 2017. "Do Charities Get More When They Ask More Often? Evidence from a Unique Field Experiment.” Journal of Behavioral and Experimental Economics 66:58-65. https://doi.org/10.1016/j.socec.2016.05.006.

Eckel, Catherine C., and Philip J. Grossman. 1996. "Altruism in Anonymous Dictator Games." Games and Economic Behavior 16 (2): 181-91. https://doi.org/10.1006/game.1996.0081.

Edwards, James T., and John A. List. 2014. “Toward an Understanding of Why Suggestions Work in Charitable Fundraising: Theory and Evidence from a Natural Field Experiment.” Journal of Public Economics 114:1-13. https://doi.org/10.1016/j.jpubeco.2014.02.002.

Engel, Christoph. 2011. "Dictator Games: A Meta Study.” Experimental Economics 14 (4): 583610. https://doi.org/10.1007/s10683-011-9283-7. 
Fielding, David, and Stephen Knowles. 2015. "Can You Spare Some Change for Charity? Experimental Evidence on Verbal Cues and Loose Change Effects in a Dictator Game." Experimental Economics 18 (4): 718-30. https://doi.org/10.1007/s10683-014-9424-x.

Fischbacher, Urs. 2007. "Z-Tree: Zurich Toolbox for Ready-Made Economic Experiments." Experimental Econonomics 10 (2): 171-78. https://doi.org/10.1007/s10683-006-9159-4.

Forsythe, Robert, Joel L. Horowitz, Nathan E. Savin, and Martin Sefton. 1994. "Fairness in Simple Bargaining Experiments." Games and Economic Behavior 6 (3): 347-69. https://doi.org/10.1006/game.1994.1021.

Gallier, Carlo, Christiane Reif, and Daniel Römer. 2017. "Repeated Pro-Social Behavior in the Presence of Economic Interventions." Journal of Behavioral and Experimental Economics 69:18-28. https://doi.org/10.1016/j.socec.2017.05.003.

Greiner, Ben. 2015. "Subject Pool Recruitment Procedures: Organizing Experiments with ORSEE." Journal of Economic Science Association 1 (1): 114-25. https://doi.org/10.1007/s40881-015-0004-4.

Grossman, Zachary, and Joël J. van der Weele. 2017. "Self-Image and Willful Ignorance in Social Decisions." Journal of the European Economic Association 15 (1): 173-217. https://doi.org/10.1093/jeea/jvw001.

Hamman, John R., George Loewenstein, and Roberto A. Weber. 2010. "Self-Interest Through Delegation: An Additional Rationale for the Principal-Agent Relationship." American Economic Review 100 (4): 1826-46. https://doi.org/10.1257/aer.100.4.1826.

Kahneman, Daniel, Jack L. Knetsch, and Richard H. Thaler. 1986. "Fairness and the Assumptions of Economics." The Journal of Business 59 (S4): S285. https://doi.org/10.1086/296367.

Kahneman, Daniel, and Amos Tversky. 1979. "Prospect Theory: An Analysis of Decision Under Risk." Econometrica 47 (2): 263. https://doi.org/10.2307/1914185.

Kamdar, Amee, Steven D. Levitt, John A. List, Brian Mullaney, and Chad Syverson. 2013. "Once and Done: Leveraging Behavioral Economics to Increase Charitable Contributions." Working Paper. 
Knutsson, Mikael, Peter Martinsson, and Conny Wollbrant. 2013. "Do People Avoid Opportunities to Donate?" Journal of Economic Behavior \& Organization 93:71-77. https://doi.org/10.1016/j.jebo.2013.07.015.

Lazear, Edward P., Ulrike Malmendier, and Roberto A. Weber. 2012. "Sorting in Experiments with Application to Social Preferences." American Economic Journal: Applied Economics 4 (1): 136-63. https://doi.org/10.1257/app.4.1.136.

Mazar, Nina, and Chen-Bo Zhong. 2010. "Do Green Products Make Us Better People?" Psychological science 21 (4): 494-98. https://doi.org/10.1177/0956797610363538.

Meer, Jonathan. 2011. "Brother, Can You Spare a Dime? Peer Pressure in Charitable Solicitation." Journal of Public Economics $95 \quad$ (7-8): 926-41. https://doi.org/10.1016/j.jpubeco.2010.11.026.

Meer, Jonathan, and Harvey S. Rosen. 2011. "The ABCs of Charitable Solicitation.” Journal of Public Economics 95 (5-6): 363-71. https://doi.org/10.1016/j.jpubeco.2010.07.009.

Merritt, Anna C., Daniel A. Effron, and Benoît Monin. 2010. "Moral Self-Licensing: When Being Good Frees Us to Be Bad." Social and Personality Psychology Compass 4 (5): 344-57. https://doi.org/10.1111/j.1751-9004.2010.00263.x.

Monin, Benoit, and Dale T. Miller. 2001. "Moral Credentials and the Expression of Prejudice." Journal of Personality and Social Psychology 81 (1): 33-43. https://doi.org/10.1037/00223514.81.1.33.

Müller, Stephan, and Holger A. Rau. 2019. "Too Cold for Warm Glow? Christmas-Season Effects in Charitable Giving." PLOS ONE $14 \quad$ (5): 00215844. https://doi.org/10.1371/journal.pone.0215844.

Müller, Stephan, and Holger A. Rau. 2020. "Motivational Crowding Out Effects in Charitable Giving: Experimental Evidence." Journal of Economic Psychology 76:102210. https://doi.org/10.1016/j.joep.2019.102210.

Rammstedt, Beatrice, Christoph J. Kemper, Mira Céline Klein, Constanze Beierlein, and Anastassiya Kovaleva. 2013. "Eine Kurze Skala Zur Messung Der Fünf Dimensionen Der Persönlichkeit: 10 Item Big Five Inventory (BFI-10).” methods, data, analyses 7 (2): 23349. 
Sahni, Navdeep S. 2015. "Effect of Temporal Spacing Between Advertising Exposures: Evidence from Online Field Experiments." Quantitative Marketing and Economics 13 (3): 203-47. https://doi.org/10.1007/s11129-015-9159-9.

Sanders, Michael, and Sarah Smith. 2016. "Can Simple Prompts Increase Bequest Giving? Field Evidence from a Legal Call Centre.” Journal of Economic Behavior \& Organization 125:179-91. https://doi.org/10.1016/j.jebo.2016.01.002.

Sass, Markus, Florian Timme, and Joachim Weimann. 2018. "On the Dynamics of Altruistic Behavior." Working Paper.

Schmitz, Jan. 2019. "Temporal Dynamics of Pro-Social Behavior: An Experimental Analysis." Experimental Economics 22 (1): 1-23. https://doi.org/10.1007/s10683-018-9583-2.

Simester, Duncan, Yu. Hu, Erik Brynjolfsson, and Eric Anderson. 2009. "Dynamics of Retail Advertising: Evidence from Field Experiment." Economic Inquiry 47 (3): 482-99. https://doi.org/10.1111/j.1465-7295.2008.00161.x.

Thaler, Richard. 1985. "Mental Accounting and Consumer Choice.” Marketing Science 4 (3): 199_ 214. https://doi.org/10.1287/mksc.4.3.199.

Trachtman, Hannah, Andrew Steinkruger, Mackenzie Wood, Adam Wooster, James Andreoni, James J. Murphy, and Justin M. Rao. 2015. "Fair Weather Avoidance: Unpacking the Costs and Benefits of "Avoiding the Ask"." Journal of the Economic Science Association 1 (1): 8-14. https://doi.org/10.1007/s40881-015-0006-2.

van Diepen, Merel, Bas Donkers, and Philip Hans Franses. 2009a. "Dynamic and Competitive Effects of Direct Mailings: A Charitable Giving Application.” Journal of Marketing Research 46 (1): 120-33. https://doi.org/10.1509/jmkr.46.1.120.

van Diepen, Merel, Bas Donkers, and Philip Hans Franses. 2009b. "Does Irritation Induced by Charitable Direct Mailings Reduce Donations?” International Journal of Research in Marketing 26 (3): 180-88. https://doi.org/10.1016/j.ijresmar.2009.03.007.

Xu, Hanyi, Laurent Bègue, and Brad J. Bushman. 2012. "Too Fatigued to Care: Ego Depletion, Guilt, and Prosocial Behavior.” Journal of Experimental Social Psychology 48 (5): 118386. https://doi.org/10.1016/j.jesp.2012.03.007. 


\section{Appendix}

\section{A.1 Instructions to be read aloud (in English)}

You are participating in an economic experiment on decision-making. You can earn money dependent on your decisions. You make your decisions anonymously and isolated from the other participants. From now on, we ask you not to speak to any other participant until the experiment is over. Please switch off your mobile phones and put them away.

In the course of the experiment you will be asked to complete a survey. Please complete the survey as thoroughly as possible. The survey will be displayed to you in a computer in the neighboring room. If you have a question while completing the survey, please come forward individually.

After the experiment, money might be transferred to the International Federation of the Red Cross and Red Crescent (IFRC). The German Red Cross, among others, belongs to this organization. We are not affiliated with this organization. However, you can be sure that the transferred money actually reaches the organization. A receipt will be posted on the bulletin board of the chair of microeconomics after the conclusion of the experiment.

We now ask you to go to the computer with your participant number. Please close the curtain and keep it close until the end of the experiment. This ensures that you are not observed during the survey. To start the survey, you must click the Next button. Thank you for your participation!

\section{A.2 On-screen instructions, decision stages, and inquiries from before and in between decision stages (in English)}

You will find 10 euros on the mat. These are destined for you. On this mat, there are three 2 euros coins, two 1 euro coins, five 20 cents coins and ten 10 cent coins. Please count the money and put it back on the mat.

While filling in the survey, you will have [once, thrice] the opportunity to reduce your initial endowment in order to increase the amount dedicated to the IFRC. No other participant will know how you decided. Regardless of how you decide, you will have to wait 30 seconds to complete the survey. 
First, some questions about your personal situation:

- How high (in euros) are your monthly expenses (including nutrition, rent, additional costs) approximately?

- What are your main income sources?

- How satisfied are you with your current life situation in general?

- How fair is the world in which we live?

- How well do you know the German Red Cross?

- How would you evaluate the German Red Cross in general?

- How well do you know the IFRC?

- How would you evaluate the IFRC in general?

- How would you evaluate the work of the IFRC?

How well do the following statements describe you?

- I think that one can generally trust people.

- I consider the global political situation threatening.

- I worry about my professional future.

- I am in general a person prepared to take risks.

-- Begin of the first decision stage --

You have now the opportunity to reduce your endowment in order to increase the amount dedicated to the IFRC.

Before your decision:

The amount dedicated to you in euros: 10.00

The amount dedicated to the organization in euros: 0.00

Please enter how much you would like to transfer from your initial endowment to the account of the organization. Enter an amount between 0 euros and 10.00. Choose an amount rounded to 0.10 euros.

Transferred amount (in euros):

After the 30 seconds, you can confirm the amount by clicking OK 
[In ENDOGENOUS (with checkbox):] I don't want to be asked again for a transfer. In this case, this will be the last request and you won't be asked thrice. You still will have to wait thirty seconds.

-- End of the first decision stage --

- What is your gender?

- What is your age?

- How big was the city where you grew up?

- What is the highest level of education your parents have completed?

- Do you study?

- If so, in which stage of your studies are you?

- If so, which degree program do you feel most likely to be assigned to?

-- Second decision stage --

(identical to the first with updated amounts)

How well do the following statements describe you?

- I am reserved.

- I am generally trusting

- I do a thorough job.

- I am relaxed, handle stress well.

- I have an active imagination.

- I am outgoing, sociable.

- I tend to find out faults with others.

- I tend to be lazy.

- I get nervous easily.

- I have few artistic interests. 


\section{-- Third decision stage --}

(identical to the first with updated amounts)

\section{B Photos}

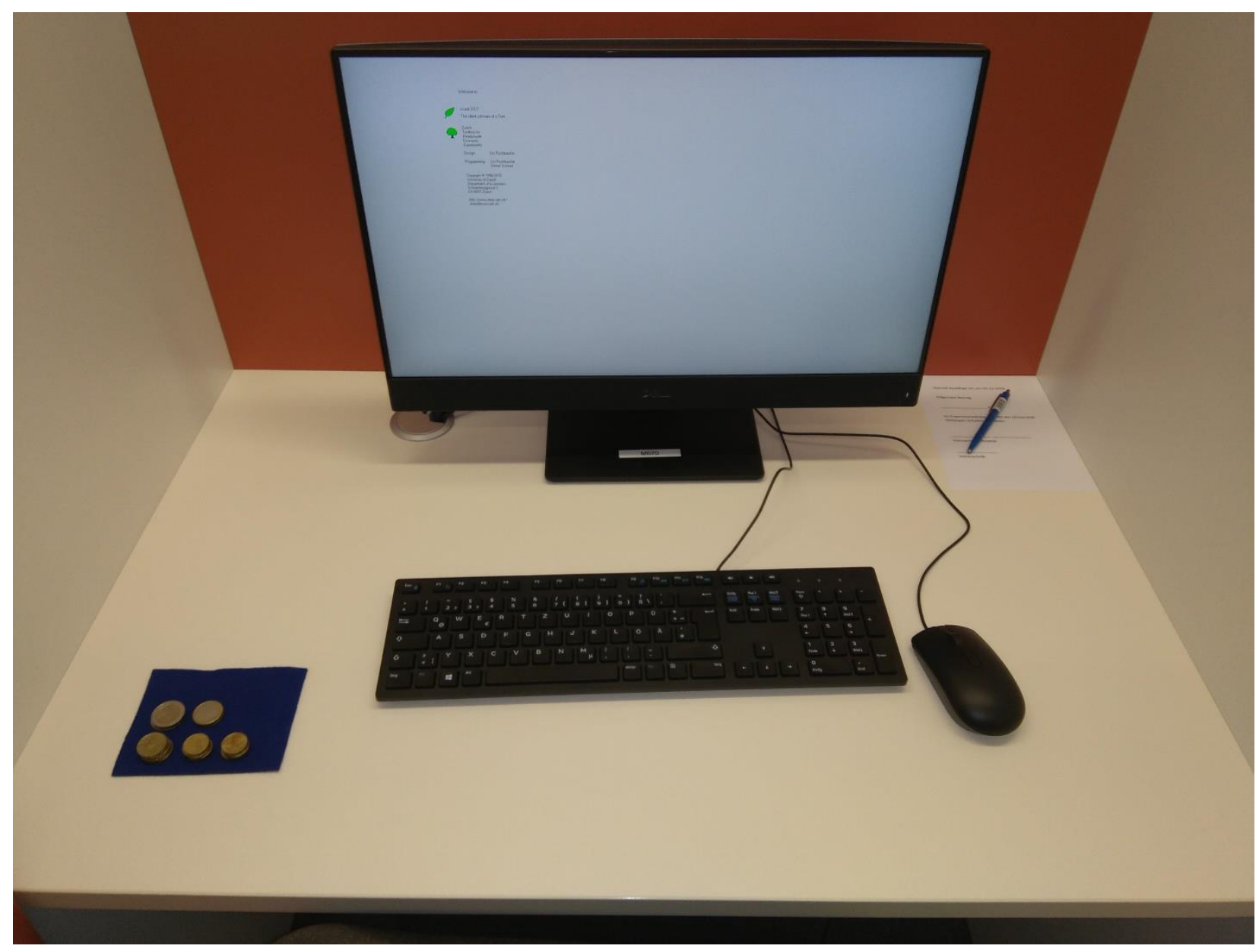

Cabin with computer, mouse, keyboard, money, the receipt and a pen. 


\title{
Chapter IV: Study 3
}

\section{Charitable giving: framing and the role of information *}

\author{
with Claudia Keser
}

\begin{abstract}
We study the impact of information on the effectiveness of a taking frame in the context of charitable giving. In our laboratory experiment, either the decision maker (giving frame) or the recipient (taking frame) receives an endowment. In both cases, the decision maker can freely decide the final allocation of the money. Besides the framing, we vary the level of (favorable) information provided about the worthiness of the receiving charity.

Participants of our experiment significantly donate more, when the decision is framed as taking rather than as giving. However, this framing effect is smaller when we provide information on the charity. We apply these findings to the ongoing debate on the use of defaults (Opt-Out vs Opt-In systems) as a strategy to increase the number of organ donor registrations. The findings imply that an Opt-Out system is likely to be most effective when the society is little informed about organ donations.
\end{abstract}

Keywords: Information, Giving, Taking, Charity, Experiment

JEL classification: C91, D64, D80

- We have received helpful comments from participants of the annual conference of the Gesellschaft für experimentelle Wirtschaftsforschung (GfeW) in Paderborn, from participants of the CollEcons colloquium at the University of Goettingen, from participants and an anonymous referee at the Meeting of the European Public Choice Society (EPCS) in Jerusalem, and from participants of the annual conference of the Verein für Socialpolitik (VfS) in Leipzig. 


\section{Introduction}

Decades of research have shown the impact of framing on decision making. In particular, whether a decision is framed positively or negatively seems to have an effect on decisions and the perception of situations (e.g., Tversky and Kahneman, 1981; Andreoni, 1995; Liberman et al., 2004; Dufwenberg et al., 2011). Also in the context of charitable giving, it apparently makes a difference whether donations decisons are framed positively or negatively (Chang and Lee, 2009; Das et al., 2008). One way to create such a change in the frame is to switch property rights, while keeping the full decisional power of the decision maker untouched. Under a giving frame, the decision maker initially holds the property rights, and any action by this individual to change the initial allocation is framed positively as giving. Under a taking frame, it is the other person or institution that holds the property rights, and any change of the allocation of resources is framed negatively as taking.

Previous experimental studies have shown an ambiguous picture concerning the effect of a taking frame on charitable giving. Grossman and Eckel (2015) report no differences of whether the decision maker receives the endowment (giving frame) or whether the recipient, in this case a charity, is endowed. Yet, Korenok et al. (2018) and Zarghamee (2017) find higher donations under the taking frame. Similarly, some studies with experimental participants as recipients report no differences of the framing (Dreber et al., 2013; Chowdhury et al., 2017; Kettner and Cecatto, 2014; Smith, 2015; Suvoy, 2003), while other studies find higher transfers to the recipient under the taking frame than under the giving frame (Krupka and Weber, 2013; Korenok et al., 2014; Oxoby and Spraggon, 2008; Brosig-Koch et al., 2017) ${ }^{50}$ Alt et al. (2018) find that the direction of the impact of the frame depends on the relation between dictator and recipient.

With our study, we want to deepen the understanding of what determines the impact of the taking frame (relative to the giving frame) on charitable giving. Following comments by Grossmann and Eckel (2015), Johnson and Goldstein (2003), and Thaler and Goldstein (2009), we argue that the frame has the largest effect when the decision maker has little information about the recipient of a donation. We concentrate on the idea that a taking frame sends a clear signal that the decision

\footnotetext{
${ }^{50}$ Note that the literature that we consider is different from the one originating in List (2007) and Bardsley (2008), where the action space of the decider varies with the frame. It is also different from studies such as by Goswami and Urminsky (2016) and Fiala and Noussair (2017), and Altmann et al. (2019), where the default but not the frame is altered.
} 
maker "should" donate a substantial amount. ${ }^{51}$ In their seminal paper, Krupka and Weber (2003) find that an allocation that leaves the recipient (in their case another subject) with less than half of the endowment is perceived as less socially appropriate under the taking frame than under the giving frame. ${ }^{52}$ Similar to the framing, the information might affect social norms. The more (positive) information about the recipient is provided, the clearer is the signal that the decision maker should donate. Aguiar et al. (2008) point out that information decreases the moral distance between decision maker and recipient, which creates a moral obligation to donate. Indeed, BrañasGarza (2006), Fong and Luttmer (2011), and Bachke et al. (2017) find that information about the worthiness of the recipient increases donations.

Hence, the more positive information about the recipient is provided, the less decision makers need the guideline provided by the frame. The information already serves as a signal to the decision makers that they should donate or that they even should donate a substantial amount. Taking frame and information are (to some extent) substitutes on this matter. Therefore, we hypothesize that an increase in the level of the provided information about the charity yields a weaker impact of the taking frame on charitable giving.

To empirically analyze the interaction between information and framing, we experimentally vary the (positive) information that agents have about the charity before being confronted with the frame. Similarly to Grossman and Eckel (2015), we apply a design that is based on a dictator game (Kahneman et al., 1986; Forsythe et al., 1994) and compare the donations under a giving frame to those under a taking frame. In order to be able to vary the level of information, the recipient in our experiment is the International Federation of the Red Cross and the Red Crescent (IFRC), a charity which is rather unknown among German students. We vary the information that we provide about the charity (none; some; much) and the frame (GIVE; TAKE) in a 3 x 2 design.

As hypothesized, we find that the impact of the taking frame decreases with the amount of information provided to the participants at the beginning of the experiment. This main result is driven by three findings. First, we find significantly higher donations under the taking frame in comparison to the giving frame in all three information regimes. Second, we find no significant differences in donations under the taking frame between the information regimes. Third, we find a

\footnotetext{
${ }^{51}$ Andreoni and Bernheim (2009) point out that a 50/50 split is considered as fair. Later in this article, we define a substantial donation as a donation of more than 29 percent of the endowment.

${ }^{52}$ In line, Faillo et al. (2019) argue that the moral costs of taking are higher than those of not giving.
} 
significant increase in donations under the giving frame, when we compare the some respectively the much information regime to the none information regime.

We apply these results to the current debate on Opt-In versus Opt-Out systems in the domain of organ donations. In an Opt-In system (giving frame), individuals have to opt-in to be a potential donor. In an Opt-Out system (taking frame), individuals are presumed to be a potential donor if they do not opt-out. Our findings suggest that the implementation of an Opt-Out system might promote organ donor registrations. Still, we identify three critical points: the decrease of the effectiveness of Opt-Out relative to Opt-In systems with increased information, some doubts whether a donation in an Opt-Out system can be seen as an informed consent, and a decrease in the effectiveness of other strategies (such as the provision of information) once an Opt-Out system is implemented. We are confident that these findings are relevant for policy makers and fundraisers.

\section{Experimental design}

The core of our experiment is a dictator game (Kahneman et al., 1986; Forsythe et al., 1994) with a charity as the recipient (Eckel and Grossman, 1996). Donations in our experiment go to an organization that is rather unknown among students in Germany: the International Federation of the Red Cross and Red Crescent (IFRC). This is in contrast to Grossman and Eckel (2015) and Korenok et al. (2018), where participants could choose the recipient of the donation from a list of charities. We compare the self-reported knowledge about the IFRC to the knowledge about the German Red Cross. In fact, the German Red Cross is part of the IFRC and the two share common goals. We find that our participants have significantly less knowledge about the IFRC than about the German Red Cross. ${ }^{53}$ Thus, our choice allows us to create a vague context in which we can vary the information about the worthiness of the organization.

Our treatment variation follows a $3 \times 2$ between-subjects design. In a first step, we vary the information regarding the charity that participants receive before being confronted with the giving or taking frame. In treatments none-GIVE and none-TAKE, we inform participants exclusively about the name of the charity and state that the German Red Cross is part of the organization. In

\footnotetext{
${ }^{53}$ Likert scale from 1 (very little knowledge) till 7 (very much knowledge); Averages: IFRC: 1.78, German Red Cross: 3.58; Wilcoxon signed-rank test: $\mathrm{N}=171, \mathrm{p}=0.000$.
} 
treatments some-GIVE and some-TAKE, we provide some additional positive information. This information is taken from the official website of the IFRC and includes the size of the organization, the URL of its website, their key areas of work, and their function. An experimenter reads the information aloud to the participants. In treatments much-GIVE and much-TAKE, we provide the name of the charity, read the information and, additionally, show a video to the participants. ${ }^{54}$ The video was produced by the Austrian Red Cross. During the video the seven fundamental principles of the IFRC are presented and read aloud in German language. The video includes some background music and seven pictures that display typical activities of the IFRC. Independently of the treatment arm, we provide the information together with some general rules of conduct, while participants are sitting in the waiting room. A transcript of the information can be found in Appendix B.

In a second step, we vary the frame. We guide the participants to their randomly assigned private cubical, where they find their endowment of ten euros. On a computer screen we present further instructions. One half of the session is privately informed that the money is intended for themselves (giving frame: none-GIVE, some-GIVE, much-GIVE). They can freely decide to decrease the initial amount on the account of themselves to increase the account of the charity. Choosing the default option by typing in ' 0 ' leads to a zero donation. The other half of the session is informed that the money is intended for the charity (taking frame: none-TAKE, some-TAKE, much-TAKE). They can freely choose to decrease the initial amount the account of the charity to increase their own. Choosing the default option by typing in ' 0 ' leads to a donation of the full endowment.

The donation decision is embedded into a questionnaire to be filled in at a computer. The same questionnaire is used as for Study 2 that was presented in Chapter III. Irrespective of their decision to donate or not, participants have to wait thirty seconds until they can exit the decision stage. This strongly diminishes differences in transaction costs between treatments. Participants are aware of the fact that they only once have the chance to donate. The questionnaire is longer than a usual post-experimental survey in order to extend the experiment to a duration of about 45 minutes. Critical inquiries, which could prime prosocial behavior, are placed after the decision. We do not use words such as 'taking', 'giving' or 'donation' before nor during the decision process.

54 Title: "Rotkreuz-Grundsätze". URL: https://www.youtube.com/watch?v=rVfOdY30miI. Uploaded by "Markus Hechenberger" on Jan 20" , 2014. Duration of 3:20 minutes. 8.075 views on April 8 2020. 
We include inquiries on topics of three categories: demographics, psychological measures and questions related to charitable giving. Building on the results of Bekkers and Wiepking (2011b), we include religiousness (donations increase with religious involvement), age (donations increase with age), being enrolled in economics (economists donate less), and having parents with a university degree (donations increase with parents' education). Considering Wiepking and Bekkers (2012), we include being female (mixed results) and monthly expenses (donations increase with income). Wiepking and Bekkers (2012) further report a positive relation between donations and parenthood. Instead of having own children, we include having younger siblings into our questionnaire. Furthermore, we include several established measurements into the questionnaire, such as the short version of the Big Five inventory (Rammstedt et al., 2013), the Social Value Orientation scale (Van Lange et al., 1997), and a modified version of the Social Desirability Scale with 17 items (Stöber, 1999). ${ }^{55}$ Furthermore, the questionnaire contains a measure on the general satisfaction with the own personal situation (Krueger et al., 2001 report that donations increase with well-being). Finally, we include some variables relating to charitable giving. Please note that these variables are potentially endogenous. We ask participants about their perception of the neediness of the charity and the efficacy of a donation (Bekkers and Wiepking, 2011a report an increase of donations with need and efficacy). We include questions on whether participants feel a joy of giving and whether donating is accordance to their self-image (Bekkers and Wiepking, 2011a report that donations increase with both joy and accordance). Lastly, we add a question on the participants' evaluation of the charity, since this is likely to be affected by the treatment variation. The set of inquiries can be found in Appendix B.

The donation process is double blind in the sense that neither the charity nor other participants can observe the amount contributed by an individual person. The experimenters are unable to relate donations to names or faces of the participants. Curtains make sure that the participants' decision making is unobserved. A photo of the private cubicle can be found in Appendix C. Payment is conducted by the participants themselves. No show-up fee is included in the payment. Participants find the endowment split into several coins. ${ }^{56}$ A photo of a typical presentation of the money can be found in Appendix C. To reduce sounds, the money is placed upon a matting. After the

\footnotetext{
${ }^{55}$ We modify the Social Desirability Scale by offering the option no to answer.

${ }^{56}$ Participants receive three 2 euro, two 1 euro, five 0.20 euro and ten 0.10 euro coins. Between zero and 10 euros every amount in increments of 0.10 euro is feasible.
} 
experiment, participants take the money that they assigned to themselves. Donated money is left on the table. Participants fill in a receipt, fold it and put it into a box. Instructions make clear that only persons unfamiliar with the purpose and the design of the experiment will revise the receipts for accounting.

We conducted our experiment in 2017 till 2019 at the University of Göttingen. We used zTree (Fischbacher, 2007) and ORSEE (Greiner, 2015). In total, 239 participants took part in 22 sessions. On average there were 40 participants in each treatment. Within one session, the treatments varied in the frame dimension. The variation regarding the information dimension took place between sessions. The average share of females was 54 percent. The average age of participants was 24 years. No significant differences between treatments with respect to these characteristics can be detected. ${ }^{57}$ In a few cases, the indicated donation did not coincide with the amount of money left in the cabin. If the participant mentioned having made a mistake in the donation decision stage, we base the analysis on the actual donation (amount of money left in the cabin). Otherwise, we continue working with the donation decision.

\section{Results}

We denote the Wilcoxon rank-sum test as rank-sum test and the Fisher's exact test as exact test. All tests are two-sided and we require $\mathrm{p}=0.05$ for significance.

\subsection{Average donations}

The average donations to the IFRC vary substantially between treatments. In none-GIVE, participants on average donate 11.6 percent of their endowment of ten euros, while they donate 52.9 percent in none-TAKE. In some-GIVE, they donate 16.5 percent of the endowment and in some-TAKE 51.4 percent. Finally, they donate 24.6 percent of the endowment in much-GIVE. In much-TAKE, they donate 46.9 percent. Figure 1 visualizes the average donations.

\footnotetext{
${ }^{57} \mathrm{We}$ find no significant differences between treatments for gender (Fisher's exact test, $\mathrm{p}=0.208$ ) and age
} (Kruskal-Wallis test, $\mathrm{p}=0.855$ ). 


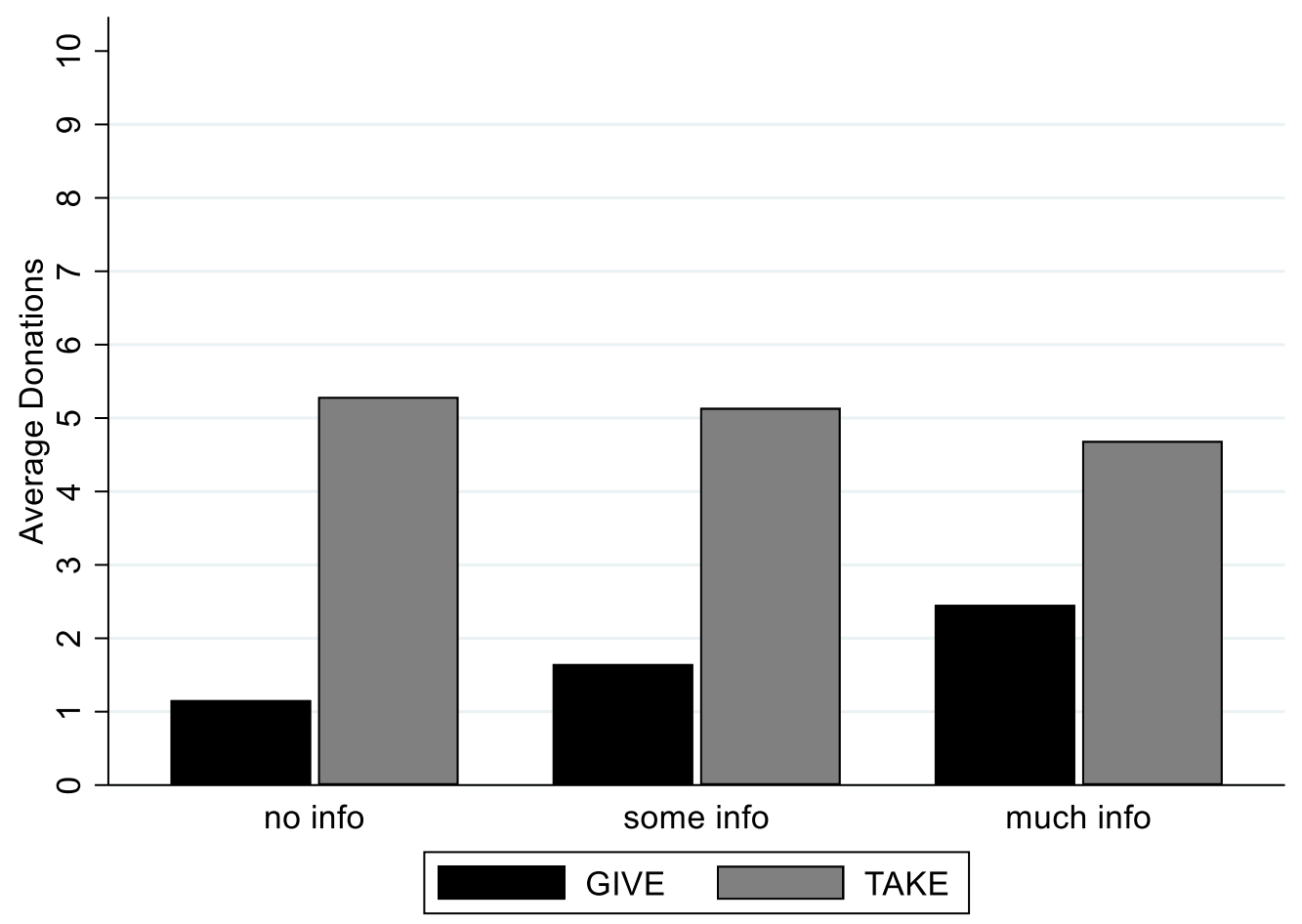

Figure 1: Average donations in euros by frame (GIVE / TAKE) and information level (none, some, much).

We observe that donations are significantly higher under the taking frame than under the giving frame (Rank-sum test: $\mathrm{p}=0.000$ ). The taking frame yields larger donations irrespective of the information environment. ${ }^{58}$ We find no statistical evidence that the variation in information would affect donations under the taking frame (Kruskal-Wallis test: $\mathrm{p}=0.685$ ). This result is confirmed by pairwise comparisons. ${ }^{59}$ Furthermore, we provide statistical evidence that the variation in information has an impact on donations under the giving frame (Kruskal-Wallis test: $\mathrm{p}=0.011$ ). Donations under the giving frame increase when some information and when much information is provided (in comparison to the none information domain). ${ }^{60}$ The difference in donations between much information and some information is statistically insignificant. ${ }^{61}$

${ }^{58}$ Rank-sum tests: none-GIVE vs none-TAKE: $\mathrm{p}=0.000$; some-GIVE vs some-TAKE: $\mathrm{p}=0.000$; muchGIVE vs much-TAKE: $\mathrm{p}=0.001$.

${ }^{59}$ Rank-sum tests: none-TAKE vs some-TAKE: $\mathrm{p}=0.788$; none-TAKE vs much-TAKE: $\mathrm{p}=0.603$; someTAKE: vs much-TAKE: $\mathrm{p}=0.380$.

${ }^{60}$ Rank-sum tests: none-GIVE vs some-GIVE: $\mathrm{p}=0.032$; none-GIVE vs much-GIVE: $\mathrm{p}=0.005$.

${ }^{61}$ Rank-sum test: some-GIVE vs much-GIVE: $\mathrm{p}=0.279$. 
Table 1: Ordinary least-squares linear regression on donation.

\begin{tabular}{ccc}
\hline Donor & $(1)$ & $(2)$ \\
\hline Taking frame & $3.207 * * *$ & $4.132 * * *$ \\
& $(0.359)$ & $(0.657)$ \\
Some information & 0.164 & 0.492 \\
Much information & $(0.456)$ & $(0.644)$ \\
Some information x & 0.342 & $1.298^{*}$ \\
taking frame & $(0.442)$ & $(0.623)$ \\
Much information $\mathrm{x}$ & & -0.642 \\
taking frame & & $(0.907)$ \\
constant & & $-1.898^{*}$ \\
$\mathrm{~N}$ & $1.626 * * *$ & $(0.878)$ \\
& $(0.377)$ & $1.157 *$ \\
\hline
\end{tabular}

Note: Standard errors in parentheses. Reference category for the taking frame: giving frame. Reference category for some information and much information: no information. * $\mathrm{p}<0.05$, ** $\mathrm{p}<0.01, * * * \mathrm{p}<0.001$.

We find some evidence that the impact of the taking frame decreases with the information provided. The taking frame (in comparison to the giving frame) increases donations by 41 percentage points (of the endowment) in the none information environment, by 35 percentage points in the some information domain, and by only 22 percentage points in the much information environment. The ordinary least-squares regression presented in Column (1) of Table 1 shows a positive coefficient of the taking frame dummy ( $\mathrm{p}<0.001$, baseline is the giving frame). The dummies for both types of additional information (pooled over both frames) are not statistically different from zero (baseline is no information). The regression results presented in Column (2) exhibit that the coefficient of interaction term between some information and the taking frame is not significantly different from zero. Importantly, we find the interaction between much information and the taking frame to have a significantly negative coefficient $(\mathrm{p}=0.032)$. This suggests that providing much information decreases the impact of the frame on donation giving. 


\subsection{Share of donors}

At the extensive margin, we find a less clear picture with respect to the interaction between framing and information (see Figure 2). In the none information environment, we find a share of donors of 0.57 under the giving frame and a share of 0.92 under the taking frame. In the some information domain, the share of donors is 0.77 under the giving and 0.79 under the taking frame. In the much information environment the impact of the frame is stronger than in the some information domain. In the much information environment, we observe a share of 0.76 under the giving and of 0.93 under the taking frame.

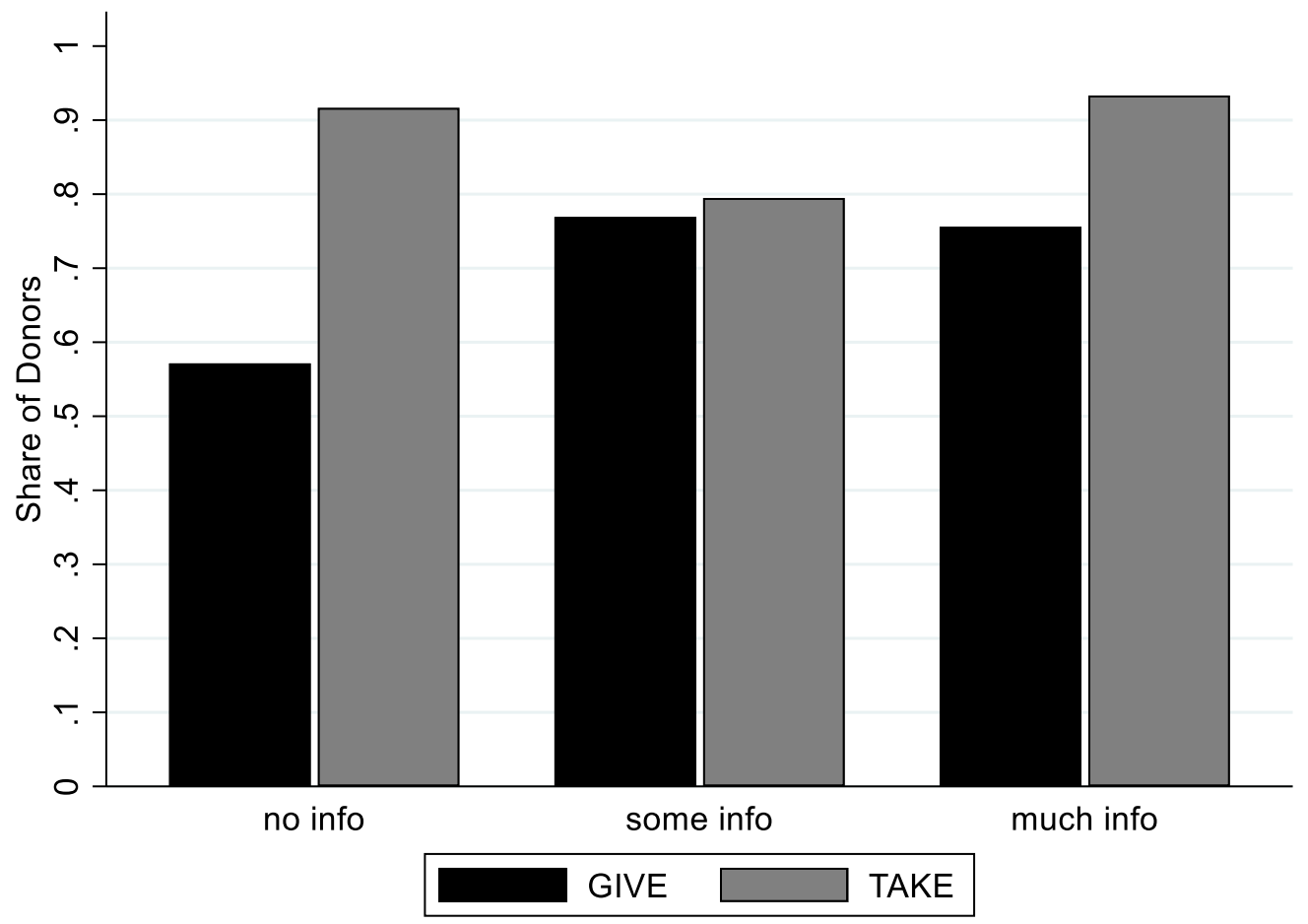

Figure 2: Share of donors by frame (GIVE / TAKE) and information level (none, some, much).

Based on non-parametric statistics, we find a significantly higher share of donors under the taking than under the giving frame when considering the none information and the much information environment. ${ }^{62}$ In the some information domain, no significant effect of the frame is detectable. ${ }^{63}$

\footnotetext{
${ }^{62}$ Exact tests: none-GIVE vs none-TAKE: $\mathrm{p}=0.001$; $m$ -

${ }^{63}$ Exact test: some-GIVE vs some-TAKE: $\mathrm{p}=0.500$.
} 
We find no significant effect of information on the share of donors under the taking frame (exact test: $\mathrm{p}=0.151) .{ }^{64}$ Similarly, we find no significant effect of information on the share of donors under the giving frame (exact test: $\mathrm{p}=0.118$ ). ${ }^{65}$ The results of a probit regression presented in Column (1) of Table A1 confirm that information does not affect the share of donors, while the taking frame (pooled over all information level) has a significantly positive impact $(\mathrm{p}=0.001)$. Table A1, Column (2) shows a significantly lower impact of the taking frame in the some environment than in the none domain $(\mathrm{p}=0.022)$. The difference in difference between the much and the none environment is statistically not significant.

\subsection{Share of donors with substantial donations}

The share of donors discussed in Subsection 3.2 of this chapter includes all individuals donating any positive amount. Figure A1 in Appendix A provides the distribution of donations per treatment. The figure shows that especially under the giving frame most subjects donated rather small amounts. To deepen our understanding, we restrict the analysis to substantial donations. For our definition of a substantial donation, we consider the finding of a meta-study by Engel (2011) that individuals in dictator games give on average 28.53 percent of the endowment. Thus, for our game, we define a donation of at least 2.90 euros to be substantial.

In the Introduction of this chapter, we argued that the taking frame sends the normative signal to individuals that they should donate a substantial amount. Indeed, Fig. 3 displays that in all of the taking treatments more than 70 percent of the individuals make a substantial donation. We observe the largest share of substantial donations under the giving frame in much-GIVE with a share of 33 percent. Exact tests show that the share of substantial donations is larger under the taking frame than under the giving frame in all information domains ( $\mathrm{p}<0.001$ in all three comparisons). A probit regression presented in Table A2, Column (1) in Appendix A confirms the positive impact of the taking frame $(\mathrm{p}<0.001)$.

\footnotetext{
${ }^{64}$ Binary exact tests confirm this result: none-Take vs some-TAKE: $\mathrm{p}=0.195$; some-TAKE vs $m u c h$-TAKE: $\mathrm{p}=0.103$; none-TAKE vs much-TAKE: $\mathrm{p}=1.000$.

${ }^{65}$ Binary exact tests confirm this result: none-GIVE vs some-GIVE: $\mathrm{p}=0.085$; some-GIVE vs much-GIVE: $\mathrm{p}=1.000 ;$ none-GIVE vs much-GIVE: $\mathrm{p}=0.096$.
} 


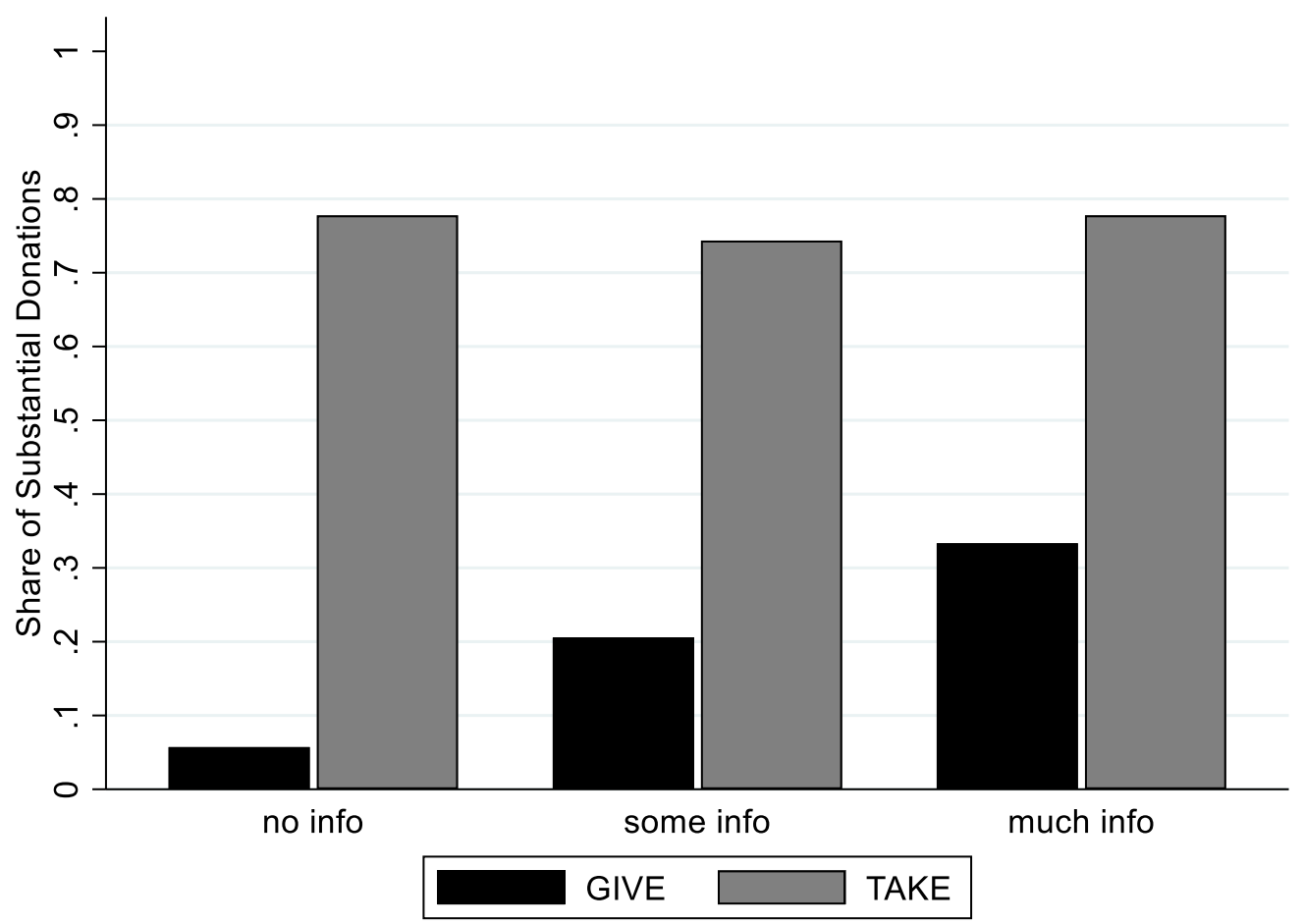

Figure 3: Share of participants who donate a substantial amount of at least 2.90 euros by frame (GIVE / TAKE) and information level (none, some, much).

Under the taking frame, an exact test shows no impact of information on the share of individuals donating a substantial amount $(\mathrm{p}=0.927) .{ }^{66}$ Under the giving frame, information does matter (exact test, $\mathrm{p}=0.009$ ). The share of substantial is significantly larger in much-GIVE than in none-GIVE (exact test, $\mathrm{p}=0.003$ ), while the comparisons of much-GIVE and some-GIVE, as well as, someGIVE and none-GIVE do not yield significant results. ${ }^{67}$ Column (2) of Table A2 confirms the positive impact of much information $(\mathrm{p}=0.036)$.

We recognize a clear trend: the relative effect of the taking frame on substantial donations decreases with information. The probit regression presented in Column (2) of Table A2 provides further statistical evidence. The negative interaction term of much information and the frame shows that the impact of the taking frame is significantly smaller in the much information environment than

\footnotetext{
${ }^{66}$ Binary exact tests confirm this result: none-Take vs some-TAKE: $\mathrm{p}=0.791$; some-TAKE vs $m u c h$ TAKE: $\mathrm{p}=0.800$; none-TAKE vs much-TAKE: $\mathrm{p}=1.000$.

${ }^{67}$ Exact tests: much-GIVE vs some-GIVE: $\mathrm{p}=0.091$, some-GIVE vs none-GIVE: $\mathrm{p}=0.142$.
} 
in the none information domain $(\mathrm{p}=0.022)$. The interaction with some information is not statistically significant.

\subsection{Analysis of the questionnaire}

Finally, we analyze which other factors beside the treatments affect donations. As described in Section 2 above, we include variables on religiousness, age, economist, parents' university degree, female, monthly expenses and younger siblings into our full model. We include the traits extraversion, agreeableness, conscientiousness, neuroticism, and openness for experiences taken from the Big Five inventory (Rammstedt et al., 2013). The model contains variables on the Social Value Orientation scale (Van Lange et al., 1997), the modified version of the Social Desirability Scale with 17 items (Stöber, 1999) and general satisfaction. As (potentially) endogenous variables, we include neediness, efficacy, joy of giving, self-image, and the evaluation of the charity. In Appendix B, we present a full list of the exact formulations and the scales used. In Appendix A, we present an OLS-regression with the full set of variables (Table A3, Column 2). Table A3, Column 1 excludes the (potentially) endogenous variables. Due to the high number of variables, we apply a least absolute shrinkage and selection operator (lasso, Tibshirani, 1996). We use the lasso with rigorous penalization of the stata package lassopack by Ahrens et al. (2020) to select variables, with the constraint that the treatment variables are selected in any case. Then we run regressions with the selected variables. Beside the treatment variables, only the variables for general satisfaction and for having the self-image to be a donor are selected. 
Table 2: Ordinary least-squares linear regression on donation.

\begin{tabular}{ccc}
\hline Donation & $(1)$ & $(2)$ \\
\hline Taking frame & $3.293^{* * *}$ & $3.253^{* * *}$ \\
Some information & $(0.352)$ & $(0.327)$ \\
Much information & -0.024 & -0.129 \\
& $(0.448)$ & $(0.417)$ \\
General satisfaction & 0.107 & -0.068 \\
& $(0.435)$ & $(0.406)$ \\
Accordance to self-image & $0.434 * * *$ & $0.318 * *$ \\
& $(0.118)$ & $(0.112)$ \\
constant & & $0.630 * * *$ \\
& & $(0.103)$ \\
$\mathrm{N}$ & -0.403 & $-2.180 * *$ \\
& $(0.664)$ & $(6.833)$ \\
\hline
\end{tabular}

Note: Standard errors in parentheses. Reference category for the taking frame: giving frame. Reference category for some information and much information: no information. $* \mathrm{p}<0.05, * * \mathrm{p}<0.01, * * * \mathrm{p}<0.001$.

Table 2 shows the results of a regression with the selected variables. In Column (1), we consider the general satisfaction variable. ${ }^{68}$ The coefficient for general satisfaction is significantly positive ( $\mathrm{p}<0.001$ ). Participants who report a higher subjective well-being are more ready to donate. The coefficient of the dummy for the taking frame is significantly positive $(\mathrm{p}<0.001)$, while the coefficients of the information dummies are not (comparable to the result presented in Table 1, Column 3). In Column (2), we add the variable on whether it is in accordance with the participant's self-image to donate to the IFRC. The variable has a significantly positive coefficient $(\mathrm{p}<0.001)$. Due to the potentially endogeneity, we do not interpret the result any further. ${ }^{69}$

\footnotetext{
${ }^{68}$ The question was asked before the donation decision stage. A Kruskal-Wallis test shows that the general satisfaction is not affected by the treatment $(\mathrm{p}=0.227)$.

${ }^{69}$ We cannot distinguish, whether donation levels determined the self-image (as an attempt of selfjustification) or whether the self-image determined donations.
} 


\section{Application to organ donations}

To some extent our findings on donations in dictator games under the giving and taking frame can contribute to the discussion on the use of Opt-In or Opt-Out organ donation systems. In both cases, the recipient is an institution dedicated to serve the public. The recipient will benefit in the future from a donation, while the potential donor's psychological or monetary costs incur immediately. Information is provided to potential donors but, due to the complexity of the situation, might be partly insufficient. The decision is morally and emotionally loaded. There are no direct incentives to donate. Individuals have the full decisional power. In the taking treatment / Opt-Out system, the good (money / organs) is dedicated to the public, even though initially the individual initially is in possession of it. Finally, similar to the literature on taking vs giving, previous studies on Opt-In vs Opt-Out systems create an ambiguous picture. Johnson and Goldstein (2003), Abadie and Gay (2006), and Ugur (2017) report that countries with an Opt-Out system exhibit a higher share of registered donors than (similar) countries with an Opt-In system. In contrast, Coppen et al. (2008) as well as Rudge and Buggins (2012) do not find such a superiority of the Opt-Out system.

The implications of our results are twofold. On the one hand, we observe higher donations and, importantly, a higher share of substantial donations under the taking than under the giving frame controlling for the information provided. This implies that an Opt-Out system ceteris paribus would lead to more registrations as organ donor than an Opt-In system. High registration costs for potential donors in Opt-In systems would reinforce this effect.

On the other hand, our results highlight three critical points with respect to the taking frame / OptOut system. The first point corresponds to our main result. The relative advantage of the taking frame decreases with information. This implies that the additional impact of an Opt-Out system is expected to be smaller the better the population is informed about the meaningfulness of organ donations. This suggests that in a well-informed society, we would expect only a small additional impact of an Opt-Out system.

Second and relatedly, the decreasing effect of the frame with information implies that a (potentially) large difference in organ donation between an Opt-Out system and an Opt-In system can be interpreted as a sign of an insufficiently informed society. Some further findings cast doubt whether automatic registrations as a donor in an Opt-Out system can be seen as an informed consent. We might compare the data collected by Johnson and Goldstein (2003) to responses of 
the Special Eurobarometer $272 \mathrm{~d}$ from the year 2007 on organ donations. ${ }^{70}$ Similar to Johnson and Goldstein (2003), we consider Germany and Austria, two countries with a comparable cultural background. While in Germany an Opt-In system is in place, in Austria an Opt-Out system is applied. Johnson and Goldstein (2003) report largely higher consent rates in Austria (0.99) than in Germany (0.12). Yet, according to the Eurobarometer less Austrians (a share of 0.33) than Germans (0.46) state that they would be willing to donate an organ immediately after death. On the one hand, with respect to Germany the discrepancy in the two shares emphasizes the insufficiency of an OptIn system to motivate willing donors to actually register as a donor. On the other hand, the case of Austria suggests that the high effective consent rate is not based on an informed consent. The result published in the Special Eurobarometer 333a stating that only a small share of Austrians (0.19) are aware of their regulatory system further supports this suggestion. ${ }^{71}$

Third, we find that information does not increase donations under the taking frame. This implies that policy makers might ignore other strategies beside the implementation of an Opt-Out system to increase the number of organ donor registrations. Beside the publication of information, these strategies include active choice (Stutzer et al., 2011; Keller et al., 2011; Putnam-Farr and Riis, 2016), public recognition (e.g., Alpizar et al., 2008, List et al., 2004, and Ariely et al., 2009 find that observability increases donations), the priority rule (Kessler and Roth, 2012) or monetary incentives (Becker and Elias, 2007). Even worse, once an Opt-Out system is implemented, policy makers might have an incentive to stop informing (see Keller et al., 2011), since information might rather decrease than increase the number of registered organ donors. Finally, policy makers in a state with an Opt-Out system might invest less in the efficiency of the transplantation system, although Deffains and Mercier Ythier (2010) report a high impact of characteristics of the transplant system, such as the level of coordination between hospitals, on the final number of organ donations.

\footnotetext{
${ }^{70}$ European Commission (2007): Europeans and organ donation. Special Eurobarometer 272. Retrieved 22.01.2021: https://ec.europa.eu/health/ph_threats/human_substance/documents/ebs272d_en.pdf

${ }^{71}$ European Commission (2010): Organ donation and transplantation. Special Eurobarometer 333a. Retrieved 22.01.2021: http://ec.europa.eu/commfrontoffice/publicopinion/archives/ebs/ebs_333a_en.pdf
} 


\section{Conclusion}

Our experiment provides evidence for our hypothesis of a decreasing impact of information on the effectiveness of a taking frame to generate donations to a charity. The difference in donations between the taking and the giving frame is smaller, the more information about the charity we provide to our participants. Reading aloud information e.g. on the key tasks of the instead of just stating the name charity (the International Federation of the Red Cross and Red Crescent) leads to a decrease of the impact of the frame, although this effect is statistically not significant. The presentation of video with the main principles of the organization leads to a significant decrease in the power of the taking frame.

This main result is grounded on three pillars. First, we find that the taking frame leads to higher donations irrespective of the information provided. Second, we find that information increases donations under the giving frame. Third, the analysis shows that participants do not react to the information when the decision is presented under the taking frame. We observe similar patterns, when analyzing the share of donors or of individual making substantial donations rather than average donations. Finally, our questionnaire reveals that participants donate more the higher their general satisfaction and that higher donations correlate with a self-image of being a donor.

Our research contributes to the literature on the impact of taking and giving frames in dictator games. Our findings suggest that the magnitude of the difference in the transferred amount between the two frames depends on the information that participants have about the recipient. This result is in line with arguments by Grossmann and Eckel (2015), Johnson and Goldstein (2003), and Thaler and Goldstein (2009) implying that the frame has little or no impact, when the context is clear.

Our research can be applied to three particular domains, where the comparison between taking and giving frames seems relevant. The first domain is online privacy (Johnson et al. 2002), where users either are asked to allow their personal data to be collected (giving) or must request that their data is not collected (taking). The second domain is church taxation. In Germany, for example, individuals have to leave their religious group, which they mostly entered by birth, to stop paying the tax (taking). In most other countries like the US, an individual may decide to enter a religious group and start to pay church tax or to voluntarily begin donating (giving).

Third, our research contributes to the discussion on Opt-In versus Opt-Out systems in organ donations. Our results suggest that the implementation of an Opt-Out system might increase the 
number of organ donor registrations. Yet, we discuss three critical points. First, the increasing effect of the frame might be smaller in a well-informed society. Second, some results cause doubt that a donation in an Opt-Out system can be seen as an informed consent. Third, a taking frame decreases the effectiveness of other strategies to promote organ donor registration such as the provision of information. We are confident that these results are valuable for policy makers as well as for fundraising agencies.

\section{References}

Abadie, Alberto, and Sebastien Gay. 2006. "The Impact of Presumed Consent Legislation on Cadaveric Organ Donation: A Cross-Country Study." Journal of health economics 25 (4): 599-620. https://doi.org/10.1016/j.jhealeco.2006.01.003.

Aguiar, Fernando, Pablo Brañas-Garza, and Luis Miller. 2008. „Moral distance in dictator games.” Judgment and Decision Making 3 (4): 344-354.

Ahrens, Achim, Christian B. Hansen, and Mark E. Schaffer. 2020. "Lassopack: Model Selection and Prediction with Regularized Regression in Stata." The Stata Journal 20 (1): 176-235. https://doi.org/10.1177/1536867X20909697.

Alpizar, Francisco, Fredrik Carlsson, and Olof Johansson-Stenman. 2008. "Anonymity, Reciprocity, and Conformity: Evidence from Voluntary Contributions to a National Park in Costa Rica." Journal of Public Economics 92 (5-6): 1047-60. https://doi.org/10.1016/j.jpubeco.2007.11.004.

Alt, Marius, Carlo Gallier, Achim Schlüter, Katherine Nelson, and Eva Anggraini. 2018. “Giving to Versus Taking from in- and Out-Group Members." Games 9 (3): 57. https://doi.org/10.3390/g9030057.

Altmann, Steffen, Armin Falk, Paul Heidhues, Rajshri Jayaraman, and Marrit Teirlinck. 2019. "Defaults and Donations: Evidence from a Field Experiment." The Review of Economics and Statistics 101 (5): 808-26. https://doi.org/10.1162/rest_a_00774.

Andreoni, James 1995. "Warm-Glow Versus Cold-Prickle: The Effects of Positive and Negative Framing on Cooperation in Experiments." The Quarterly Journal of Economics 110 (1): 121. https://doi.org/10.2307/2118508. 
Andreoni, James, and B. Douglas Bernheim. 2009. "Social Image and the 50-50 Norm: A Theoretical and Experimental Analysis of Audience Effects." Econometrica 77: 16071636. https://doi.org/10.3982/ECTA7384

Ariely, Dan, Anat Bracha, and Stephan Meier. 2009. "Doing Good or Doing Well? Image Motivation and Monetary Incentives in Behaving Prosocially." American Economic Review 99 (1): 544-55. https://doi.org/10.1257/aer.99.1.544.

Bachke, Maren Elise, Frode Alfnes, and Mette Wik. 2017. "Information and Donations to Development Aid Projects." Journal of Behavioral and Experimental Economics 66:2328. https://doi.org/10.1016/j.socec.2016.04.015.

Bardsley, Nicholas. 2008. "Dictator Game Giving: Altruism or Artefact?" Experimental Economics 11 (2): 122-33. https://doi.org/10.1007/s10683-007-9172-2.

Becker, Gary S., and Julio Jorge Elías. 2007. "Introducing Incentives in the Market for Live and Cadaveric Organ Donations." Journal of Economic Perspectives 21 (3): 3-24. https://doi.org/10.1257/jep.21.3.3.

Bekkers, René, and Pamala Wiepking. 2011. "A Literature Review of Empirical Studies of Philanthropy." Nonprofit and Voluntary Sector Quarterly 40 (5): 924-73. https://doi.org/10.1177/0899764010380927.

Bekkers, René, and Pamala Wiepking. 2011. "Who Gives? A Literature Review of Predictors of Charitable Giving Part One: Religion, Education, Age and Socialisation.”Voluntary Sector Review 2 (3): 337-65. https://doi.org/10.1332/204080511X6087712.

Brañas-Garza, Pablo. 2006. "Poverty in dictator games: Awakening solidarity." Journal of $\begin{array}{lllll}\text { Economic Behavior } \quad \& \quad \text { Organization } & \text { 306-320. }\end{array}$ https://doi.org/10.1016/j.jebo.2004.10.005

Brosig-Koch, Jeannette, Thomas Riechmann, and Joachim Weimann. 2017. "The Dynamics of Behavior in Modified Dictator Games." PLOS ONE 12 (4): e0176199. https://doi.org/10.1371/journal.pone.0176199.

Chang, Chun-Tuan, and Yu-Kang Lee. 2009. "Framing Charity Advertising: Influences of Message Framing, Image Valence, and Temporal Framing on a Charitable Appeal.” 
Journal of Applied Social Psychology 39 (12): 2910-35. https://doi.org/10.1111/j.15591816.2009.00555.x.

Chowdhury, Subhasish M., Joo Young Jeon, and Bibhas Saha. 2017. "Gender Differences in the Giving and Taking Variants of the Dictator Game." Southern Economic Journal 84 (2): 474-83. https://doi.org/10.1002/soej.12223.

Coppen, Remco, Roland D. Friele, Sjef K. M. Gevers, Geke A. Blok, and Jouke van der Zee. 2008. "The Impact of Donor Policies in Europe: A Steady Increase, but Not Everywhere." BMC health services research 8:235. https://doi.org/10.1186/1472-6963-8-235.

Das, Enny, Peter Kerkhof, and Joyce Kuiper. 2008. "Improving the Effectiveness of Fundraising Messages: The Impact of Charity Goal Attainment, Message Framing, and Evidence on Persuasion." Journal of Applied Communication Research 36 (2): 161-75. https://doi.org/10.1080/00909880801922854.

Deffains, Bruno, and Jean Mercier Ythier. 2010. "Optimal Production of Transplant Care Services." Journal of Public Economics $94 \quad$ (9-10): 638-53. https://doi.org/10.1016/j.jpubeco.2010.04.002.

Dreber, Anna, Tore Ellingsen, Magnus Johannesson, and David G. Rand. 2013. "Do People Care About Social Context? Framing Effects in Dictator Games.” Experimental Economics 16 (3): 349-71. https://doi.org/10.1007/s10683-012-9341-9.

Dufwenberg, Martin, Simon Gächter, and Heike Hennig-Schmidt. 2011. "The Framing of Games and the Psychology of Play." Games and Economic Behavior 73 (2): 459-78. https://doi.org/10.1016/j.geb.2011.02.003.

Eckel, Catherine C., and Philip J. Grossman. 1996. "Altruism in Anonymous Dictator Games." Games and Economic Behavior 16 (2): 181-91. https://doi.org/10.1006/game.1996.0081.

Engel, Christoph. 2011. "Dictator Games: A Meta Study.” Experimental Economics 14 (4): 583610. https://doi.org/10.1007/s10683-011-9283-7.

Faillo, Marco, Matteo Rizzolli, and Stephan Tontrup, S. 2019. "Thou shalt not steal: Taking aversion with legal property claims." Journal of Economic Psychology 71: 88-101. https://doi.org/10.1016/j.joep.2018.08.009 
Fiala, Lenka, and Charles N. Noussair. 2017. "Charitable Giving, Emotions, and the Default Effect.” Economic Inquiry 55 (4): 1792-1812. DOI: 10.1111/ecin.12459.

Fischbacher, Urs. 2007. "z-Tree: Zurich toolbox for ready-made economic experiments." Experimental Economics 10 (2): 171-78. https://doi.org/10.1007/s10683-006-9159-4.

Fong, Christina M., and Erzo F.P. Luttmer. 2011. "Do Fairness and Race Matter in Generosity? Evidence from a Nationally Representative Charity Experiment." Journal of Public Economics 95 (5-6): 372-94. https://doi.org/10.1016/j.jpubeco.2010.07.010.

Forsythe, Robert, Joel L. Horowitz, Nathan E. Savin, and Martin Sefton. 1994. "Fairness in Simple Bargaining Experiments." Games and Economic Behavior 6 (3): 347-69. https://doi.org/10.1006/game.1994.1021.

Goswami, Indranil, and Oleg Urminsky. 2016. "When Should the Ask Be a Nudge? The Effect of Default Amounts on Charitable Donations.” Journal of Marketing Research 53 (5): 82946. https://doi.org/10.1509/jmr.15.0001.

Greiner, Ben. 2015. "Subject pool recruitment procedures: Organizing experiments with ORSEE." Journal of the Economic Science Association 1 (1): 114-25. https://doi.org/10.1007/s40881-015-0004-4.

Grossman, Philip J., and Catherine C. Eckel. 2015. "Giving Versus Taking for a Cause." Economics Letters 132:28-30. https://doi.org/10.1016/j.econlet.2015.04.002.

Johnson, Eric J., Steven Bellman, and Gerald L. Lohse. 2002. "Defaults, Framing and Privacy: Why Opting In - Opting Out." Marketing Letters 13 (1): 5-15. https://doi.org/10.1023/A:1015044207315.

Johnson, Eric J., and Daniel Goldstein. 2003. "Medicine. Do Defaults Save Lives?” Science 302 (5649): 1338-39. https://doi.org/10.1126/science.1091721.

Kahneman, Daniel, Jack L. Knetsch, and Richard H. Thaler. 1986. "Fairness and the Assumptions of Economics.” The Journal of Business 59 (S4): S285. https://doi.org/10.1086/296367.

Keller, Punam Anand, Bari Harlam, George Loewenstein, and Kevin G. Volpp. 2011. "Enhanced Active Choice: A New Method to Motivate Behavior Change." Journal of Consumer Psychology 21 (4): 376-83. https://doi.org/10.1016/j.jcps.2011.06.003. 
Kessler, Judd B., and Alvin E. Roth. 2012. "Organ Allocation Policy and the Decision to Donate." American Economic Review 102 (5): 2018-47. https://doi.org/10.1257/aer.102.5.2018.

Kettner, Sara Elisa, and Smarandita Ceccato. 2014. "Framing matters in gender-paired dictator games." Working Paper No. 557.

Korenok, Oleg, Edward L. Millner, and Laura Razzolini. 2014. "Taking, Giving, and Impure Altruism in Dictator Games." Experimental Economics 17 (3): 488-500. https://doi.org/10.1007/s10683-013-9379-3.

Korenok, Oleg, Edward L. Millner, and Laura Razzolini. 2018. "Taking Aversion.” Journal of Economic Behavior \& Organization 150:397-403. https://doi.org/10.1016/j.jebo.2018.01.021.

Krueger, R. F., B. M. Hicks, and M. McGue. 2001. "Altruism and Antisocial Behavior: Independent Tendencies, Unique Personality Correlates, Distinct Etiologies.” Psychological science 12 (5): 397-402. https://doi.org/10.1111/1467-9280.00373.

Krupka, Erin L., and Roberto A. Weber. 2013. "Identifying Social Norms Using Coordination Games: Why Does Dictator Game Sharing Vary?" Journal of the European Economic Association 11 (3): 495-524. https://doi.org/10.1111/jeea.12006.

Liberman, Varda, Steven M. Samuels, and Lee Ross. 2004. "The Name of the Game: Predictive Power of Reputations Versus Situational Labels in Determining Prisoner's Dilemma Game Moves." Personality \& Social Psychology Bulletin 30 (9): 1175-85. https://doi.org/10.1177/0146167204264004.

List, John A. 2007. "On the Interpretation of Giving in Dictator Games." Journal of Political Economy 115 (3): 482-93. https://doi.org/10.1086/519249.

List, John A., Robert P. Berrens, Alok K. Bohara, and Joe Kerkvliet. 2004. "Examining the Role of Social Isolation on Stated Preferences." American Economic Review 94 (3): 741-52. https://doi.org/10.1257/0002828041464614.

Oxoby, Robert J., and John Spraggon. 2008. "Mine and Yours: Property Rights in Dictator Games." Journal of Economic Behavior \& Organization 65 (3-4): 703-13. https://doi.org/10.1016/j.jebo.2005.12.006. 
Putnam-Farr, Eleanor, and Jason Riis. 2016. ““'Yes/No/Not Right Now”: Yes/No Response Formats Can Increase Response Rates Even in Non-Forced-Choice Settings.” Journal of Marketing Research 53 (3): 424-32. https://doi.org/10.1509/jmr.14.0227.

Rammstedt, Beatrice, Christoph J. Kemper, Mira Céline Klein, Constanze Beierlein, and Anastassiya Kovaleva. 2017. “A Short Scale for Assessing the Big Five Dimensions of Personality: 10 Item Big Five Inventory (BFI-10)." methods, data, analyses 7(2): 233-248. DOI: $10.12758 /$ mda.2013.013.

Rudge, Chris J., and Elisabeth Buggins. 2012. "How to Increase Organ Donation: Does Opting Out Have a Role?" Transplantation $93 \quad$ (2): 141-44. https://doi.org/10.1097/TP.0b013e31823a2411.

Smith, Alexander. 2015. "On the Nature of Pessimism in Taking and Giving Games." Journal of Behavioral and Experimental 54:50-57. https://doi.org/10.1016/j.socec.2014.10.005.

Stöber, Joachim. 1999. "Die Soziale-Erwünschtheits-Skala-17 (SES-17): Entwicklung Und Erste Befunde Zu Reliabilität Und Validität.” Diagnostica 45 (4): 173-77. https://doi.org/10.1026//0012-1924.45.4.173.

Stutzer, Alois, Lorenz Goette, and Michael Zehnder. 2011. "Active Decisions and Prosocial Behaviour: A Field Experiment on Blood Donation.” The Economic Journal 121 (556): F476-F493. https://doi.org/10.1111/j.1468-0297.2011.02477.x.

Suvoy, Ryan. 2003. "The Effects of Give and Take Framing in Dictator Games.” Honor Thesis.

Thaler, Richard H., and Cass R. Sunstein. 2009. Nudge: Improving Decisions About Health, Wealth, and Happiness. New York, NY: Penguin.

Tibshirani, Robert. 1996. "Regression Shrinkage and Selection via the Lasso." Journal of the Royal Statistical Society: Series B (Methodological) $58 \quad$ (1): 267-88. https://doi.org/10.1111/j.2517-6161.1996.tb02080.x.

Tversky, A., and D. Kahneman. 1981. "The Framing of Decisions and the Psychology of Choice." Science 211 (4481): 453-58. https://doi.org/10.1126/science.7455683.

Ugur, Zeynep Burcu. 2015. “Does Presumed Consent Save Lives? Evidence from Europe.” Health economics 24 (12): 1560-72. https://doi.org/10.1002/hec.3111. 
Van Lange, Paul A. M., De Bruin, Ellen M. N., Wilma Otten, and Jeffrey A. Joireman. 1997. "Development of Prosocial, Individualistic, and Competitive Orientations: Theory and Preliminary Evidence." Journal of Personality and Social Psychology 73 (4): 733-46. https://doi.org/10.1037/0022-3514.73.4.733.

Wiepking, Pamala, and René Bekkers. 2012. "Who Gives? A Literature Review of Predictors of Charitable Giving. Part Two: Gender, Family Composition and Income." Voluntary Sector Review 3 (2): 217-45. https://doi.org/10.1332/204080512X649379.

Zarghamee, Homa S., Kent D. Messer, Jacob R. Fooks, William D. Schulze, Shang Wu, and Jubo Yan. 2017. "Nudging Charitable Giving: Three Field Experiments." Journal of Behavioral and Experimental Economics 66:137-49. https://doi.org/10.1016/j.socec.2016.04.008. 


\section{Appendix}

\section{A. Additional tables and figures}

Table A1: Probit regression on donating a positive amount.

\begin{tabular}{ccc}
\hline Donor & $(1)$ & $(2)$ \\
\hline Taking frame & $0.659 * *$ & $1.203^{* *}$ \\
& $(0.194)$ & $(0.368)$ \\
Some information & 0.094 & 0.556 \\
& $(0.232)$ & $(0.308)$ \\
Much information & 0.364 & 0.512 \\
& $(0.235)$ & $(0.295)$ \\
Some information $\mathrm{x}$ & & $-1.116^{*}$ \\
taking frame & & $(0.486)$ \\
Much information $\mathrm{x}$ & & -0.394 \\
taking frame & & $(0.510)$ \\
constant & 0.380 & 0.180 \\
$\mathrm{~N}$ & $(0.184)$ & $(0.213)$ \\
\hline
\end{tabular}

Note: Standard errors in parentheses. Reference category for the taking frame: giving frame. Reference category for some information and much information: no information. * $\mathrm{p}<0.05$, ** $\mathrm{p}<0.01, * * * \mathrm{p}<$ 0.001 
Table A2 Probit regression on donating a substantial amount.

\begin{tabular}{ccc}
\hline Substantial donation & $(1)$ & $(2)$ \\
\hline Taking frame & $1.567 * * *$ & $2.344 * * *$ \\
& $(0.184)$ & $(0.414)$ \\
Some information & 0.209 & 0.756 \\
& $(0.235)$ & $(0.411)$ \\
Much information & $0.478^{*}$ & $1.148 * *$ \\
Some information $\mathrm{x}$ & $(0.228)$ & $(0.393)$ \\
taking frame & & -0.866 \\
Much information $\mathrm{x}$ & & $(0.520)$ \\
taking frame & & $-1.148 *$ \\
constant & & $(0.502)$ \\
$\mathrm{N}$ & $(0.206)$ & $-1.159 * * *$ \\
& 239 & $(0.342)$ \\
\hline
\end{tabular}

Note: A substantial amount is defined as donation of more than 2.90 euros. Standard errors in parentheses. Reference category for the taking frame: giving frame. Reference category for some information and much information: no information. $* \mathrm{p}<0.05$, ** $\mathrm{p}<0.01$, *** $\mathrm{p}<0.001$. 
Table A3: Ordinary least-squares linear regression on donation.

\begin{tabular}{|c|c|c|}
\hline Donation & (1) & (2) \\
\hline Taking frame & $\begin{array}{c}3.279 * * * \\
(0.365)\end{array}$ & $\begin{array}{c}3.238 * * * \\
(0.345)\end{array}$ \\
\hline Some information & $\begin{array}{c}-0.027 \\
(0.461)\end{array}$ & $\begin{array}{l}-0.119 \\
(0.432)\end{array}$ \\
\hline Much information & $\begin{array}{c}0.133 \\
(0.455)\end{array}$ & $\begin{array}{l}-0.123 \\
(0.457)\end{array}$ \\
\hline Religiousness & $\begin{array}{c}-0.056 \\
(0.101)\end{array}$ & $\begin{array}{l}-0.079 \\
(0.098)\end{array}$ \\
\hline Age & $\begin{array}{c}-0.045 \\
(0.048)\end{array}$ & $\begin{array}{c}-0.170 \\
(0.046)\end{array}$ \\
\hline Economist & $\begin{array}{c}0.027 \\
(0.428)\end{array}$ & $\begin{array}{c}0.192 \\
(0.402)\end{array}$ \\
\hline Parents with university degree & $\begin{array}{c}0.058 \\
(0.385)\end{array}$ & $\begin{array}{l}-0.112 \\
(0.361)\end{array}$ \\
\hline Female & $\begin{array}{l}-0.021 \\
(0.408)\end{array}$ & $\begin{array}{l}-0.080 \\
(0.397)\end{array}$ \\
\hline Monthly expenses & $\begin{array}{c}-0.001 \\
(0.001)\end{array}$ & $\begin{array}{l}-0.001 \\
(0.001)\end{array}$ \\
\hline Younger siblings & $\begin{array}{c}-0.285 \\
(0.375)\end{array}$ & $\begin{array}{c}-0.278 \\
(0.357)\end{array}$ \\
\hline Extroversion & $\begin{array}{l}-0.087 \\
(0.224)\end{array}$ & $\begin{array}{c}0.010 \\
(0.213)\end{array}$ \\
\hline Agreeableness & $\begin{array}{c}0.350 \\
(0.224)\end{array}$ & $\begin{array}{c}0.188 \\
(0.216)\end{array}$ \\
\hline Conscientiousness & $\begin{array}{c}0.129 \\
(0.232)\end{array}$ & $\begin{array}{c}0.007 \\
(0.220)\end{array}$ \\
\hline Neuroticism & $\begin{array}{c}0.256 \\
(0.215)\end{array}$ & $\begin{array}{c}0.232 \\
(0.204)\end{array}$ \\
\hline Openness to experience & $\begin{array}{c}0.153 \\
(0.200)\end{array}$ & $\begin{array}{c}0.171 \\
(0.190)\end{array}$ \\
\hline Prosocial & $\begin{array}{c}0.314 \\
(0.421)\end{array}$ & $\begin{array}{c}0.097 \\
(0.399)\end{array}$ \\
\hline Social Desirability Scale & $\begin{array}{c}-0.0281 \\
(0.071)\end{array}$ & $\begin{array}{c}-0.014 \\
(0.066)\end{array}$ \\
\hline
\end{tabular}


$\begin{array}{lcc}0.379 * * & 0.300^{*} \\ \text { General satisfaction } & (0.134) & (0.129)\end{array}$

Neediness of the IFRC

$-0.090$

0.158

Efficacy of a donation

0.180

(0.122)

Joy of donating

$-0.171$

(0.128)

Self-image as donor

$0.598 * * *$

(0.127)

Evaluation of the IFRC

0.114

(0.191)

$-0.605$

$-2.295$

constant

(2.218)

(2.302)

$\begin{array}{lll}\mathrm{N} & 239 & 239\end{array}$

Note: Standard errors in parentheses. $* \mathrm{p}<0.05, * * \mathrm{p}<0.01$, *** $\mathrm{p}<0.001$. 

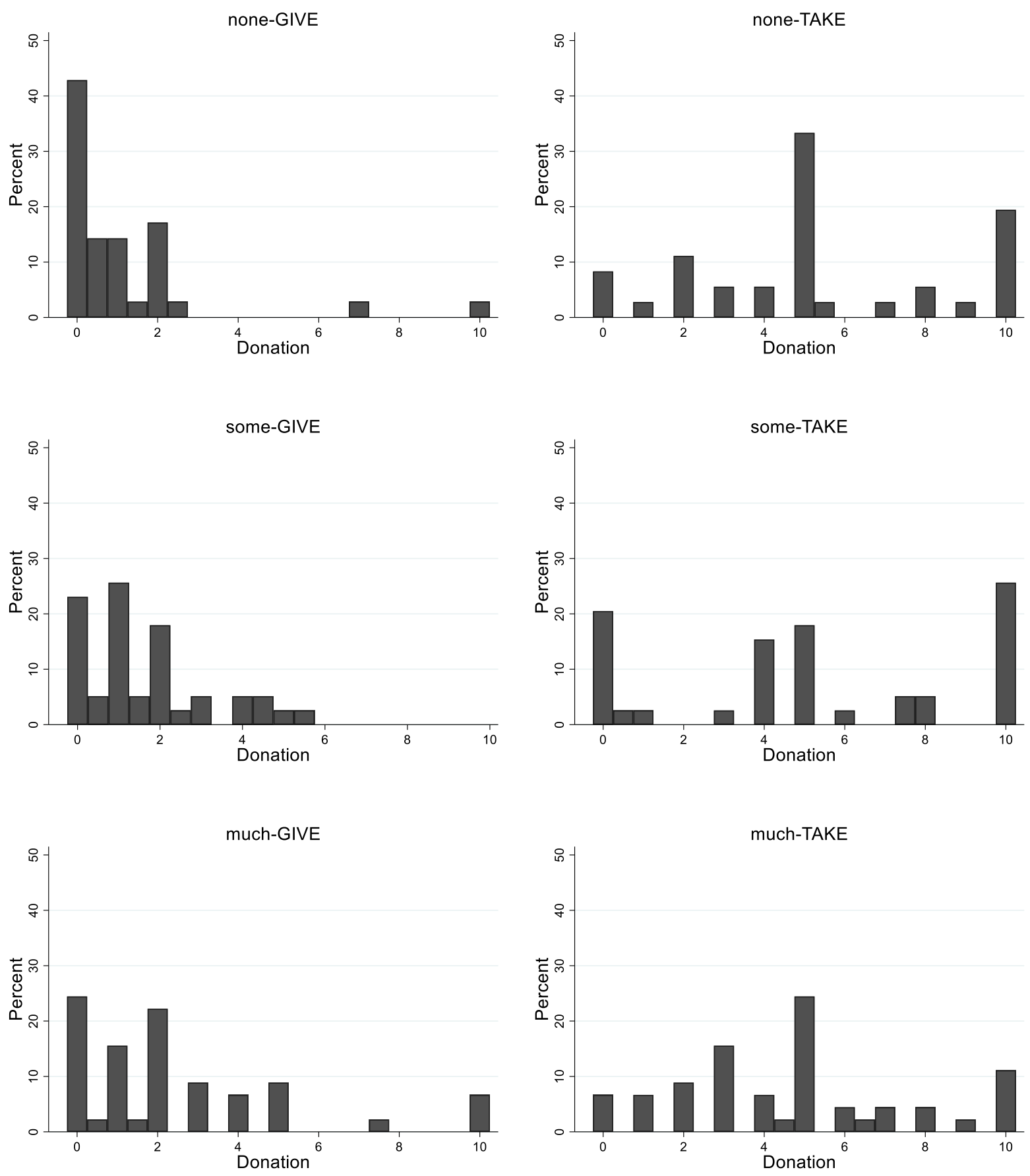

Figure A1: Histogram of donations in euros by treatment. Bin width: 0.50 . 


\section{B. Instructions and inquiries}

General instructions to be read aloud (English/German):

You are participating in an economic experiment on decision-making. You can earn money dependent on your decisions. You make your decisions anonymously and isolated from the other participants. From now on, we ask you not to speak to any other participant until the experiment is over. Please switch off your mobile phones and put them away.

Sie nehmen an einem wirtschaftswissenschaftlichen Entscheidungsexperiment teil. Abhängig von Ihren

Entscheidungen können Sie bares Geld verdienen. Sie treffen dazu Ihre Entscheidungen anonym und isoliert von anderen. Ab jetzt, bitten wir Sie nicht mehr mit anderen zu kommunizieren bis das Experiment beendet ist. Bitte schalten Sie zudem Ihre Mobiltelefone aus und stecken Sie sie weg.

In the course of the experiment you will be asked to complete a survey. Please complete the survey as thoroughly as possible. The survey will be displayed to you in a computer in the neighboring room. If you have a question while completing the survey, please come forward individually.

Im Laufe des Experiments werden Sie gebeten einen Fragebogen auszufüllen. Füllen Sie den Fragebogen bitte so gewissenhaft wie möglich aus. Der Fragebogen wird Ihnen an einem Computer im Nachbarraum angezeigt. Falls Sie während des Ausfüllens eine Frage haben, so kommen Sie bitte einzeln nach vorne.

-- Information provision (see below) -

We are not connected to the organization. However, you can be sure that the transferred money actually reaches the organization. A receipt will be posted on the bulletin board of the chair of microeconomics after the conclusion of the experiment.

Wir stehen in keiner Verbindung zu dieser Organisation. Sie können sich jedoch sicher sein, dass das transferierte Geld die Organisation tatsächlich erreicht. Eine Quittung wird nach Abschluss des

Experiments am Schwarzen Brett der Professur für Mikroökonomik ausgehängt.

We now ask you to go to the computer with your participant number. Please close the curtain and keep it close until the end of the experiment. This ensures that you are not observed during the survey. To start the survey, you must click the Next button. Thank you for your participation!

Wir bitten Sie nun, sich zu dem Computer mit Ihrer Teilnehmernummer zu begeben. Bitte schließen Sie den Vorhang und halten Sie ihn bis zum Ende des Experiments geschlossen. Dies gewährleistet, dass Sie während Ihren Entscheidungen unbeobachtet sind. Um mit dem Fragebogen zu beginnen, müssen Sie auf die <Weiter>-Taste klicken. Vielen Dank für Ihre Teilnahme!

-- Information provision in much information environment only (see below)-- 
Information in the none information environment to be read aloud(English/German):

After the experiment, money might be transferred to the International Federation of the Red Cross and Red Crescent (IFRC). The German Red Cross, among others, belongs to this organization.

„Nach dem Experiment wird gegebenenfalls Geld an die Internationale Rotkreuz- und RothalbmondBewegung (IFRC) transferiert. Zu dieser Organisation gehört unter anderem das Deutsche Rote Kreuz.“

Additional information in the some information environment to be read aloud (English/German):

The International Federation of the Red Cross and Red Crescent (IFRC) is the world's largest humanitarian network. Their website is accesable via www.ifrc.org. Together with its 190 national societies they are focusing their work in three key areas: 1) disaster response and recovery, 2) development and 3) promoting social inclusion and peace. Their task is to coordinate in the case of an international catastrophe, the promotion of the cooperation between the national societies and the representation of the national societies in the international context.

„Die Internationale Rotkreuz- und Rothalbmond-Bewegung ist das weltweit größte humanitäre Netzwerk. Ihre Internetpräsenz ist unter www.ifrc.org erreichbar. Zusammen mit ihren 190 nationalen Gesellschaften fokussiert sie sich auf drei Kernbereiche: 1.) Hilfe und Wiederaufbau bei Katastrophen. 2.) Entwicklungsarbeit und 3.) Förderung von Frieden und sozialer Inklusion. Ihre Aufgabe ist die Koordination im internationalen Katastrophenfall, die Förderung der Kooperation zwischen den nationalen Gesellschaften und die Repräsentation der nationalen Gesellschaften im internationalen

Kontext.“

Additional information in the much information environment to be read aloud (English/German):

We are now showing you a video, that points out the fundamental principles of the International Federation of the Red Cross and Red Crescent. The video is freely available on www.youtube.com.

„Wir zeigen Ihnen nun ein Video, dass die Grundsätze der Internationale Rotkreuz- und RothalbmondBewegung aufzeigt. Das Video ist auf www.youtube.com frei verfügbar.“ 


\section{Transcript of the video (English/German):}

\section{Humanity}

The International Red Cross and Red Crescent Movement, born of a desire to bring assistance without discrimination to the wounded on the battlefield, endeavors, in its international and national capacity, to prevent and alleviate human suffering wherever it may be found. Its purpose is to protect human life and health and to ensure respect for the human being. It promotes mutual understanding, friendship, cooperation and lasting peace amongst all people.

Menschlichkeit

Die internationale Rotkreuz- und Rothalbmond-Bewegung, entstanden aus dem Willen, den Verwundeten der Schlachtfelder unterschiedslos Hilfe zu leisten, bemüht sich in ihrer internationalen und nationalen Tätigkeit, menschliches Leiden überall und jederzeit zu verhüten und zu lindern. Sie ist bestrebt, Leben und Gesundheit zu schützen und der Würde des Menschen Achtung zu verschaffen. Sie fördert gegenseitiges Verständnis, Freundschaft, Zusammenarbeit und einen dauerhaften Frieden unter allen Völkern.“

\section{Impartiality}

It makes no discrimination as to nationality, race, religious beliefs, class or political opinions. It endeavors to relieve the suffering of individuals, being guided solely by their needs, and to give priority to the most urgent cases of distress.

Unparteilichkeit

Die Rotkreuz- und Rothalbmond-Bewegung unterscheidet nicht nach Nationalität, Rasse, Religion, sozialer Stellung oder politischer Überzeugung. Sie ist einzig bemüht, den Menschen nach dem Maß ihrer Not zu helfen und dabei den dringendsten Fällen den Vorrang zu geben.“

\section{Neutrality}

In order to continue to enjoy the confidence of all, the movement may not take sides in hostilities or engage at any time in controversies of a political, racial, religious or ideological nature.

Neutralität

Um sich das Vertrauen aller zu bewahren, enthält sich die Rotkreuz- und Rothalbmond-Bewegung der Teilnahme an Feindseligkeiten wie auch, zu jeder Zeit, an politischen, rassischen, religiösen oder ideologischen Auseinandersetzungen." 
Independence

The Movement is independent. The National Societies, while auxiliaries in the humanitarian services of their governments and subject to the laws of their respective countries, must always maintain their autonomy so that they may be able at all times to act in accordance with the principles of the Movement.

Unabhängigkeit

Die Rotkreuz- und Rothalbmond-Bewegung ist unabhängig. Wenn auch die Nationalen Gesellschaften den Behörden bei ihrer humanitären Tätigkeit als Hilfsgesellschaften zur Seite stehen und den jeweiligen

Landesgesetzen unterworfen sind, müssen sie dennoch eine Eigenständigkeit bewahren, die ihnen gestattet, jederzeit nach den Grundsätzen der Rotkreuz- und Rothalbmond-Bewegung zu handeln.“

Voluntary service

It is a voluntary relief movement not prompted in any manner by desire for gain.

Freiwilligkeit

Die Rotkreuz- und Rothalbmond-Bewegung verkörpert freiwillige und uneigennützige Hilfe ohne jedes Gewinnstreben."

\section{Unity}

There can be only one Red Cross or one Red Crescent Society in any one country. It must be open to all. It must carry its humanitarian work throughout its territory.

Einheit

In jedem Land kann es nur eine einzige Nationale Rotkreuz- oder Rothalbmond-Gesellschaft geben. Sie muss allen offen stehen und ihre humanitäre Tätigkeit im ganzen Gebiet ausüben.“ 


\section{Universality}

The International Red Cross and Red Crescent Movement. In which all Societies have equal status and share equal responsibilities and duties in helping each other, is worldwide.

Universalität

Die Rotkreuz- und Rothalbmond-Bewegung ist weltumfassend. In ihr haben alle Nationalen Gesellschaften gleiche Rechte und die Pflicht, einander zu helfen.“

\section{$\underline{\text { On screen instructions }}$}

You will find 10 euros on the mat. These are destined for you [for the IFRC]. On this mat there are three 2 euro coins, two 1 euro coins, five 20 cents coins and ten 10 cent coins. Please count the money and put it back on the mat.

Auf der Matte vor Ihnen finden Sie 10 Euro. Diese sind für Sie [für die Internationale Rotkreuz- und Rothalbmond-Bewegung] bestimmt. Auf dieser Matte befinden sich drei 2 Euro Münzen, zwei 1 Euro Münzen, fünf 20 Cent Münzen und zehn 10 Cent Münzen. Bitte zählen Sie das Geld nach und legen es anschließend zurück auf die Matte.

While filling in the survey, you will have once the opportunity to reduce your initial endowment in order to increase the amount dedicated to the IFRC [ ... to reduce the IFRC's initial endowment in order to increase the amount dedicated to you.] No other participant will know how you decided. Regardless of how you decide, you will have to wait 30 seconds to complete the survey.

Während des Ausfüllens des Fragebogens werden Sie 1x die Möglichkeit erhalten, den für Sie vorgesehenen Betrag auf Matte zu reduzieren, um damit den Betrag für die Internationale Rotkreuz- und

Rothalbmond-Bewegung zu erhöhen. [... den für die Internationale Rotkreuz- und RothalbmondBewegung vorgesehenen Betrag auf Matte zu reduzieren, um damit den Betrag für Sie zu erhöhen.] Kein anderer Teilnehmer wird erfahren wie Sie sich entschieden haben. Unabhängig davon, wie Sie sich entscheiden, müssen Sie 30 Sekunden warten bis Sie den Fragebogen weiter ausfüllen können. 


\section{Decision stage (English/German):}

You have now the opportunity to reduce your endowment in order to increase the amount dedicated to the IFRC. [... to reduce the endowment of the IFRC in order to increase the amount dedicated to you.]

Before your decision:

The amount dedicated to you in euros: 10.00 [0.00]

The amount dedicated to the organization in euros: 0.00 [10.00]

Please enter how much you would like to transfer from your initial endowment to the account of the organization. [... from the charity's initial endowment to your account.] Enter an amount between 0 euros and 10.00. Choose an amount rounded to 0.10 euro.

Transferred amount (in euros):

After the 30 seconds, you can confirm the amount by clicking OK

Sie haben nun die Möglichkeit den für Sie bestimmten Betrag zu reduzieren, um damit den Betrag für die Internationale Rotkreuz- und Rothalbmond-Bewegung zu erhöhen. [... den für die Internationale Rotkreuz- und Rothalbmond-Bewegung bestimmten Betrag zu reduzieren, um damit den Betrag für Sie zu erhöhen.]

Vor Ihrer Entscheidung:

Der für Sie bestimmte Betrag in Euro: 10.00 [0.00]

Der für die Organisation bestimmte Betrag in Euro: 0.00 [10.00]

Bitte tragen Sie ein, wie viel Sie von dem für Sie bestimmten Betrag zu dem für die Organisation bestimmten Betrag übertragen möchten. [... wie viel Sie von dem für die Organisation bestimmten Betrag zu dem für Sie bestimmten Betrag übertragen möchten.] Tragen Sie dazu einen Betrag zwischen 0 Euro und 10.00 Euro ein. Wählen Sie einen auf 0,10 Euro gerundeten Betrag.

Übertragener Betrag (in Euro):

Nach Ablauf der 30 Sekunden können Sie den Betrag mit einem Klick auf OK bestätigen. 
Inquiries (in chronological order) in English and in the original language German with the respective scales.

\begin{tabular}{|c|c|}
\hline Variable & Inquiry \\
\hline Monthly expenses & $\begin{array}{l}\text { How high (in euros) are your monthly expenses (including } \\
\text { nutrition, rent, additional costs) approximately? } \\
\text { Range: } 0 \text { - } 9999 \\
\text { „Wie hoch (in Euro) sind Ihre monatlichen Ausgaben ungefähr } \\
\text { (inklusive Verpflegung, Miete, Nebenkosten)?“ } \\
\text { Wertebereich: } 0 \text { - } 9999\end{array}$ \\
\hline General satisfaction & $\begin{array}{l}\text { How satisfied are you with your current life situation in general? } \\
\text { Scale: } 1=\text { very unsatisfied;7=very satisfied } \\
\text { „Wie zufrieden sind Sie mit Ihrer gegenwärtigen generellen } \\
\text { Lebenssituation?“ } \\
\text { Skala: } 1=\text { "sehr unzufrieden";7="sehr zufrieden" }\end{array}$ \\
\hline Evaluation of the IFRC & $\begin{array}{l}\text { How would you evaluate the IFRC in general? } \\
\text { Scale: } 1=\text { very bad;7=very good } \\
\text { „Wie würden Sie die Internationale Rotkreuz- und Rothalbmond- } \\
\text { Bewegung allgemein bewerten?“" } \\
\text { Skala: } 1=\text { "sehr schlecht";7="sehr gut" }\end{array}$ \\
\hline \multicolumn{2}{|c|}{ - Donation decision - } \\
\hline Female & $\begin{array}{l}\text { What is your gender? } \\
\text { Option for ,1“": female } \\
\text { „Was ist Ihr Geschlecht?“" } \\
\text { Option für „1“: weiblich }\end{array}$ \\
\hline Age & $\begin{array}{l}\text { What is your age? } \\
\text { Range: } 16-99 \\
\text { „Wie alt sind Sie?“ } \\
\text { Wertebereich:16-99 }\end{array}$ \\
\hline Parents with university degree & $\begin{array}{l}\text { What is the highest level of education that your parents have } \\
\text { completed? } \\
\text { Degrees for "1": university degree, phd } \\
\text { „Was ist der höchste Bildungsabschluss Ihrer Eltern?" } \\
\text { Abschlüsse für „1": Hochschulabschluss, Promotion }\end{array}$ \\
\hline
\end{tabular}




\section{Economist}

Big Five

Neediness of the IFRC

Efficacy of a donation

Self-image as donor

Prosocial

Joy of donating

Religiousness
Which degree program you feel the most assigned to? Programs for "1": business administration, economics, commercial engineer

„Welchem Studiengang fühlen Sie sich am ehesten zugeordnet?“

Studiengänge für "1": Betriebswirtschaftslehre, Volkswirtschaftslehre, Wirtschaftsingenieur

See Rammstedt et al., 2013.

In your opinion, how needy is the IFRC?

Scale: $1=$ very low neediness; $7=$ very high neediness

„Was meinen Sie, wie hilfsbedürftig ist die Internationale Rotkreuzund Rothalbmond-Bewegung?"

Skala: 1="sehr wenig hilfsbedürftig"; 7="sehr hilfsbedürftig"

In your opinion, can a small donation to the International Red Cross and Red Crescent Movement already make a difference?

Scale: $1=$ no difference; $7=" a$ big difference"

„Was meinen Sie, kann eine kleine Spende für die Internationale

Rotkreuz- und Rothalbmond-Bewegung bereits einen Unterschied machen?"

Skala: 1="keinen Unterschied"; 7="einen großen Unterschied"

How well does the following statement describe you? It corresponds to my self-image to donate to the IFRC.

Scale: $1=$ very little; $7=$ very much

„Wie sehr trifft die folgende Aussage auf Sie zu? Es entspricht meinem Selbstbild, für die Internationale Rotkreuz- und RothalbmondBewegung zu spenden."

Skala: $1=$ "sehr wenig"; 7 = "sehr stark"

See Social Value Orientation scale by Van Lange et al., 1997.

How well does the following statement describe you? It is fun for me to donate.

Scale: $1=$ very little; $7=$ very much

„Wie sehr trifft die folgende Aussage auf Sie zu? Es macht mir Spaß zu spenden."

Skala: $1=$ "sehr wenig"; 7 = "sehr stark“

How religious would you think you are?

Scale: $1=$ very little; $7=$ very much

„Als wie religiös würden Sie sich einschätzen?“

Skala: 1="sehr wenig"; 7 = "sehr stark" 
Do you have younger siblings?

Younger siblings

Options: $1=$ yes; $0=$ no

„Haben Sie jüngere Geschwister?“

Optionen: 1="Ja"; $0=$ "Nein"

Social Desirability Scale

See Stöber, 1999. Modification: we offered an “I don’t want to answer" option.

\section{Photos}

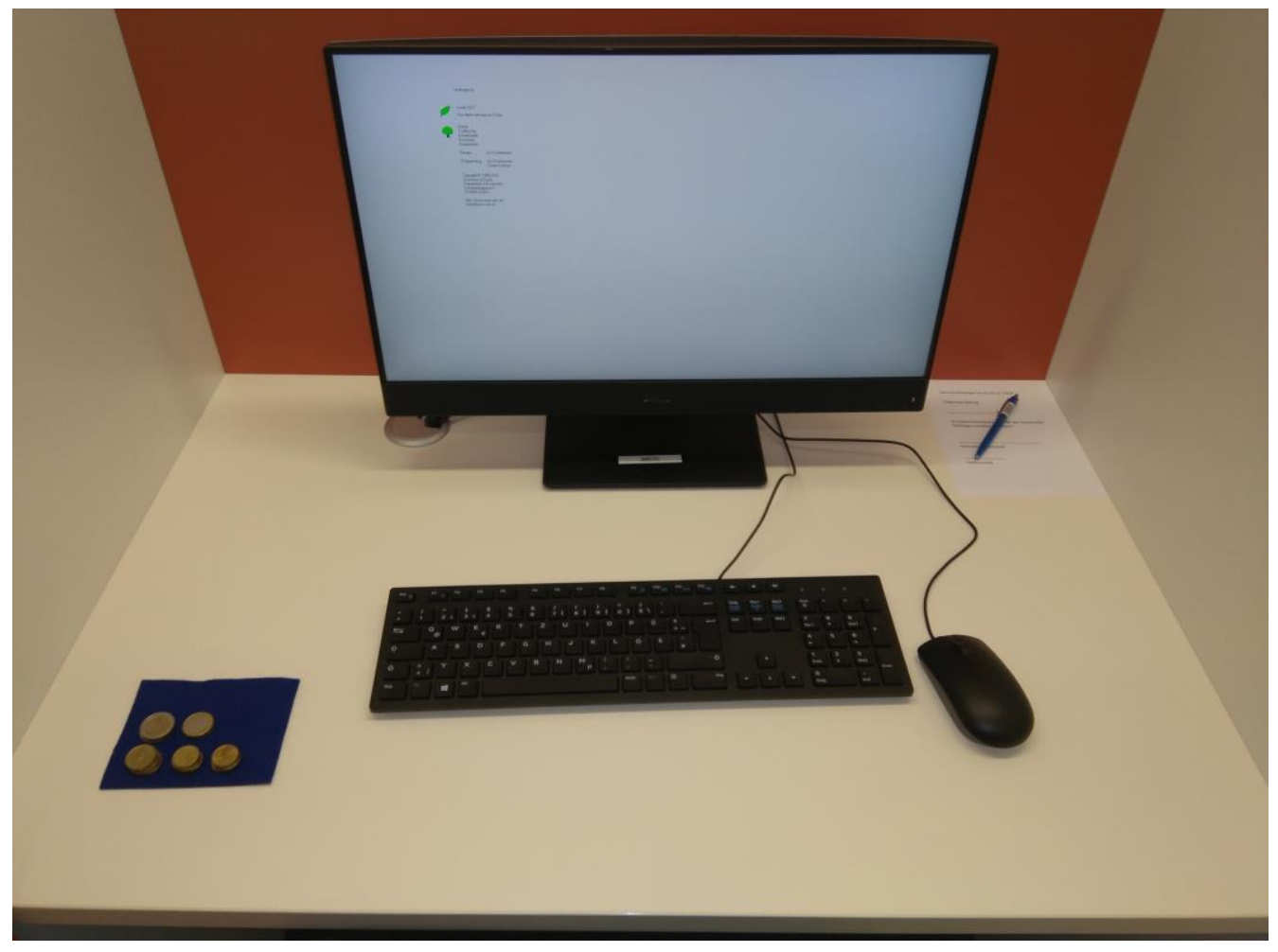

Cubicle with computer, keyboard, mouse, money, a pen and the receipt. 


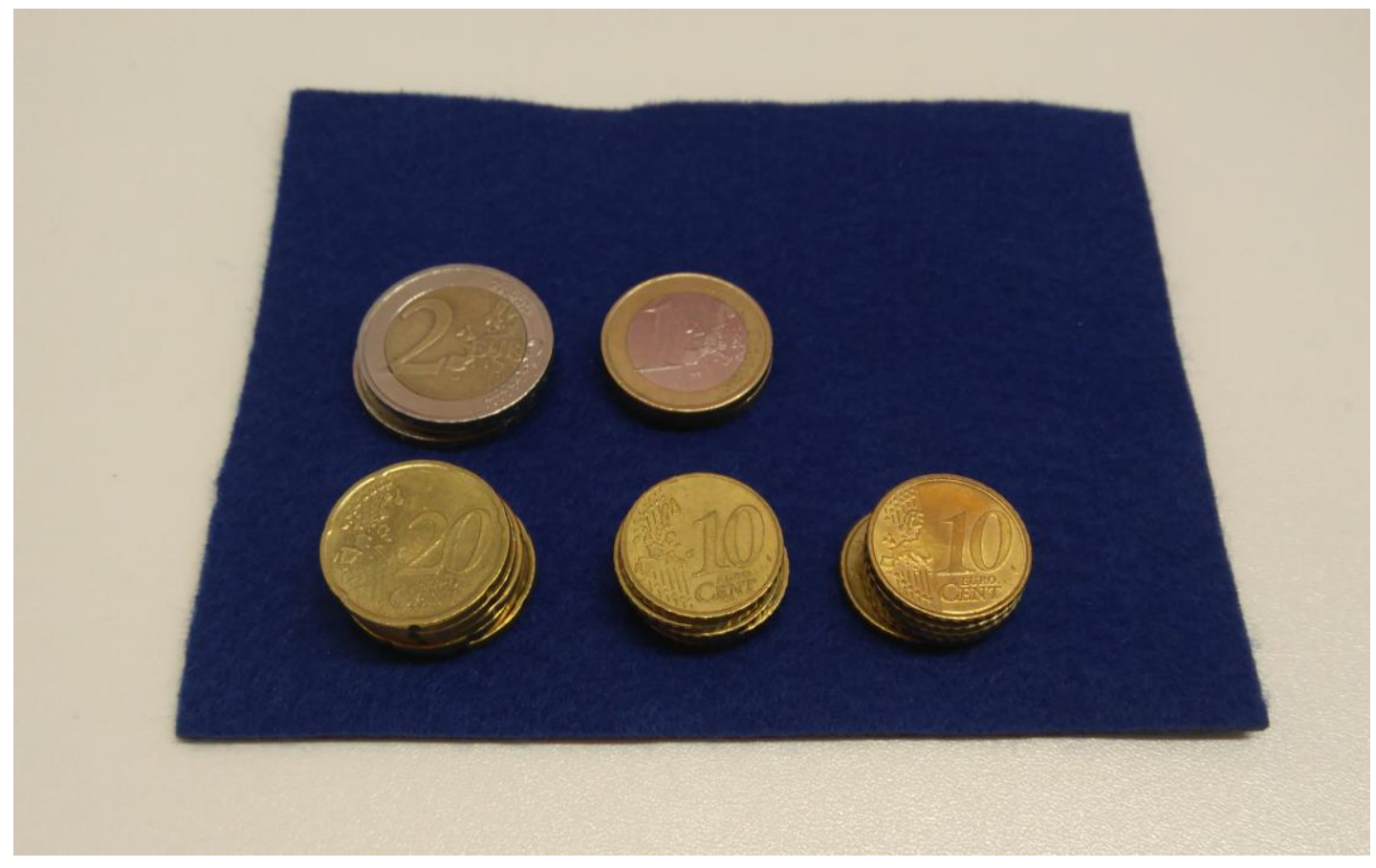

Presentation of the money. 


\section{Chapter V: Conclusion}

The starting point of this dissertation is that it is in the interest of society to foster prosocial behavior. This notion is almost tautological when we define prosocial behavior as acts towards reaching the social optimum (in other words, what is best for society as aggregate of relevant others) instead of the private optimum of the agent. Far more debatable is how to foster prosocial behavior. In this thesis, I consider three measures: the implementation of a reputation system, asking agents directly to act prosocially, and a taking frame.

While several studies provide evidence on the positive effect of these measures on prosocial behavior (e.g. Keser, 2003 for reputation systems; Freeman, 1997 for asking; and Korenok, 2014 for the taking frame), it remains unclear under which conditions the strategies have the desired impact. First, reputation systems build on individuals who are rating their interaction partners. A distortion in rating giving might weaken the power of the systems to foster prosocial behavior. Second, being asked once seems to be crucial for charitable giving: most individuals only give when being solicited (Yöruk, 2008, 2009). Yet, asking repeatedly might induce defensive strategies (Diamond and Noble, 2001) and, thus, have adverse effects. Third, there may be a positive effect of a taking frame (in comparison to a giving frame) on donations when the context is vague. However, comments by Grossmann and Eckel (2015), Johnson and Goldstein (2003), and Thaler and Goldstein (2009) suggest that the frame may have little power when sufficient information about the recipient of a potential donation is provided. These concerns with respect to the robustness of the positive effect of the measures on prosocial behavior are the driving force of the three studies conducted for this dissertation.

In Study 1, which is joint work with Claudia Keser, we analyze the effect of induced distortions in rating giving. We apply a trust game (Berg et al., 1995), in which trustors and trustees interact repeatedly under the constraint that no pair might meet twice in a row. In this game, trustors are invited to invest a share of their endowment. Then, the investment gets tripled by the experimenter and trustees might return a share of the amount received. Similar to Keser (2003), we allow trustors to rate trustees after the interaction. Ratings are visible to subsequent interaction partners of trustees. 
In our experimental study, we consider three treatments: POSNEG, POS, and NEG. In POSNEG, trustors can give a positive rating, a negative rating, or no rating after the interaction. In POS, trustors can give a positive rating or no rating. This represents a positive distortion in rating giving. In NEG, they can give a negative rating or no rating. This represents a negative distortion in rating giving. In line with our prediction, we find significantly higher trustworthiness and higher trust in NEG than in POS. The trustworthiness in POS is moderately lower than in POSNEG, with the difference being insignificant. Trust is significantly lower in POS than in POSNEG. This highlights that a distortion toward positive ratings might be detrimental for the power of reputation systems in promoting prosocial acts.

In Study 2, I analyze the effect of repeated donation requests on prosocial behavior and the dynamics of charitable giving. The heart of the experimental design is a version of the dictator game (Kahneman et al., 1986; Forsythe et al., 1994). In treatment ONCE, participants have a single time the possibility to donate to a charity. In THRICE, they can donate in three decision stages with one endowment, one recipient, and one time information provision about the recipient. In treatment ENDOGENOUS, participants can avoid subsequent asks after the first decision stage.

I find that the mere repetition of the donation request leads to only a slight increase in donations. Offering the option to avoid the ask yields the largest average donation. None of the differences in aggregate donations are significant. Most important, individuals who do not avoid the repetition of the ask in ENDOGENOUS donate significantly more than participants in ONCE. Focusing on such warm-list individuals seems to be a fruitful strategy in order to foster charitable giving and to decrease solicitation costs.

In Study 3, which is again joint work with Claudia Keser, we analyze how the impact of a taking frame on charitable giving is affected by the provision of information. Our experimental design allows to separately examine the effect of the two factors and, additionally, their cross effect. As in Study 2, we use a dictator game (Kahneman et al., 1986; Forsythe et al., 1994) with a charity as the recipient. In a first step, we vary the information about the recipient between nearly none (only the name of the charity), some (name and the main operative goals of the charity), and much information (name, operative goals, and the main principles of the charity). In a second step, we either apply a giving frame or a taking frame. Under the giving frame, the participant is endowed and can transfer money to the charity. Under the taking frame, the charity receives an endowment and the participants can freely transfer money from the charity to their account. 
We have three main results. First, we find a positive effect of the taking frame (in comparison to the giving frame) on donations under all three information levels. Second, we find that donations under the giving frame increase with the level of information. Third, we find that donations under the taking frame do not increase with information. Considering these three results together gives us that information about the charity weakens the effect of the taking frame on donations. We apply these findings in the field of organ donations and argue that we might only expect a large effect of Opt-Out system (taking frame) in comparison to an Opt-In system (giving frame) if the society is insufficiently informed.

Taken together, I find that the positive impact of the three measures (reputation systems, donation requests, and the taking frame) on prosocial behavior is to some extent robust. Even a distorted reputation system yields substantial trust and trustworthiness. Repeating donation requests leads to some slight increase in charitable giving, especially driven by those who like to donate repeatedly. The taking frame has a positive impact on donations, even when extensive information about the recipient is provided. Nevertheless, market designers, fundraisers, and policy makers should carefully consider the institutional environment within which the strategies are applied when forming their expectation about the impact of the measures on prosocial behavior.

Furthermore, decision makers should consider other strategies that might foster prosocial behavior. Examples might be measures that increase the observability of the action (Alpizar et al., 2008; List et al., 2004; Ariely et al., 2009), granting some kind of priority to individuals behaving prosocially (Kessler and Roth, 2012 on the case of organ donation), or forcing agents to take an active choice (Stutzer et al., 2011; Keller et al., 2011; Putnam-Farr and Riis, 2016). Benabou and Tirole (2006) point out that some measures such as rewards and punishment can crowd out prosocial motivations. This implies that the implementation of new strategies must be accompanied with a rigid evaluation of their impact. Finally, Bohnet and Huck (2004) observe that a reputation system only has a positive effect on prosocial behavior when it is in action. Once the reputation system is abolished, any positive effect disappears. Contrary to this, charities having a warm-list of individuals who like to be asked repeatedly for a donation might rather benefit from such a list in the long run than in the short run. Therefore, decision makers should take long-term effects into consideration when they are implementing measures to foster prosocial behavior.

As a last step, I want to illustrate the relevance of the findings presented in dissertation by providing a further application of the main results. In Study 3, we applied the results of the laboratory 
experiment on the impact of a taking frame to the case of organ donations. With some degree of abstraction, the experimental results discussed in this thesis have important implications on how to foster compliance with response measures in pandemics. During pandemics such as the COVID19 pandemic, governments use several strategies to prevent contagion. Measures are, for example, lockdowns, closures of schools and borders, the isolation of infected individuals, and social distancing, in general (Flaxman et al., 2020). While measures like the closure of schools can be directly implemented, others such as social distancing in private space are far less enforceable by the executive forces of a state. Therefore, respecting social distance rules in private life may be seen as a prosocial act. Potentially infected individuals voluntarily reduce their social activity for the protection of others. In the following, I discuss the three strategies discussed in this thesis (reputation systems, solicitation, and taking frame) as measures to foster the prosocial compliance with social distancing rules.

First, (informal) reputation systems might foster prosocial compliance. The information about behavior of individuals may be spread via newspapers, television, and other mass media (for famous individuals) or in local circles. Following social distancing rules improves the reputation, while not following the rules worsens the reputation. Assuming that individuals care for their reputation, the results of Study 1 show that is most relevant to spread negative information. I consider the share of rounds in Study 1 in which trustees were trustworthy in the sense that they returned more than the investment. As reported in Subsection 3.6 of Chapter II, the share of rounds in which trustees are trustworthy is significantly lower in POS than in POSNEG and NEG. The share of such rounds is around 70 percent in the latter two treatments. This indicates that threat of being reported as not following social distancing rules might create an incentive to comply with the rules.

Second, governments might remind citizens about the social distancing rules. With respect to this measure, I might draw some cautious conclusions from the results of Study 2 as presented in Subsections 3.1 of Chapter III. On the one hand, around two third of individuals donate a positive amount (with only small differences between treatments) to a rather unknown charity. On the other hand, the median donation is only ten percent of the endowment. Repeating donation requests does not alter the median total amount donated. This implies that purely reminding individuals of the possibility of social distancing might be insufficient when there is little information about the worthiness of the measure. 
Third, suitable framing might foster compliance with social distancing rules. Soofi et al. (2020) point out that communicating the reason for the measure under a loss frame (measure decreases odds of mortality) instead of a gain frame (measure increases odds of survival) might foster compliance. Furthermore, the authors state that which action (compliance or non-compliance) is the default might affect actual behavior. In line with these conjectures, the results of Study 3 highlight that a taking frame increases donations to a charity. Figure 3 in Subsection 3.3 of Chapter IV shows that the share of substantial donation is more than 70 percent under the taking frame, while it is below 35 percent under the giving frame. This suggests that framing social distancing as an act of not-taking rather than as giving might foster compliance with the distancing rules. Besides, the findings presented Study 3 indicate that information about worthiness of the cause might promote compliance with preventive measures.

Overall, the experimental results presented in this dissertation have highlighted the positive impact of several measures designed to foster prosocial behavior. The analysis allows for an understanding of circumstances under which the measures are most effective. The findings can be applied to a multitude of domains in which prosocial behavior is socially desirable. Examples of such domains are organ donations or compliance with contagion prevention measures during pandemics. 


\section{References (Chapter I and Chapter V)}

Alpizar, Francisco, Fredrik Carlsson, and Olof Johansson-Stenman. 2008. "Anonymity, reciprocity, and conformity. Evidence from voluntary contributions to a national park in Costa Rica." Journal of Public Economics 92 (5-6): 1047-1060. DOI: 10.1016/j.jpubeco.2007.11.004.

Andreoni, James, and Justin M. Rao. 2011. "The power of asking. How communication affects selfishness, empathy, and altruism.” Journal of Public Economics 95 (7-8): 513-520. DOI: 10.1016/j.jpubeco.2010.12.008.

Ariely, Dan, Anat Bracha, and Stephan Meier. 2009. "Doing Good or Doing Well? Image Motivation and Monetary Incentives in Behaving Prosocially." American Economic Review 99 (1): 544-555. DOI: 10.1257/aer.99.1.544.

Bénabou, Roland, and Jean Tirole. 2006. "Incentives and Prosocial Behavior." American Economic Review 96 (5): 1652-1678. DOI: 10.1257/aer.96.5.1652.

Berg, Joyce, John Dickhaut, and Kevin McCabe. 1995. "Trust, Reciprocity, and Social History." Games and Economic Behavior 10 (1): 122-42. https://doi.org/10.1006/game.1995.1027.

Boero, Riccardo, Giangiacomo Bravo, Marco Castellani, and Flaminio Squazzoni. 2009. "Reputational Cues in Repeated Trust Games." The Journal of Socio-Economics 38 (6): 871-77. https://doi.org/10.1016/j.socec.2009.05.004.

Bohnet, Iris, and Steffen Huck. 2004. "Repetition and Reputation. Implications for Trust and Trustworthiness When Institutions Change.” American Economic Review 94 (2): 362-366. DOI: $10.1257 / 0002828041301506$.

Bolton, Gary, Ben Greiner, and Axel Ockenfels. 2013. "Engineering Trust: Reciprocity in the Production of Reputation Information." Management Science 59 (2): 265-85. https://doi.org/10.1287/mnsc.1120.1609.

Brosig-Koch, Jeannette, Thomas Riechmann, and Joachim Weimann. 2017. "The dynamics of behavior in modified dictator games." PLOS ONE 12 (4): e0176199. DOI: 10.1371/journal.pone.0176199. 
Chowdhury, Subhasish M, Joo Young Jeon, and Bibhas Saha. 2017. "Gender Differences in the Giving and Taking Variants of the Dictator Game." Southern Economic Journal 84 (2): 474-483. DOI: 10.1002/soej.12223.

Dellarocas, Chrysanthos, and Charles A. Wood. 2008. "The Sound of Silence in Online Feedback: Estimating Trading Risks in the Presence of Reporting Bias.” Management Science 54 (3): 460-76. https://doi.org/10.1287/mnsc.1070.0747.

Diamond, William D., and Stephanie M. Noble. 2001. "Defensive responses to charitable direct mail solicitations.” Journal of Interactive Marketing 15 (3): 2-12. DOI: 10.1002/dir.1012.

Dreber, Anna, Tore Ellingsen, Magnus Johannesson, and David G. Rand. 2013. "Do people care about social context? Framing effects in dictator games.” Experimental Economics 16 (3): 349-371. DOI: 10.1007/s10683-012-9341-9.

Eckel, Catherine C., and Philip J. Grossman. 1996. "Altruism in Anonymous Dictator Games." Games and Economic Behavior 16 (2): 181-191. DOI: 10.1006/game.1996.0081.

Flaxman, Seth, Swapnil Mishra, Axel Gandy, H. Juliette T. Unwin, Thomas A. Mellan, and Helen Coupland et al. 2020. "Estimating the effects of non-pharmaceutical interventions on COVID-19 in Europe.” Nature 584: 257-261. https://doi.org/10.1038/s41586-020-2405-7

Freeman, Richard B. 1997. "Working for Nothing. The Supply of Volunteer Labor.” Journal of Labor Economics 15 (1, Part 2): 140-166. DOI: 10.1086/209859.

Forsythe, Robert, Joel L. Horowitz, Nathan E. Savin, and Martin Sefton. 1994. "Fairness in Simple Bargaining Experiments." Games and Economic Behavior 6 (3): 347-369. DOI: 10.1006/game.1994.1021.

Johnson, Eric J., and Daniel Goldstein. 2003. “Medicine. Do defaults save lives?” Science 302 (5649): 1338-1339. DOI: 10.1126/science.1091721.

Kahneman, Daniel, Jack L. Knetsch, and Richard H. Thaler. 1986. "Fairness and the Assumptions of Economics.” Journal of Business 59: 285-300. DOI: 10.1086/296367.

Keller, Punam Anand, Bari Harlam, George Loewenstein, and Kevin G. Volpp. 2011. "Enhanced active choice. A new method to motivate behavior change." Journal of Consumer Psychology 21 (4): 376-383. DOI: 10.1016/j.jcps.2011.06.003. 
Keser, Claudia. 2003. "Experimental games for the design of reputation management systems." IBM Systems Journal 42 (3): 498-506. https://doi.org/10.1147/sj.423.0498.

Kessler, Judd B., and Alvin E. Roth. 2012. "Organ Allocation Policy and the Decision to Donate." American Economic Review 102 (5): 2018-2047. DOI: 10.1257/aer.102.5.2018.

Kettner, Sara Elisa, and Ceccato, Smarandita. 2014. "Framing matters in gender-paired dictator games." Working Paper No. 557.

Korenok, Oleg, Edward L. Millner, and Laura Razzolini. 2014. "Taking, giving, and impure altruism in dictator games." Experimental Economics 17 (3): 488-500. DOI: 10.1007/s10683-013-9379-3.

Krupka, Erin L., and Roberto A. Weber. 2013. "Identifying Social Norms Using Coordination Games: Why Does Dictator Game Sharing Vary?" Journal of the European Economic Association 11 (3): 495-524. DOI: 10.1111/jeea.12006.

List, John A., Robert P Berrens, Alok K. Bohara, and Joe Kerkvliet. 2004. Examining the Role of Social Isolation on Stated Preferences. American Economic Review 94 (3): 741-752. DOI: $10.1257 / 0002828041464614$.

Lumeau, Marianne, David Masclet, and Thierry Pénard. 2015. "Reputation and social (dis)approval in feedback mechanisms: An experimental study." Journal of Economic Behavior \& Organization 112: 127-40. https://doi.org/10.1016/j.jebo.2015.02.002.

Masclet, David, and Thierry Pénard. 2012. "Do Reputation Feedback Systems Really Improve Trust Among Anonymous Traders? An Experimental Study.” Applied Economics 44 (35): 4553-73. https://doi.org/10.1080/00036846.2011.591740.

Mazar, Nina, and Chen-Bo Zhong. 2010. "Do green products make us better people?" Psychological science 21 (4), S. 494-498. DOI: 10.1177/0956797610363538.

Merritt, Anna C., Daniel A. Effron, and Benoît Monin. 2010. "Moral Self-Licensing. When Being Good Frees Us to Be Bad." Social and Personality Psychology Compass 4 (5), S. 344-357. DOI: 10.1111/j.1751-9004.2010.00263.x.

Monin, Benoît, and Dale T. Miller. 2001. "Moral credentials and the expression of prejudice." Journal of Personality and Social Psychology 81 (1): 33-43. DOI: 10.1037/00223514.81.1.33. 
Putnam-Farr, Eleanor; Riis, Jason (2016): ““'Yes/No/Not Right Now”. Yes/No Response Formats Can Increase Response Rates Even in Non-Forced-Choice Settings." Journal of Marketing Research 53 (3): 424-432. DOI: 10.1509/jmr.14.0227.

Oxoby, Robert J, and John Spraggon. 2008. "Mine and yours. Property rights in dictator games." Journal of Economic Behavior \& Organization 65 (3-4): 703-713. DOI: 10.1016/j.jebo.2005.12.006.

Smith, Alexander. 2015. "On the nature of pessimism in taking and giving games." Journal of Behavioral and Experimental Economics 54: 50-57. DOI: 10.1016/j.socec.2014.10.005.

Stutzer, Alois, Lorenz Goette, and Michael Zehnder. 2011. "Active Decisions and Prosocial Behaviour. A Field Experiment on Blood Donation.” The Economic Journal 121 (556), F476-F493. DOI: 10.1111/j.1468-0297.2011.02477.x.

Suvoy, Ryan. 2003. "The Effects of Give and Take Framing in Dictator Games.” Honor Thesis.

Tadelis, Steven. 2016. "Reputation and Feedback Systems in Online Platform Markets." Annual Review of Economics 8 (1): 321-40. https://doi.org/10.1146/annurev-economics-080315015325 .

Thaler, Richard H, and Cass R. Sunstein. 2009. Nudge. Improving decisions about health, wealth, and happiness. New York, NY: Penguin.

van Diepen, Merel, Bas Donkers, and Philip Hans Franses. 2009. "Dynamic and Competitive Effects of Direct Mailings. A Charitable Giving Application.” Journal of Marketing Research 46 (1):120-133. DOI: 10.1509/jmkr.46.1.120.

Yörük, Barış K. 2008. "The power of asking in volunteering. Evidence from a matched sample." Economics Letters 99 (1): 79-84. DOI: 10.1016/j.econlet.2007.05.035.

Yörük, Barış K. 2009. "How responsive are charitable donors to requests to give?" Journal of Public Economics 93 (9-10): 1111-1117. DOI: 10.1016/j.jpubeco.2009.06.001. 